\title{
S3-Leitlinie „Aszites, spontan bakterielle Peritonitis, hepatorenales Syndrom“"
}

\author{
German S3-Guideline “Ascites, spontaneous bacterial peritonitis, hepatorenal \\ syndrome"
}

Authors

Affiliations
A. L. Gerbes ${ }^{1}$, V. Gülberg ${ }^{2}$, T. Sauerbruch ${ }^{3}$, R. Wiest ${ }^{4}$, B. Appenrodt ${ }^{3}$, M. J. Bahr ${ }^{5}$, M. M. Dollinger ${ }^{6}$, M. Rössle ${ }^{7}$, M. Schepke ${ }^{8}$

Die Institutsangaben sind am Ende des Beitrags gelistet.
Bibliography

DOI http://dx.doi.org/10.1055/

s-0031-1273405

Z Gastroenterol 2011; 49:

749-779 @ Georg Thieme

Verlag KG Stuttgart · New York .

ISSN 0044-2771

\section{Correspondence}

\section{Prof. Dr. Alexander L. Gerbes}

Med. Klinik und Poliklinik 2,

Leber Centrum München,

Klinikum der LMU München

Marchioninistr. 15

81377 München

sekretariat.gerbes@med.uni-

muenchen.de

\section{Diagnostik des Aszites}

I.1. Einleitung: Ursachen des Aszites

1.2. Wann soll eine diagnostische Aszitespunktion durchgeführt werden?

I.3. Technik, Komplikationen und Kontraindikationen der Aszitespunktion

I.3.1 Sollen Gerinnungsfaktoren vor einer Aszitespunktion substituiert werden?

I.3.2 Welche Kontraindikationen zur Aszitespunktion bestehen?

I.4. Diagnostik bei Aszitespunktion

I.4.1 Welche Untersuchungen sind obligater Bestandteil der initialen Aszitespunktion?

1.4.2 Welche Untersuchungen sind optionaler Bestandteil einer Aszitespunktion?

I.4.3 Welche zytologischen Untersuchungen sollen durchgeführt werden?

1.5. Spezifische Diagnostik bei Patienten mit Aszites bedingt durch ein Budd-Chiari-Syndrom (BCS) oder sinusoidales Obstruktionssyndrom

I.6. Welche Parameter weisen auf eine sekundäre bakterielle Peritonitis hin?

II. Therapie des Aszites

II.1. Wann bedarf ein Patient mit Aszites einer Therapie?

II.2. Was ist die Rolle der nicht medikamentösen Basistherapie?

II.3. Wie wird die medikamentöse Therapie des Aszites durchgeführt?

II.4. Wie wird der therapierefraktäre und rezidivierende Aszites behandelt?

III. Spontan bakterielle Peritonitis

III.1. Einleitung: Definition, Inzidenz und Prognose einer spontanbakteriellen Peritonitis (SBP) bzw. eines Bakteraszites

III.2. Wann und wie sollte eine Primärprophylaxe einer SBP durchgeführt werden?

III.3. Wie sollte eine SBP behandelt werden?

III.4. Wie sollte die Sekundärprophylaxe und Nachsorge einer SBP aussehen?

IV. Hepatorenales Syndrom

IV.1. Einleitung: Definition

IV.2. Welchen Stellenwert hat die Albumingabe in der Therapie des HRS?

IV.3. Welchen Stellenwert haben Vasokonstriktoren in der Therapie des HRS?
IV.4. Gibt es einen Stellenwert des transjugulären intrahepatischen portosystemischen Shunts (TIPS) bei HRS?

IV.5. Wann ist ein Nierenersatzverfahren beim HRS indiziert und welchen Stellenwert haben Leberersatzverfahren?

IV.6. Wie beeinflusst das HRS die Indikation zur und den Verlauf nach Lebertransplantation?

V. Hepatischer Hydrothorax

V.1. Einleitung: Definition

V.2. Welche Untersuchungen sind zur Abklärung eines hepatischen Hydrothoraxes notwendig?

V.3. Wie sollten Patienten mit hepatischem Hydrothorax therapiert werden?

V.4. Wie sollten Patienten mit rezidivierendem hepatischem Hydrothorax therapiert werden?

V.5. Spontan bakterielles Empyem (SBEM)

V.5.1 Wie wird ein spontan bakterielles Empyem (SBEM) diagnostiziert und therapiert? Abkürzungsverzeichnis Literatur

Die vorliegende Leitlinie wurde erstellt durch die Deutsche Gesellschaft für Verdauungs- und Stoffwechselkrankheiten (Leitung: Prof. Dr. med. A. L. Gerbes, Medizinische Klinik und Poliklinik II, Klinikum der Universität München Großhadern; Prof. Dr. T. Sauerbruch, Medizinische Klinik und Poliklinik I, Universitätsklinikum Bonn) in Zusammenarbeit mit folgenden Fachgesellschaften/ Organisationen:

- Deutsche Gesellschaft für Allgemein- und Viszeralchirurgie (DGAV)

- Deutsche Gesellschaft für Ernährungsmedizin (DGEM)

- Deutsche Gesellschaft für Infektiologie (DGI)

- Deutsche Gesellschaft für Nephrologie (DGfN)

- Deutsche Gesellschaft für Pathologie (DGP)

- Deutsche Röntgengesellschaft (DRG)

- Lebertransplantierte Deutschland e.V. 


\section{Leitlinienstruktur}

$\nabla$

\section{Geltungsbereich und Gültigkeitsdauer der Leitlinie}

Der Inhalt dieser Leitlinie ist auf die medizinische Versorgung bei bestehendem Aszites, spontan bakterieller Peritonitis und hepatorenalem Syndrom von erwachsenen Patienten gerichtet. Die Versorgung von Kindern und Jugendlichen ist nicht Gegenstand dieser Leitlinie. Auch die Therapie des Aszites bei malignen und anderen Grunderkrankungen ist nicht Gegenstand der Leitlinie. Patienten mit Aszites, hepatorenalem Syndrom oder spontan bakterieller Peritonitis sind meist in einem fortgeschrittenen Stadium der Leberzirrhose. Daher sollte immer auch die mögliche Indikation für eine Lebertransplantation erwogen werden. Auf diesen Aspekt wird in der Leitlinie nicht weiter eingegangen.

Die Leitlinie hat eine Gültigkeitsdauer von 5 Jahren.

\section{Arbeitsgruppenmitglieder}

Die verschiedenen thematischen Aspekte wurden in verschiedenen Arbeitsgruppen bearbeitet. Die Mitglieder der Arbeitsgruppen sind in nachstehender $\bullet$ Tab. 1 aufgeführt. Die Leiter der Arbeitsgruppen sind durch Fettdruck des Namens hervorgehoben.

Tab. 1 Themenkomplexe und Mitglieder der Arbeitsgruppen.

\begin{tabular}{l} 
Arbeitsgruppe 1 „Diagnostik des Aszites“ \\
Dr. med. Appenrodt, B., Medizinische Klinik und Poliklinik I, Universi- \\
tätsklinikum Bonn \\
Prof. Dr. med. Baretton, G., Institut für Pathologie, Universitätsklinikum \\
Dresden, Deutsche Gesellschaft für Pathologie \\
Dr. med. Buggisch, P., Leberzentrum Hamburg, IFI, Asklepiosklinik \\
St. Georg, Hamburg \\
Prof. Dr. med. Gelbmann, C., Internistische Praxis - Gastroenterologie, \\
Facharztzentrum Regensburg, Regensburg \\
\hline PD Dr. med. Heller, J., Innere Medizin/Gastroenterologie, Marienhaus \\
Klinikum im Kreis Ahrweiler, Bad Neuenahr-Ahrweiler \\
\hline Prof. Dr. med. Holstege, A., Medizinische Klinik I, Klinikum Landshut \\
\hline Prof. Dr. med. Rössle, M., Praxis Zentrum für Gastroenterologie und \\
Endokrinologie, Freiburg \\
Arbeitsgruppe 2 „Therapie des Aszites“ \\
PD Dr. med. Bahr, M. J., Medizinische Klinik I, Sana Kliniken, Lübeck \\
PD Dr. med. Dr. phil. Biecker, E., Medizinische Klinik für Gastroenterolo- \\
gie und Hepatologie, Helios-Klinikum Siegburg \\
\hline PD Dr. med. Jakobs, T. F., Institut für Klinische Radiologie, Klinikum \\
Großhadern, Klinikum der Universität München, Deutsche Röntgen- \\
gesellschaft \\
\hline Prof. Dr. med. Plauth, M., Klinik für Innere Medizin, Städtisches Klinikum \\
Dessau, Deutsche Gesellschaft für Ernährungsmedizin \\
Prof. Dr. med. Dr. h. c. Reiser, M., Institut für Klinische Radiologie, Klini- \\
kum Großhadern, Klinikum der Universität München, Deutsche Rönt- \\
gengesellschaft \\
PD Dr. med. Schepke, M., Medizinische Klinik für Gastroenterologie und \\
Hepatologie, Helios-Klinikum Siegburg \\
Dr. med. Steib, C., Medizinische Klinik und Poliklinik II, Klinikum der Uni- \\
versität München Großhadern
\end{tabular}

Arbeitsgruppe 3 „Spontan bakterielle Peritonitis“

Prof. Dr. med. Glück, T., Innere Abteilung, Kreisklinik Trostberg, Kliniken Südostbayern AG

Prof. Dr. med. Salzberger, B., Innere Medizin I, Universitätsklinikum Regensburg, Deutsche Gesellschaft für Infektiologie
Methodik

In dieser Leitlinie sind die Evidenzgrade nach dem OxfordSchema angegeben ( Tab.2). Die Empfehlungen sind so formuliert, dass sie die Stärke der Empfehlungen widerspiegeln ( $\bullet$ Abb.1). Eine Ausnahme stellen 5 Empfehlungen dar, die als sog. „Klinischer Konsens-Punkt“ (KKP) die gute klinische Praxis in der Behandlung beschreiben.

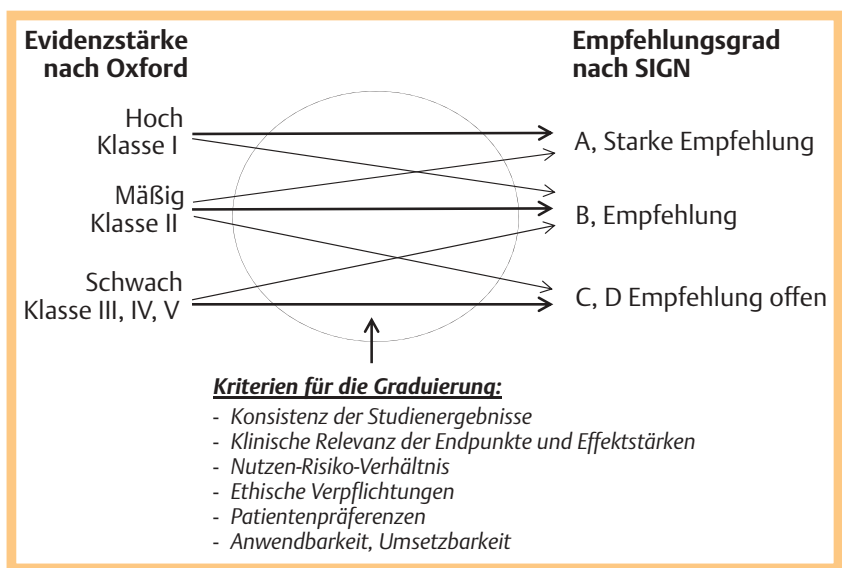

Abb. 1 Überleitung der Evidenzstärke in Empfehlungsgrade (modifizierte Abbildung aus "Lehrbuch Evidenzbasierte Medizin in Klinik und Praxis“, Hrsg. Kunz et al., Deutscher Ärzte-Verlag, 2007, Seite 367).

Tab. 1 (Fortsetzung)

Prof. Dr. med. Trautwein, C., Medizinische Klinik III, Universitätsklinikum Aachen

PD Dr. med. Wiest, R., Innere Medizin I, Universitätsklinikum Regensburg Arbeitsgruppe 4 „Hepatorenales Syndrom“

Prof. Dr. med. Gerken, G., Klinik für Gastroenterologie und Hepatologie, Universitätsklinikum Essen

PD Dr. med. Gülberg, V., Medizinische Klinik Innenstadt mit Schwerpunkt Gastroenterologie, Klinikum der Universität München Prof. Dr. med. Dr. h.c. Heemann, U., Medizinische Klinik, Abteilung für Nephrologie, Klinikum rechts der Isar der TU München, Deutsche Gesellschaft für Nephrologie

PD Dr. med. Rifai, K., Klinik für Gastroenterologie, Hepatologie und Endokrinologie, Medizinische Hochschule Hannover

Prof. Dr. med. Schlitt, H., Klinik und Poliklinik für Chirurgie, Universitätsklinikum Regensburg, Deutsche Gesellschaft für Allgemein- und Viszeralchirurgie

Prof. Dr. med. Wasmuth, H. E., Medizinische Klinik III, Universitätsklinikum Aachen

Arbeitsgruppe 5 „Hepatischer Hydrothorax“

PD Dr. med. Dollinger, M. M., PhD, Universitätsklinik und Poliklinik für Innere Medizin I, Universitätsklinikum Halle

Prof. Dr. med. Ghofrani, A., Medizinische Klinik II, Universitätskliniken Gießen und Marburg, Standort Gießen

PD Dr. med. Jakobs, T. F., Institut für Klinische Radiologie, Klinikum Großhadern, Klinikum der Universität München, Deutsche Röntgengesellschaft

Prof. Dr. med. Kujath, P., Klinik für Chirurgie, Universitätsklinikum Schleswig-Holstein, Campus Lübeck, Deutsche Gesellschaft für Allgemein- und Viszeralchirurgie

Prof. Dr. med. Dr. h.c. Reiser, M., Institut für Klinische Radiologie, Klinikum Großhadern, Klinikum der Universität München, Deutsche Röntgengesellschaft

Dr. med. Zipprich, A., Universitätsklinik und Poliklinik für Innere Medizin, Universitätsklinikum Halle 
Tab. 2 Klassifikation der Evidenz nach dem Oxford-Schema. ${ }^{1}$

\begin{tabular}{|c|c|}
\hline Evidenzgrad & Beschreibung \\
\hline la & $\begin{array}{l}\text { „Evidenz“ durch systematisches Review randomisierter } \\
\text { kontrollierter Studien (RCT) }\end{array}$ \\
\hline Ib & „Evidenz“ durch eine geeignet geplante RCT \\
\hline Ic & Alle-oder-Keiner-Prinzip \\
\hline Ila & $\begin{array}{l}\text { „Evidenz“ durch systematisches Review gut geplanter } \\
\text { Kohortenstudien }\end{array}$ \\
\hline IIb & $\begin{array}{l}\text { „Evidenz“ durch eine gut geplante Kohortenstudie/RCT } \\
\text { mäßiger Qualität (z. B. < } 80 \% \text { Follow-up) }\end{array}$ \\
\hline Ilc & „Evidenz" durch Outcome-Research-Studien \\
\hline IIla & $\begin{array}{l}\text { „Evidenz“ durch systematisches Review gut geplanter } \\
\text { Fallkontrollstudien }\end{array}$ \\
\hline IIIb & „Evidenz“ durch eine Fallkontrollstudie \\
\hline IV & $\begin{array}{l}\text { „Evidenz“ durch Fallserien/Kohorten- und Fallkontroll- } \\
\text { studien mäßiger Qualität }\end{array}$ \\
\hline V & $\begin{array}{l}\text { Expertenmeinung ohne explizite kritische Bewertung } \\
\text { oder basierend auf physiologischen Modellen, Labor- } \\
\text { forschungsresultaten oder „first principles“ }\end{array}$ \\
\hline
\end{tabular}

Hinsichtlich der weiteren, ausführlichen Details zum organisatorischen Ablauf sowie zu den methodischen Grundlagen der S3-Leitlinienerstellung (Literaturrecherche, Klassifikation der Evidenz- und Empfehlungsgrade, Konsensusprozess etc.) wird auf den Leitlinienmethodenreport verwiesen, der separat im gleichen Heft der Zeitschrift für Gastroenterologie (S. 780-787) abgedruckt ist.

\section{Diagnostik des Aszites \\ $\nabla$}

\section{I.1. Einleitung: Ursachen des Aszites}

Das Auftreten von Aszites signalisiert in der Regel eine schwere Erkrankung und erfordert daher eine diagnostische Abklärung. Neben der Anamnese und der körperlichen Untersuchung gehören Laboruntersuchungen der Leberwerte, Nierenfunktion sowie der Serum- und Urinelektrolyte zur Primärdiagnostik. Anschließend folgt die gezielte ätiologisch ausgerichtete Diagnostik entsprechend der Wahrscheinlichkeit einer speziellen Organerkrankung. Bei etwa 75\% der Patienten ist die Ursache im Bereich der Leber zu finden [1]. Hierzu gehören auch die vaskulären Erkrankungen der Leber, insbesondere das Budd-Chiari-Syndrom (BCS) und das sinusoidale Obstruktionssyndrom (früher als venocclusive disease bezeichnet).

Wesentlich für die Differenzialdiagnostik des Aszites ist die diagnostische Parazentese. Sie muss insbesondere die Fragen klären, ob es sich um einen malignen oder infizierten Aszites handelt. Hier kann der makroskopische Aspekt erste Hinweise geben. Hämorrhagischer Aszites kann ein Zeichen für Malignität sein, jedoch kann dieser auch Folge eines Traumas, einer Pankreatitis oder - sehr selten - einer Peritonealtuberkulose sein. Trüber Aszites kann Ausdruck einer hohen Leukozytenzahl oder eines hohen Eiweißgehalts sein [2]. Milchig-trüber bzw. chylöser Aszites ist pathognomisch für Aszites mit einer hohen Konzentration von Chylomikronen und Triglyceriden (>200 mg/dl) [3, 4]. Die häufigsten Ursachen des chylösen Aszites sind maligne Erkrankungen und die portale Hypertension [4]. Eine laborchemische und zytologische Aufarbeitung des Punktats ist obligatorisch ( Tab. 3).

\section{Tab. 3 Ursachen des Aszites.}

Ursachen des Aszites
hepatische Ursache:
Leberzirrhose
akute Leberschädigung
Budd-Chiari-Syndrom (BCS)/sinusoidales Obstruktionssyndrom
kardiale Genese:
Rechtsherzinsuffizienz
Pericarditis constrictiva
Globalherzinsuffizienz
maligne Ursache:
Peritonealmetastasen
Malignom der Leber
entzündliche Ursache:
bakterielle (sekundäre) Peritonitis
tuberkulöse Peritonitis
nephrotisches Syndrom
Pankreatitis, Pankreasfisteln
Myxödem
Lymphfistel
biliäre Genese (z. B. Gallefisteln nach Gallenblasen/-gangs-Operationen,
Gallenblasenruptur/-perforation)

\section{I.2. Wann soll eine diagnostische Aszitespunktion durchgeführt werden?}

\section{Empfehlung}

Eine diagnostische Aszitespunktion soll in der Regel bei neu aufgetretenem Aszites erfolgen. Außerdem soll sie bei allen Patienten mit Zirrhose und Komplikationen sowie bei nicht elektiver stationärer Aufnahme durchgeführt werden. (A), Konsens: 100\%

\section{Kommentar}

Bei jedem neu aufgetretenen Aszites erfolgt die diagnostische Punktion zur Klärung der Genese [2].

Bei jeder Verschlechterung des Allgemeinzustands von Patienten mit Leberzirrhose und Aszites, neu aufgetretenen Komplikationen der Leberzirrhose oder bei Verschlechterung der Leberfunktionsparameter (wie Bilirubin, INR, Albumin) sowie anderer laborchemischer Parameter wie Kreatinin, Harnstoff soll eine diagnostische Aszitespunktion zum Ausschluss einer spontan bakteriellen Peritonitis (SBP) erfolgen [1, 2] (Evidenzgrad IIa). Bei Patienten mit bekanntem Aszites, die nicht elektiv stationär aufgenommen werden, ist ebenfalls eine diagnostische Aszitespunktion indiziert, da eine hohe Prävalenz von Infektionen bei diesen Patienten mit Aszites besteht [5] (Evidenzgrad IIb).

Die SBP geht als inflammatorische Reaktion mit einer vermehrten Zytokinausschüttung einher. Klinisch kann es zu einer Aggravation bestehender oder Auftreten neuer Komplikationen wie hepatorenalem Syndrom oder hepatischer Enzephalopathie kommen. Eine nicht diagnostizierte und somit nicht therapierte SBP ist mit einer erhöhten Mortalität assoziiert.

Wiederholte diagnostische Aszitespunktionen sind bei Patienten in ambulanter Behandlung im stabilen klinischen Zustand und mit stabilen laborchemischen Parametern nicht notwendig. Die Prävalenz von Infektionen ist bei dieser Patientengruppe sehr niedrig. Bei 400 Aszitespunktionen bei ambulanten Patienten wurden in einem Zeitraum von 2 Jahren insgesamt 8 Episoden einer spontan bakteriellen Peritonitis (2\%) diagnostiziert [6-9] (Evidenzgrad Ib). 
Bei kurzfristig wiederholten therapeutischen Punktionen ist eine zusätzliche diagnostische Analyse des Punktats nur im Bedarfsfalle erforderlich.

\section{I.3. Technik, Komplikationen und Kontraindikationen der Aszitespunktion}

Empfehlung

Die Parazentese soll nach Aufklärung des Patienten unter sterilen Bedingungen durchgeführt werden. (A), Konsens: $100 \%$

Die erste Punktion sollte nach sonografischer Kontrolle durchgeführt werden. Eine Venenverweilkanüle oder eine andere Punktionskanüle wird an geeigneter Stelle (typische Stelle: linker unterer Quadrant des Bauches) durch die Bauchdecke in den Aszites vorgeschoben. (B), Konsens: $100 \%$

\section{Kommentar}

Technik

Unter einer Aszitespunktion oder Parazentese versteht man die Gewinnung von Flüssigkeit aus dem Peritonealraum mit diagnostischer oder therapeutischer Intention. Nach den allgemein geltenden Richtlinien für Krankenhaushygiene und Infektprävention gilt eine Aszitespunktion als invasive Maßnahme und soll daher unter sterilen Bedingungen erfolgen [10]. Die Komplikationsrate einer Aszitespunktion ist als gering einzuschätzen (s.u.), dennoch ist jeder Patient vor Punktion über mögliche Komplikationen aufzuklären. Zur diagnostischen Punktion können dünnkalibrige Kanülen gewählt werden. Bei der therapeutischen Punktion des Aszites können Venenverweilkanülen [11], 17G Metall-Kanülen [12], Pigtailkatheter [13] oder weitere speziell entwickelte Punktionsnadeln mit mehreren Seitenlöchern [11, 14] eingesetzt werden. In Deutschland werden für die Parazentese meist Venenverweilkanülen eingesetzt. Nachteile sind eine geringe Knickstabilität, nur eine Öffnung am Distalende, was zu häufigeren Repositionen führen kann, sowie schwierige Befestigungsmöglichkeiten an der Bauchdecke [11]. Vorteile sind jedoch die generelle Verfügbarkeit und die geringen Kosten. Vor Durchführung der Parazentese erfolgt eine Aufklärung des Patienten über den Eingriff.

Eine vorherige Sonografie zur Festlegung des Punktionsorts soll durchgeführt werden. Bei geringer Punktatmenge kann die Punktion auch unter direkter sonografischer Steuerung durchgeführt werden $[15,16]$. Der Ultraschall erlaubt nicht nur, Fehlpunktionen zu vermeiden [15] und die optimale Punktionsstelle zu finden [16], sondern auch eine Einschätzung des Aszitesvolumens [17, 18]. In einer Studie war die Aszitesausdehnung im linken lateralen unteren Quadranten des Abdomens bei Linksschräglage ausgeprägter als infraumbilical in Rückenlage [16]. Der rechte untere Quadrant des Abdomens kann grundsätzlich auch als Punktionsstelle aufgesucht werden, hat aber den Nachteil eines z.B. unter Laktulosegabe evtl. geblähten Zökums oder einer Narbe nach Appendektomie mit der Gefahr einer Darmperforation. Weiterhin sollte die Punktionsstelle unter Berücksichtigung des mutmaßlichen Verlaufs der epigastrischen Gefäße erfolgen. „Blindpunktionen“ sollten bei Verfügbarkeit eines Ultraschallgeräts nicht durchgeführt werden $[15,16]$ (Evidenzgrad IIb) Ausnahmen können kurzfristig wiederholte therapeutische Parazentesen bei massivem Aszites unter Beachtung der vormaligen Punktionsstellen darstellen.

Der Einstich erfolgt unter sterilen Bedingungen [11, 15] mit oder ohne vorheriger lokaler Betäubung mit einem Lokalanäs- thetikum. Zur Vermeidung einer Fistelbildung werden ein schräger Einstich im $45^{\circ}$-Winkel oder die „Z-Durchstichtechnik“ empfohlen.

\section{Komplikationen}

Diagnostische Parazentesen sind nicht mit schwerwiegenden Komplikationen verbunden, eine höhere Komplikationsrate besteht bei den therapeutischen Parazentesen [19-21]. Die häufigste Komplikation der therapeutischen Parazentesen ist mit 5\% ein protrahierter Austritt von Aszites durch den Stichkanal [19]. Dies kann durch Lagerung des Patienten auf die dem Stichkanal gegenüberliegende Seite, Wahl eines schrägen Stichkanals, vollständiges Ablassen des Aszites oder ggf. eine Tabaksbeutelnaht verhindert werden [19, 22]. Eine Peritonitis oder ein Bauchdeckenabszess nach Darmperforation fand sich jeweils nur bei 1 von 242 Parazentesen [25] (Evidenzgrad IIb). Blutungen (Einblutungen in die Bauchdecke oder intraperitoneale Blutungen) sind die häufigsten Komplikationen, aber mit 0,19-1\% der Parazentesen selten [19-27]. Nur kasuistisch wurden lebensbedrohliche Blutungsereignisse (0,016\%) beschrieben [23, 26, 27] (Evidenzgrad IIb).

\section{I.3.1. Sollen Gerinnungsfaktoren vor einer Aszitespunktion substituiert werden?}

\section{Empfehlung}

Die prophylaktische Gabe von Blutprodukten zur Vermeidung von Blutungskomplikationen ist in der Regel nicht erforderlich und wird auch bei erniedrigten Thrombozytenzahlen und Gerinnungsfaktoren nicht empfohlen (B); Ausnahmen können jedoch eine disseminierte intravasale Koagulopathie (DIC) (B) und/oder Thrombozyten <20000/ $\mu$ l und/oder Quick <20 bzw. INR > 2,5 darstellen. (D), Konsens: 100\%

\section{Kommentar}

Die Parazentese ist auch bei Patienten mit verlängerter PTT (bis $2 \times$ oberer Normwert) oder niedrigen Thrombozytenzahlen

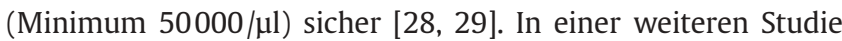
traten auch bei noch ausgeprägteren Thrombozytopenien (Mi-

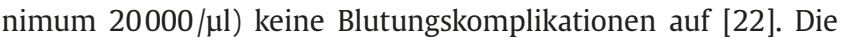
üblichen Gerinnungsanalysen geben das Blutungsrisiko von Patienten mit einer Leberzirrhose nicht wieder, da meist ein ausgewogener Abfall aller Parameter vorliegt, der die Koagulation des Blutes nicht beeinträchtigt [30] (Evidenzgrad IIb).

Die prophylaktische Substitution von Blutprodukten (Thrombozytenkonzentrate, „fresh frozen Plasma“ [FFP], Gerinnungsfaktoren) wird daher im Allgemeinen vor einer Parazentese nicht empfohlen [28] (Evidenzgrad IIb).

Allerdings kann eine Gerinnungsoptimierung durch Gabe von Blutprodukten (FFP, Thrombozytenkonzentrate) bei einer massiv eingeschränkten Gerinnungssituation mit Thrombozyten $<20000 / \mu l$ und/oder einem INR > 2,5 bzw. Quick-Wert <20\% vor Aszitesparazentese erwogen werden (Evidenzgrad V).

\section{I.3.2. Welche Kontraindikationen zur Aszitespunktion bestehen?}

\section{Empfehlung}

Es gibt keine absoluten Kontraindikationen für eine Aszitespunktion. Das Vorliegen einer disseminierten intravasalen Koagulopathie (DIC) oder ein eingeschränkter perkutaner Zugangsweg zum Aszites können relative Kontraindikationen darstellen. (D), Konsens: 100\% 


\section{Kommentar}

Absolute Kontraindikationen für eine diagnostische Aszitespunktion bestehen nicht.

Das Vorliegen einer disseminierten intravasalen Koagulopathie (DIC) stellt eine relative Kontraindikation dar, die nach Abwägung des Risikos und der Notwendigkeit einer diagnostischen Punktion und ggf. nach Substitution von Gerinnungsfaktoren individuell entschieden werden sollte. Wegen des sehr geringen Risikos einer Blutungskomplikation [22, 29] und der fehlenden Einschätzbarkeit des Blutungsrisikos mit den üblichen Labortests bei Patienten mit Leberzirrhose [30] ist in allen anderen Fällen eine Aszitespunktion möglich. Ein stark erhöhter Kreatininwert ( $>6 \mathrm{mg} / \mathrm{dl}$ ) wurde als Risikofaktor für eine Blutungskomplikation beschrieben [29], sodass eine längere Nachbeobachtung in diesen Fällen stattfinden sollte (Evidenzgrad IIb).

Ein mögliches Problem stellt ein eingeschränkter Zugang zum Aszites-gefülltem Peritonealraum dar. Der Zugangsweg kann durch vergrößerte solide Organe (Hepatosplenomegalie, Zystennieren), Tumoren oder stark gefüllte Hohlorgane (luftgefüllte Darmschlingen bei Ileus, Darmadhäsionen an der Bauchwand, Harnblasenatonie, Harnabflussstörungen) behindert sein. Organverletzungen sind durch ultraschallgesteuerte Punktionen zu vermeiden (Evidenzgrad IIb). Da die Literatur zu I.3.3 nicht konsistent ist, wurde trotz des Evidenzgrads eine Abstufung auf Empfehlung „D“ vorgenommen.

\section{I.4. Diagnostik bei Aszitespunktion \\ I.4.1. Welche Untersuchungen sind obligater Bestandteil der initialen Aszitespunktion?}

\section{Empfehlung}

Bei der initialen Aszitespunktion sollten die Zellzahl, nach Möglichkeit mit Zelldifferenzierung, und das Gesamteiweiß im Aszites bestimmt sowie eine mikrobiologische Kultur angelegt werden. (B), Konsens: $100 \%$

Eine Beimpfung von aeroben und anaeroben Blutkulturflaschen mit mindestens $10-20 \mathrm{ml}$ Aszitesflüssigkeit sollte bei der initialen Aszitesdiagnostik, bei stationären Patienten sowie bei der Diagnostik einer spontan bakteriellen Paritonitis (SBP) erfolgen. Dies sollte unmittelbar am Patientenbett unter sterilen Bedingungen durchgeführt werden. (B), Konsens: 100\%

\section{I.4.2. Welche Untersuchungen sind optionaler Bestandteil einer Aszitespunktion?}

\section{Empfehlung}

Bei Verdacht auf malignen Aszites soll eine zytologische Diagnostik durchgeführt werden. (A), Konsens: $100 \%$

Eine zusätzliche Bestimmung der Cholesterin- oder CEA-Spiegel im Aszites kann zur Differenzierung maligner/nicht maligner Aszites durchgeführt werden. (B), Konsens: 100\%

Die Bestimmung des Serum-Aszites-Albumin-Gradienten (SAAG) ist im Regelfall nicht erforderlich (B). Die Anwendung von Leukozytenteststreifen (sog. „Urinstix“) zum semiquantitativen Nachweis von Leukozyten im Aszites wird als alleiniges Nachweisverfahren nicht empfohlen. (A), Konsens: $100 \%$

\section{Kommentar}

\section{Zellzahl/-differenzierung}

Eine Zellzählung und -differenzierung sollte bei jeder initialen Aszitespunktion erfolgen. Sie ist eine valide und schnelle Untersuchung. Dabei gilt eine Gesamtzellzahl $>500 / \mu \mathrm{l}$ als diagnostischer Hinweis auf eine SBP bzw. sekundäre Peritonitis [31]. Die Zelldifferenzierung ist jedoch der „Goldstandard“ in der Diagnostik der SBP. Dabei ist das diagnostische Kriterium für eine SBP eine Erhöhung der segmentkernigen Granulozyten $>250 / \mu l$ [32-34] (siehe Kapitel SBP). Eine maschinelle Zelldifferenzierung ist gegenüber der manuellen Differenzierung, die zeit- und personalaufwendig ist, gleichwertig [31]. Allerdings ist die maschinelle Differenzierung nicht in jedem Labor verfügbar bzw. zertifiziert, sodass in diesen Fällen eine manuelle Differenzierung erfolgen sollte (Evidenzgrad Ib).

Die Erythrozytenzahl im Aszites ist meist niedrig $(<1000 / \mu \mathrm{l})$. Bei hämorrhagischem Aszites (Erythrozyten $>50000 / \mu \mathrm{l}$ ) kann es zu einer falsch hohen Zellzahl kommen. Hier sollte ein Korrekturfaktor für die sonstige Zellzählung wie folgt angewendet werden: Subtraktion der Granulozytenzahl um jeweils 1 pro 250 Erythrozyten/ul [32].

Lymphozytärer Aszites mit einem Überwiegen des Lymphozytenanteils ist häufig bei Lymphomen, aber auch bei abdomineller Tuberkulose zu finden. Zur weiteren Differenzierung sind zusätzliche immunzytochemische bzw. -histochemische oder mikrobiologische Untersuchungen hilfreich [4].

\section{Gesamteiweiß im Aszites}

Ein niedriges Gesamteiweiß $(<1,5 \mathrm{~g} / \mathrm{dl})$ im Aszites korreliert mit einer geringeren Opsonierungsfähigkeit, die mit einer höheren Inzidenz einer SBP einhergeht und damit potenziell zur Identifikation von Patienten für eine primär prophylaktische Antibiotika-Gabe verwendet werden kann (siehe Kapitel SBP) [35-38] (Evidenzgrad Ib).

\section{Serum-Aszites-Albumin-Gradient (SAAG)}

Die Bestimmung des SAAGs (Differenz zwischen der Albuminkonzentration im Serum und im Aszites) kann hilfreich sein zur Differenzierung zwischen portal-hypertensiver und nicht portal-hypertensiver Genese des Aszites. Dabei soll die Bestimmung der beiden Werte (Albumin im Blut und Aszites) am selben Untersuchungstag erfolgen [39]. Ein SAAG >1,1 g/dl spricht mit einer Treffsicherheit von $97 \%$ für eine portale Hypertension als Ursache des Aszites [40], während ein Gradient <1,1 g/dl zu etwa 95\% auf eine andere Ursache des Aszites hinweist (Peritonealmetastasen, Pankreatitis, Tuberkulose, Myxödem) [39, 40] (Evidenzgrad Ib). Die Bestimmung des SAAG und des Gesamteiweißes im Aszites kann zur Differenzierung des kardialen Aszites herangezogen werden: Bei kardialer Aszitesursache ist der SAAG ebenfalls $>1,1 \mathrm{~g} / \mathrm{dl}$, da es sich hierbei um ein Filtrat handelt. Die Eiweißkonzentration ist jedoch in der Regel bei kardialem Aszites > 2,5 g/dl, bei zirrhotischem Aszites <2,5 g/dl [41].

\section{Mikrobiologische Diagnostik}

Bei Patienten mit Aszites in ambulanter Behandlung mit stabilem Verlauf sind wiederholte diagnostische Untersuchungen im Aszites nicht notwendig, da die Prävalenz von Infektionen sehr niedrig ist (etwa 2\%) [6-9] (Evidenzgrad Ib).

Bei Verdacht auf infektiösen Aszites beinhaltet die Diagnostik als grundlegende Untersuchung neben der Zellzahl mit Differenzierung auch die Beimpfung von Bakterienkulturflaschen mit Aszitespunktat. Das positive Ergebnis der Bakterienkultur 
beweist zum einen die bakterielle Besiedlung des Aszites und gibt Hinweise auf eine evtl. vorliegende Infektion, zum anderen kann nach Antibiogramm gezielt antibiotisch therapiert werden. In prospektiven Studien konnte eine höhere Sensitivität der Bakterienkultur gezeigt werden, wenn a) die Kulturflaschen direkt am Bett des Patienten beimpft werden und b) mindestens $10 \mathrm{ml}$ Punktat beimpft werden [42-44] (Evidenzgrad Ib).

Allerdings liegen selbst bei dieser Methodik häufig negative Kulturergebnisse vor: Nur bei 36-59\% der Patienten mit einer

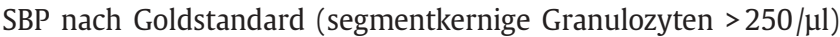
kann eine bakterielle Besiedlung durch die Bakterienkultur nachgewiesen werden [43-46]. Ursächlich für die niedrige Zahl positiver Kulturergebnisse ist wahrscheinlich die geringe Konzentration von Bakterien in der Aszitesflüssigkeit, im Gegensatz zu anderen Körperflüssigkeiten wie z. B. im Urin [44].

In mehreren teilweise multizentrischen Studien wurde untersucht, ob durch den Einsatz von Teststreifen, die primär für die Urinanalyse entwickelt wurden, die Diagnose einer SBP schnell und zuverlässig gestellt werden kann. Das Prinzip basiert auf einer Farbreaktion, die durch Leukozytenesterase bei entsprechender Leukozytenkonzentration im Punktat abläuft. Diese Studien zeigten, dass die diagnostische Methode der Teststreifen eine Sensitivität von 64,7-100\% und eine Spezifität von $99-100 \%$ besitzt [47-52]. Vorteile sind ein rasches Ergebnis, eine hohe Verfügbarkeit, eine einfache Handhabung und niedrige Kosten. In einer aktuellen multizentrischen Studie wurde bei 1041 stationären und ambulanten Patienten mit Leberzirrhose und Aszites der Einsatz von Urin-Teststreifen zur Diagnostik der SBP mit der Frage nach Sensitivität und Spezifität dieses Testverfahrens erneut untersucht. Es zeigte sich hier eine deutlich geringere Sensitivität von nur 45,3\% bei einer Spezifität von 99,2\% [53], sodass nach diesen Ergebnissen und nach einer aktuellen systematischen Analyse aller Studien [54] die Teststreifen lediglich als mögliche Ergänzung zur üblichen Aszitesdiagnostik verwendet werden sollten, wenn ein klinisch-chemisches Labor nicht unmittelbar zur Verfügung steht (Evidenzgrad Ia).

Diagnostik bei Verdacht auf malignen Aszites

Maligner Aszites ist die zweithäufigste Ursache des Aszites und sollte daher in der Diagnostik frühzeitig in Betracht gezogen werden. Standard in der Diagnostik des malignen Aszites ist die zytologische Untersuchung des Aszites. Die Sensitivität der Zytologie liegt bei $83 \%$, wenn eine Probe untersucht wird und steigt bis auf 97\%, wenn 3 Proben untersucht werden [55]. Der Einsatz der DNA-Zytometrie kann möglicherweise die Sensitivität verbessern [56], ist in der Routinediagnostik aber nicht verfügbar.

Die Konzentration von Cholesterin im Aszites kann in der diagnostischen Sequenz zur Differenzierung maligne/nicht maligne hilfreich sein (Normwert im Aszites $<45 \mathrm{mg} / \mathrm{dL}$ ) [57]. Für diesen Parameter konnte eine Sensitivität bis zu 91\% und eine Spezifität bis zu 95\% gezeigt werden [58]. Bei einem Cholesterinwert $>45 \mathrm{mg} / \mathrm{dl}$ sollten als weitere diagnostische Schritte eine zytologische Untersuchung des Aszites und eine CEA-Bestimmung im Aszites erfolgen [59, 60]. Diese diagnostische Kombination erreicht dann einen positiven Vorhersagewert von 92\% [58] (Evidenzgrad Ib). Die CEA-Bestimmung im Aszites alleine hat bei einem Cut-off-Wert von $>5 \mathrm{ng} / \mathrm{ml}$ eine Sensitivität von nur 51\% [60]. Zusammen mit der zytologischen
Diagnostik steigt diese auf $80 \%$ bei gleichbleibender Spezifität von $100 \%$ [59] (Evidenzgrad Ib).

Makroskopisch imponiert maligner Aszites häufig milchigtrüb/chylös oder hämorrhagisch [2, 4].

Fraglich hilfreiche Laborparameter im Aszites sind die Asziteskonzentrationen von Eiweiß, LDH und Fibronektin. Ein Eiweißgehalt von $>3 \mathrm{~g} / \mathrm{dl}$ im Aszites hat einen positiven Vorhersagewert von $85 \%$ und erlaubt somit keine ausreichende Diskriminierung zwischen maligner und nicht maligner Genese des Aszites [58]. Ein LDH-Spiegel $>400 \mathrm{U} / 1$ oder eine Aszites-Serum-LDH-Ratio >0,6 sind charakteristisch für ein Exsudat. Dabei ist jedoch eine genaue Abgrenzung eines malignen Aszites nicht möglich [61]. Fibronektin ist ein Glykoprotein, das eine Rolle bei der Regulierung der Zellorganisation spielt. Es konnte gezeigt werden, dass bei malignem Aszites die Fibronektinspiegel signifikant höher waren im Vergleich zu nicht malignem Aszites. Einen einheitlichen Cut-off-Wert gibt es jedoch aktuell nicht, weshalb Fibronektin derzeit nicht als diagnostisches Kriterium für malignen Aszites in Betracht kommt $[62,63]$. Die Bestimmung des SAAG $<1,1 \mathrm{~g} / \mathrm{dl}$ hat eine mit $62 \%$ nicht ausreichende Sensitivität in der Abgrenzung zum nicht malignen Aszites [64]. In einer weiteren großen Analyse konnte bei $75 \%$ aller Patienten mit einem SAAG <1,1 g/dl kein maligner Aszites nachgewiesen werden [65]. Die Bestimmung des SAAG ist daher nicht ausreichend diskriminant bei dem Verdacht auf malignen Aszites (Evidenzgrad IIb).

Zusammenfassend differenzieren daher die Bestimmung der Eiweiß-, LDH- und Fibronektinkonzentration im Aszites sowie des Serum-Aszites-Albumin-Gradienten (SAAG) nicht ausreichend zwischen malignem und nicht malignem Aszites und sollten daher nicht zusätzlich bestimmt werden.

Die Bestimmung von anderen Tumormarkern wie CA19-9, CA15-3, CA125 und AFP im Aszites zur Differenzierung zwischen malignem und nicht malignem Aszites wird ebenfalls nicht empfohlen [59, 64, 65].

Bei Verdacht auf ein hepatozelluläres Karzinom oder auf Lebermetastasen ohne Peritonealmetastasen ist o.g. diagnostischer Algorithmus bei meist negativem Ergebnis als alleinige Diagnostik nicht zu empfehlen [60].

\section{I.4.3. Welche zytologischen Untersuchungen sollen durchgeführt werden?}

\section{Empfehlung}

Bei Verdacht auf malignen Aszites soll eine zytologische Diagnostik durchgeführt werden. (A), Konsens: 100\%

\section{Kommentar}

Bei klinischem Verdacht auf Malignität und bisher fehlendem Nachweis im Punktat sollte eine mehrmalige Wiederholung der Punktion erfolgen, um die Chance zu erhöhen, Tumorzellen aus dem Punktat zu isolieren [66-68] (Evidenzgrad Ib). Da die zytologische Treffsicherheit abhängig von der Menge des untersuchten Materials ist, sollten stets möglichst große Volumina bzw. mehrere Proben (mindestens 50-100 ml) verwendet werden [66-68] (Evidenzgrad Ib).

Das gesamte Punktat sollte aufgearbeitet werden, da die Zellausbeute abhängig vom Punktatvolumen ist. Ist der Transport z.B. aus Infrastrukturgründen nicht möglich, sollte das Punktat ca. eine Stunde lang an einem erschütterungsfreien Ort zum Sedimentieren stehen gelassen werden und anschließend der 
Sedimentanteil in $100 \mathrm{ml}$ nativer Ergussflüssigkeit eingesandt werden [67] (Evidenzgrad IIb).

Aszites aus einer Drainage sollte nicht mehr als wenige Stunden gesammelt werden, da die Gefahr der bakteriellen Kontamination und damit der Autolyse erhöht ist [67]. Bei großer Menge an Punktionsflüssigkeit oder bei Drainageflüssigkeit sollte jeweils die letzte gewonnene Fraktion eingesendet werden, da diese den höheren Zellgehalt an vitalen Zellen aufweist [68].

Der Versand sollte möglichst zügig und nativ in sterilen, bruchsicheren und dicht schließenden Gefäßen erfolgen, unter diesen Bedingungen ist die Ergussflüssigkeit $2-3$ Tage haltbar, ohne dass die Zellen morphologisch und immunologisch Schaden nehmen [66]. Ist kein sofortiger Versand möglich, sollte das Punktionsmaterial bei $4{ }^{\circ} \mathrm{C}$ gelagert werden. Da seröse Flüssigkeiten gute Nährmedien sind, halten sich die Zellen darin bis zu $24 \mathrm{~h}$ bei Raumtemperatur, bei $4^{\circ} \mathrm{C}$ auch bis zu $48 \mathrm{~h}$ [67].

Wichtig für eine treffsichere zytologische Diagnostik ist die Mitteilung wesentlicher klinischer Befunde und der diagnostischen Fragestellung durch den behandelnden Arzt [66]. Dabei sind detaillierte Angaben zu zugrunde liegenden Erkrankungen, wie z.B. Herzinsuffizienz und auch therapeutische Maßnahmen, wie z.B. Chemo- oder Strahlentherapie hilfreich [66]. Lavageflüssigkeiten (z.B. intraoperative Abdominallavage) sollten als solche gekennzeichnet werden [67].

Technische Bearbeitung im Labor

Bei geringen Ergussvolumina oder klaren Transsudaten bzw. bei resuspendierten zellarmen Sedimenten, bei denen eine geringe Zellzahl zu erwarten ist, können Zytozentrifugenpräparate angefertigt werden $[66,69]$.

Größere Flüssigkeitsmengen sollten in Portionen von 500 $1000 \mathrm{ml}$ bei $1500-2500$ Umdrehungen pro min $(700 \mathrm{~g}) 10 \mathrm{~min}$ zentrifugiert werden. Muss das Punktat aufgeteilt werden, sollten die Sedimente gemischt und nochmals zentrifugiert werden.

Befinden sich Gewebspartikel oder Präzipitate bzw. Fibrinflocken im Erguss, sollten diese in Paraffin eingebettet werden [67]. Hiervon können dann gefärbte Paraffinschnitte angefertigt werden [66].

Die zytologische Diagnostik erfolgt an May-Grünwald-Giemsa (MGG)-Präparaten; andere Färbemethoden werden kontrovers diskutiert [66, 67, 69].

Eine Eisenfärbung kann zusätzlich zum Nachweis hämosiderinspeichernder Makrophagen, eine PAS-Färbung bei V.a. eine Infiltration durch ein monozellulär schleimbildendes Karzinom durchgeführt werden [67].

Eine Gramfärbung ist in der Regel nicht indiziert, da die Keimkonzentration meist zu gering ist, sodass nur in Einzelfällen ein Keimnachweis gelingt [70].

\section{Standardisierte lichtmikroskopische Beurteilung}

Die Befundung sollte standardisiert nach der unten folgenden - von den Deutschen Gesellschaften für Pathologie und Zytologie erarbeiteten - Nomenklatur für die extragenitale Zytologie erfolgen [66, 68-72].

1. Angabe des eingesandten Untersuchungsmaterials, ggf. auch der klinischen Verdachtsdiagnose laut Begleitschein.

2. Beschreibung des erhaltenen Untersuchungsmaterials (Typ, Makroskopie/Farbe, Menge).
3. Beschreibung der Zellbilder, ggf. mit Hinweisen auf Erhaltungszustand und Repräsentativität.

4. Stufung der Malignitätswahrscheinlichkeit

- bösartige Zellen nicht nachweisbar (negativ) ( $0 \%$ )

- bösartige Zellen nicht auszuschließen (zweifelhaft) (ca. $30 \%$ )

- bösartige Zellen wahrscheinlich (dringender Verdacht) (ca. 60\%)

- bösartige Zellen nachweisbar (positiv) (100\%)

- unzureichendes Untersuchungsmaterial (mit Begründung: nekrotische, autolytische und osmotisch geschädigte Zellen)

5. Diagnose im Klartext, möglichst unter Verwendung von „preferred terms" der ICD-O-M bzw. des SNOMED, ggf. Angabe von Ausschlussdiagnosen, evtl. Hinweis auf mangelhafte Repräsentativität, unzureichenden Erhaltungszustand oder Präparationsartefakte. Weiterhin Kommentare, Empfehlungen, Stellungnahme zu klinischen Fragestellungen.

Die Papanicolaou(Pap)-Klassifikation eignet sich nicht für die extragenitale Zytodiagnostik und sollte nicht verwendet werden [72]. Die Verwendung von Nomenklaturen der Krebsvorsorgezytologie des Gebärmutterhalses (nach Papanicolaou) sollte außerhalb dieses Diagnostikfelds eingestellt werden. Auch die aktuellen Versionen (Münchner Nomenklatur II und Bethesda-Nomenklatur II) heben ausschließlich auf die Befundung von Gebärmutterhalsabstrichen ab. Sie sind ungeeignet zur Befundmitteilung in der Punktionszytologie [72].

\section{Etablierte Zusatztechniken}

Bei malignitätsverdächtigen oder nicht eindeutigen Befunden können zusätzliche immunzytochemische bzw. immunhistochemische (nach Anfertigen eines Zellblocks) Untersuchungen durchgeführt werden, um die Treffsicherheit der zytologischen Untersuchung zu erhöhen. Dabei können auch geringe Anzahlen von Karzinomzellen durch den Nachweis epithelspezifischer Antigene identifiziert werden [71].

\section{Treffsicherheit}

Die konventionelle Ergusszytologie besitzt eine Sensitivität von $58 \%$, eine Spezifität von $97 \%$ und einen mittleren positiven Prädiktionswert von 99\% sowie einen negativen Prädiktionswert von $80 \%$. Circa $5 \%$ der zytologischen Diagnosen sind zweifelhaft/unklar [73]. Die diagnostische Genauigkeit lässt sich mittels Immunzytochemie und DNA-Zytometrie erhöhen [66, 72, 74-77] (Evidenzgrad Ib).

\section{I.5. Spezifische Diagnostik bei Patienten mit Aszites bedingt durch ein Budd-Chiari-Syndrom (BCS) oder sinusoidales Obstruktionssyndrom}

Aszites ist ein charakteristisches Symptom des BCS [78-81]. Aus diesem Grunde muss das BCS in der Differenzialdiagnose von Patienten mit Aszites berücksichtigt werden. Insbesondere die Kombination von rasch auftretendem Aszites, Schmerzen im rechten Oberbauch und deutlich erhöhten Leberwerten sollten den Blick auf das BCS lenken. Das BCS ist definiert als eine Ausflussbehinderung der Leber, die auf jeder Stufe des venösen Abflusses von den kleinen Lebervenen bis hin zum Übergang in den rechten Vorhof auftreten kann [82, 83]. Hierdurch entstehen eine portale Hypertension, Ischämie und noduläre Hyperplasie der Leber. Die Lokalisation der Ausflussbehinderung liegt in den westlichen Ländern vorwiegend in den Lebervenen (etwa 90\%) mit oder ohne gleichzeitig vorliegen- 
der Thrombose der V. cava inferior. Letztere tritt in etwa $30 \%$ auf und ist Folge einer Kompression der V. cava inferior durch Vergrößerung des Lobus caudatus der Leber, die zum vollständigen Verschluss der intra- und infrahepatischen V. cava inferior führen kann. Bei etwa 15\% der Patienten liegt bei Diagnosestellung zusätzlich eine Pfortaderthrombose vor [79, 84]. Das sinusoidale Obstruktionssyndrom (früher veno-occlusive disease), welches ebenfalls zu Aszites führt, wird vom BCS abgegrenzt, da es sich ätiologisch, morphologisch und therapeutisch von diesem grundlegend unterscheidet [79, 84].

\section{Empfehlung}

Bei der initialen Diagnostik eines Aszites ist es empfehlenswert, ein BCS oder sinusoidales Obstruktionssyndrom auszuschließen. Dies trifft insbesondere für Patienten mit rasch progredienter und unklarer Lebererkrankung oder mit hohem Eiweißgehalt (>3 g/dl) im Aszites zu. (D), Konsens: 100\%

Die Duplex-Sonografie stellt das bildgebende Mittel der 1. Wahl dar. Ein zusätzliches Verfahren (CT oder MRT) sollte im Falle einer eingeschränkten Beurteilbarkeit oder Diskordanz zwischen Klinik und sonografischem Befund durchgeführt werden. (C), Konsens: $100 \%$

Die Diagnose eines sinusoidalen Obstruktionssyndroms sollte durch die charakteristische Anamnese und, im Bedarfsfall, histologisch erfolgen. (B), Konsens: 100\%

\section{Kommentar}

Bei Patienten mit unklarer Lebererkrankung muss eine vaskuläre Ursache der Aszitesbildung ausgeschlossen werden. Die Duplex-Sonografie kann mit einer Spezifität und Sensitivität von $85 \%$ die Diagnose eines BCS sichern [85]. In einer Studie aus dem Jahre 1993 [86] wurden Ultraschall, CT und MRT mit dem Goldstandard Pathologie/Histologie bei Lebertransplantation verglichen. Hier zeigte der Ultraschall bei $65 \%$, die CT bei 50\% und die MRT bei $80 \%$ der Patienten ein korrektes Ergebnis. Zieht man die Weiterentwicklung der Ultraschallsysteme in den vergangenen 15-20 Jahren in Betracht, dann kann man annehmen, dass die Ergebnisse für den Ultraschall heute deutlich besser ausfallen. Insofern kann bei Übereinstimmung von klinischer Diagnose und Ultraschallbefund auf weitere Methoden verzichtet werden [78, 79]. Bei schlechten Untersuchungsbedingungen oder fehlender Übereinstimmung mit der Klinik sollten weitere Bildgebungsmethoden eingesetzt werden [78, 79] (Evidenzgrad II b).

Bei sehr begrenztem Befund (z.B. Web in der Lebervene) kann eine angiografische Darstellung mit Bestimmung des Druckgradienten notwendig sein. Wegen der geringen Fallzahlen liegen keine publizierten Daten oder Empfehlungen vor (Evidenzgrad IV).

Nach dem bildgebenden Nachweis eines BCS ist die Abklärung der Thrombophilie notwendig. Hierzu gehören folgende Untersuchungen: Blutbild, Plasmakonzentrationen der Gerinnungsfaktoren und -inhibitoren, Gendefekte in den Faktoren 5 und Prothrombin, Antiphospholipid-AK und Lupus-Antikoagulans, Flow-Zytometrie für paroxysmale nächtliche Hämoglobinurie (PNH) und Ausschluss eines Morbus Behçet. Außerdem sollten myeloproliferative Erkrankungen durch eine JAK2-Genanalyse und evtl. Knochenmarksbiopsie evaluiert werden. Bei etwa $50 \%$ der Patienten liegt eine myeloproliferative Ursache vor und in etwa 35\% der Fälle liegen mehrere Ursachen (inkl. orale Antikonzeptiva) vor [79, 87-89] (Evidenzgrad II a).
Das sinusoidale Obstruktionssyndrom ist meistens durch eine charakteristische Anamnese zu diagnostizieren [79, 90] (Evidenzgrad II b). Es wird fast ausschließlich durch Toxine und Medikamente verursacht und tritt vorwiegend im Zusammenhang mit der Knochenmarkstransplantation auf.

\section{I.6. Welche Parameter weisen auf eine sekundäre bakterielle Peritonitis hin?}

\section{Empfehlung}

Der Verdacht auf eine sekundäre Peritonitis sollte bei Nachweis von mehr als einer Erregerspezies, einem Nichtansprechen auf eine antibiotischen Therapie nach $48 \mathrm{~h}$ oder einer stark erhöhten Zellzahl im Aszites gestellt werden. (B), Konsens: 100\%

Bei Verdacht auf eine sekundär bakterielle Peritonitis soll zeitnah eine Bildgebung des Abdomens erfolgen. (A), Konsens: 100\%

\section{Kommentar}

\section{Sekundäre Peritonitis}

Die sekundäre bakterielle Peritonitis bei Patienten mit einer portalen Hypertension beschreibt eine bakterielle Peritonitis durch eine abdominelle Infektionsquelle (z. B. Abszess, Perforation) und ist mit bis zu 15\% aller Peritonitiden deutlich seltener als die spontan bakterielle Peritonitis [91]. Da die Mortalität der sekundären bakteriellen Peritonitis mit 50-80\% sehr hoch ist [91, 92], ist ein invasives Vorgehen (z. B. Operation, Abszessdrainage) in der Regel notwendig.

In einer retrospektiven Analyse waren Bauchschmerzen signifikant häufiger bei Patienten mit einer sekundären als bei Patienten mit einer spontan bakteriellen Peritonitis nachweisbar (79 vs. 49\%) [91]. Die Zellzahl im Aszites ist durchschnittlich höher bei einer sekundären Peritonitis im Vergleich zur SBP (91), einen evaluierten Cut-off-Wert gibt die Studienlage jedoch nicht. Laborchemisch ergaben sich bei einer sekundär bakteriellen Peritonitis folgende Konstellationen: Eiweißgehalt im Aszites > $1 \mathrm{~g} / \mathrm{l}$, Glukose im Aszites <2,7 mmol/l, Aszites-LDH oberhalb der oberen Normgrenze des Serum-LDH-Wertes. Die Sensitivität dieser Kriterien liegt zwischen 66 und 97\% und die Spezifiät bis zu 90\% [91, 93-95]. Die Erhöhung des Carcinoembrionalen Antigens (CEA) und der alkalischen Phosphatase (AP) können ebenfalls Hinweise auf eine sekundär bakterielle Peritonitis geben. In einer Untersuchung wurde ein CEA $>5 \mathrm{ng} / \mathrm{ml}$ (Vorkommen in Enterozyten) und die alkalische Phosphatase (AP) > 240 U/1 im Aszites bestimmt. Die Sensitivität für das Vorliegen eines dieser Kriterien zur Unterscheidung sekundäre vs. primäre Peritonitis lag bei $92 \%$, wobei nicht nur Patienten mit einer Leberzirrhose einbezogen wurden [96]. Diese Aszitesparameter sind jedoch zu einer genauen Diagnosestellung einer sekundär bakteriellen Peritonitis und insbesondere zur Fokussuche nicht ausreichend (Evidenzgrad IIb). Bei Verdacht auf sekundäre Peritonitis soll daher immer eine zusätzliche schnittbildgebende radiologische Untersuchung durchgeführt werden. Die intraabdominelle Infektquelle konnte in $91,3 \%$ der Fälle durch eine abdominelle Computertomografie nachgewiesen werden [91] (Evidenzgrad IIb). 


\section{Therapie des Aszites}

\section{II.1. Wann bedarf ein Patient mit Aszites einer Therapie?}

\section{Empfehlungen}

Aszites sollte bei klinischer Nachweisbarkeit behandelt werden. Die Dringlichkeit einer Therapie steigt mit zunehmender Symptomatik. (KKP), Konsens: 100\%

Ziel einer Aszitestherapie ist die symptomatische Kontrolle des Aszites, nicht das vollständige Verschwinden des Aszites in der Bildgebung. (D), Konsens: $100 \%$

\section{Kommentar}

Der klinisch nicht nachweisbare, inapparente Aszites ist asymptomatisch. Für eine Prognoseverbesserung durch Behandlung eines inapparenten Aszites liegen keine Daten vor. Gegenteilig kann eine zu aggressive diuretische Therapie zur Entwicklung oder Verschlechterung einer hepatischen Enzephalopathie oder zum prärenalen Nierenversagen führen [97, 98]. Daher besteht bei klinisch nicht nachweisbarem Aszites keine Indikation zur spezifischen Therapie, die über Maßnahmen im Rahmen der Grunderkrankung hinaus geht (Evidenzgrad V).

Die Entwicklung eines klinisch apparenten Aszites zeigt das Voranschreiten der Leberzirrhose mit signifikant schlechterer Prognose an [99]. Eine besonders schlechte Prognose weisen Patienten mit refraktärem oder intraktablem Aszites auf [100, 101]. Sekundärkomplikationen wie die spontan bakterielle Peritonitis und das hepatorenale Syndrom können akut lebensbedrohlich sein $[102,103]$.

Die Datenlage zur Frage, ob die symptomatische Therapie eines Aszites zu einer Verbesserung des Überlebens oder zu geringeren Raten an Sekundärkomplikationen führt, ist spärlich. Daher kommt dem klinischen Befinden des Patienten bei der Indikationsstellung und Intensität der Aszitestherapie eine zentrale Rolle zu. Mögliche Symptome bei Aszites sind abdominelles Völlegefühl, Bauchschmerzen oder Dyspnoe.

$\mathrm{Zu}$ den genannten Empfehlungen liegen keine gezielten Studien vor. Trotz niedriger Evidenzlage waren sich die Experten im Empfehlungsgrad einig.

\section{II.2. Was ist die Rolle der nicht medikamentösen Basistherapie?}

\section{Empfehlungen}

Patienten mit Leberzirrhose und Aszites sollen eine ausreichend eiweißhaltige Ernährung (empfohlene Eiweißzufuhr: 1,2-1,5g× $\mathrm{kg}^{-1} \times \mathrm{Tag}^{-1}$ ) mit ausreichendem Energiegehalt (Nichteiweißenergie $25 \mathrm{kcal} \times \mathrm{kg}^{-1} \times \mathrm{Tag}^{-1}$ ) erhalten. (A), Konsens: $100 \%$

Alle Patienten sollen aufgeklärt werden, dass eine zusätzliche Salzzufuhr zu einer Verschlechterung des Krankheitsbildes führen kann. (KKP), Konsens: $100 \%$

Für Patienten, die mit einer diuretischen Therapie gut zu führen sind, ist der Nutzen einer diätetischen Kochsalzrestriktion nicht erwiesen (B). Patienten mit refraktärem oder schwierig zu behandelndem Aszites sollten eine diätetische Kochsalzrestriktion (max. $5 \mathrm{~g} / \mathrm{Tag} \mathrm{NaCl}$, entsprechend $85 \mathrm{mmol}$ Natrium) einhalten. (KKP), Konsens: 100\% Bei Patienten mit einem Serum-Natrium von $>125 \mathrm{mmol} / \mathrm{l}$ ist eine Flüssigkeitsrestriktion nicht erforderlich, bei Patienten mit einer ausgeprägten Hyponatriämie ( $<125 \mathrm{mmol} / \mathrm{l})$ kann eine Flüssigkeitsrestriktion von 1,5I/Tag sinnvoll sein. (D), Konsens: $94,4 \%$

\section{Kommentar}

Patienten mit Leberzirrhose sind, insbesondere wenn Aszites vorliegt, mehrheitlich mangelernährt. Dabei treten einerseits ein Eiweißmangel und Muskelatrophie, andererseits ein Überschuss an extrazellulärem Wasser auf. Daher liegen die BMIWerte meist im Normbereich [104, 105]. Diese Situation wird oft durch Appetitlosigkeit und Verlangsamung im Rahmen einer hepatischen Enzephalopathie aggraviert [106, 107] und verschlechtert die Prognose [108, 109]. Die Mangelernährung kann mittels Anamnese und klinischer Untersuchung diagnostiziert werden. Bedside-Methoden, wie das „Subjective Global Assessment" oder die Bestimmung von Phasenwinkel oder Körperzellmasse mittels Bioimpedanzanalyse, können zur Kategorisierung bzw. Quantifizierung dienen [110, 111].

Eiweißmangel begünstigt die Aszitesbildung. Die Behandlung der Mangelernährung mit ausreichender Zufuhr von Energie (Nichteiweißenergie $\left.25 \mathrm{kcal} \times \mathrm{kg}^{-1} \times \mathrm{Tag}^{-1}\right)$, Eiweiß $(1,2-1,5 \mathrm{~g} \times$ $\mathrm{kg}^{-1} \times \mathrm{Tag}^{-1}$ ), Vitaminen (insbesondere der B-Gruppe) und Spurenelementen (insbesondere Zink) ist Bestandteil der Basistherapie. Die europäischen Ernährungsleitlinien empfehlen primär die orale bzw. enterale Gabe [112]. Erst bei Versagen oder Nichtanwendbarkeit dieser Modalitäten sollte eine parenterale Gabe erfolgen [113]. Die adäquate Ernährungstherapie kann nicht nur die Körperzusammensetzung, sondern auch das Überleben verbessern [107, 114, 115] (Evidenzgrad Ib). Unzureichende spontane Nahrungsaufnahme oder ärztlich verordnete Nahrungskarenz (>12 h) können eine Katabolie induzieren, die über erhöhten Abbau von Körpereiweiß die Ausbildung einer hepatischen Enzephalopathie begünstigt [116]. Die früher geübte Eiweißrestriktion bei der hepatischen Enzephalopathie ist ohne belegten Vorteil, verschlechtert die Eiweißbilanz und sollte in der Regel unterlassen werden [117] (Evidenzgrad IIb). Bei Leberzirrhose sind die Geschmackserkennung und Geschmackschwellen für salzig, süß und sauer gestört [118]. Diese Störungen werden durch Hypomagnesiämie (z.B. durch Diuretika) verstärkt. Unter realistischen Umständen lässt sich eine Kochsalzrestriktion auf 5-6g NaCl/Tag (ca. 85$100 \mathrm{mmol}$ ) erreichen [119-121] (Evidenzgrad V). Eine diätetische Kochsalzrestriktion als Basismaßnahme bei Zirrhose birgt die Gefahr, dass diese zwar den Energie- und Eiweißbedarf deckende, jedoch fast geschmacklose Kostform nicht befolgt wird und die gesamte Eiweiß- und Energieaufnahme reduziert werden [119].

Nur bei ausreichender Natriumausscheidung im Urin kann eine negative $\mathrm{NaCl}$-Bilanz erreicht werden. Daher kommen für eine Aszitestherapie mittels alleiniger Kochsalzrestriktion ausschließlich Patienten mit einer Natriumausscheidung von mehr als $80 \mathrm{mmol} / 24 \mathrm{~h}$ infrage. Patienten mit geringerer Natriumausscheidung im Urin bedürfen der Gabe von Diuretika. In einer randomisiert-kontrollierten Studie wurde gezeigt, dass auf eine extreme Kochsalzrestriktion ( $10 \mathrm{mmol} \mathrm{Na/Tag}$ ) bei Einsatz von Diuretika verzichtet werden kann [122]. Eine französische, multizentrische, randomisiert-kontrollierte Studie zeigte bei Kochsalzrestriktion von $21 \mathrm{mmol} /$ Tag eine effektivere Aszitesmobilisierung in den ersten 14 Tagen, jedoch keinen Unterschied nach 90 Tagen [123]. Eine Diät mit einer strengen Kochsalzrestriktion ( $50 \mathrm{mmol}$ entsprechend ca. $3 \mathrm{~g}$ Natrium/ Tag) brachte in einer Studie keinen Vorteil gegenüber einer nur moderaten Kochsalzrestriktion (120 mmol/Tag, entsprechend etwa $7 \mathrm{~g}$ Salz) [124]. Da die oben aufgeführten Studien mit strenger und in der Praxis kaum durchzuführender Restriktion der Kochsalzaufnahme gegenüber einer nur modera- 
ten Kochsalzrestriktion keinen wesentlichen Vorteil gezeigt haben, wird eine Kochsalzrestriktion auf unter $5 \mathrm{~g} / \mathrm{Tag}$ nicht empfohlen.

Um die Rate der Aszitesneubildung und damit die Frequenz der Parazentesenotwendigkeit zu minimieren, sollten Patienten mit refraktärem Aszites wenn möglich eine kochsalzarme Kost erhalten. Eine Verbesserung des Überlebens durch eine Kochsalzrestriktion wurde nur für Patienten nach gastrointestinaler Blutung gezeigt [123].

Trotz niedriger Evidenzlage waren sich die Experten im Empfehlungsgrad einig.

Die Datenlage zum Einfluss körperlicher Aktivität bei Zirrhose ist schmal, insbesondere ist der Einfluss auf die Entwicklung von Komplikationen und das Überleben schlecht untersucht. Eine kontrollierte Cross-over-Studie zeigte [125] bei Patienten mit Leberzirrhose oder Herzinsuffizienz, dass Bettruhe die Wirkung einer Diuretikagabe hinsichtlich der Diurese, Natriumexkretion und glomerulärer Filtrationsrate (GFR) steigert und die Herzfrequenz niedriger ist. Eine generelle Empfehlung zu langen Bettruhephasen bei Zirrhose lässt sich aus diesen Daten nicht ableiten, da die katabolen Effekte mangelnden Trainings nicht ausreichend untersucht sind (Evidenzgrad V). Bei Patienten mit Leberzirrhose und Aszites findet sich nicht selten eine Verdünnungshyponatriämie. Eine Studie an 997 Zirrhosepatienten zeigte lediglich bei 1,2\% eine Hyponatriämie von $\leq 120 \mathrm{mmol} / \mathrm{l}$ bzw. bei $5,7 \%$ der Patienten von $\leq 125 \mathrm{mmol} / \mathrm{l}$ [126]. Eine weitere Studie [127] fand bei 753 wegen Leberzirrhose zur Transplantation evaluierten Patienten (63\% mit Aszites) bei $8 \%$ eine Hyponatriämie von $<130 \mathrm{mmol} / \mathrm{l}$. In dieser Patientengruppe bestand für Serum-Natriumwerte im Bereich von $120-135 \mathrm{mmol} / \mathrm{l}$ eine umgekehrt proportionale Beziehung zwischen Hyponatriämie und dem Risiko, innerhalb von 6 Monaten zu versterben [127]. Das Wissen um die ungünstige Prognose der Hyponatriämie bei Zirrhose ist nicht neu [128] und hat zum Vorschlag des modifizierten MELD-Scores geführt [129].

Da in der Regel eine Verdünnungshyponatriämie ohne einen Ganzkörper-Natriummangel vorliegt, ist eine Kochsalzgabe bei zirrhotischem Aszites nicht indiziert. Ohnehin sollte ein schneller Ausgleich bei chronischer Hyponatriämie nicht erfolgen, da er das Risiko ernsthafter Komplikationen wie einer zentralen pontinen Myelinolyse birgt [130, 131].

Bei Patienten mit ausgeprägter Hyponatriämie wird zu einer Flüssigkeitsrestriktion geraten. Allerdings existieren weder Daten über die Wirksamkeit einer Flüssigkeitsrestriktion, noch über den Natriumwert im Serum, bei dem eine Flüssigkeitsrestriktion initiiert werden sollte. Als sinnvolle Schwelle wird ein Serumnatrium von unterhalb $120-125 \mathrm{mmol} / \mathrm{l}$ angesehen [132] (Evidenzgrad V). Flüssigkeitsrestriktion bedeutet häufig aber eine signifikante Einschränkung der Lebensqualität des Patienten und sollte daher längerfristig nur bei im Einzelfall erwiesener Wirksamkeit und Notwendigkeit angeordnet werden.

\section{II.3. Wie wird die medikamentöse Therapie des Aszites durchgeführt?}

\section{Empfehlungen}

Als Diuretikum der ersten Wahl soll der orale Aldosteronantagonist Spironolacton eingesetzt werden (A). Die Initialdosis beträgt in der Regel $100 \mathrm{mg} / \mathrm{Tag}$. (D), Konsens: 100\%
Bei unzureichender Aszitesmobilisation sollte die Medikation mit einem Schleifendiuretikum ergänzt werden. (B), Konsens: 100\% Bei Patienten mit ausgeprägtem oder länger bestehendem Aszites sollte initial eine Kombinationstherapie aus Spironolacton und einem Schleifendiuretikum erwogen werden. (B), Konsens: 100\% Bei ausgeprägter Hyponatriämie ( $<125$ mmol/l), klinisch manifester hepatischer Encephalopathie oder einer deutlichen Nierenfunktionsverschlechterung sollte auf Diuretika verzichtet werden. (B), Konsens: 100\%

\section{Kommentar}

Das primäre Diuretikum zur Behandlung des Aszites ist der kompetitive Aldosteronantagonist Spironolacton [123, 124, 133-135] (Evidenzgrad IV). Spironolacton greift in das bei Leberzirrhose aktivierte Renin-Angiotensin-Aldosteron-System ein und hemmt am distalen Tubulus die Rückresorption von Natriumionen. Im Gegenzug werden Kaliumionen retiniert.

Bei Patienten mit moderaten Aszitesmengen beträgt die Anfangsdosis einer oralen Monotherapie einmal tgl. 100-200 mg Spironolacton [136]. In der Monotherapie ist Furosemid der Gabe von Spironolacton unterlegen. Es sollte daher nur in begründeten Einzelfällen benutzt werden [135] (Evidenzgrad Ib). Der Erfolg der diuretischen Therapie wird durch tägliche Gewichtskontrolle überwacht. Angestrebt wird ein Gewichtsverlust von nicht mehr als $500 \mathrm{~g} / \mathrm{Tag}$ bei Patienten ohne periphere Ödeme bzw. von nicht mehr als $1000 \mathrm{~g} / \mathrm{Tag}$ bei Patienten mit peripheren Ödemen [137]. Ein ausreichender Flüssigkeitsverlust ist erreicht, wenn klinisch kein oder nur eine geringe Menge Aszites vorliegt und keine peripheren Ödeme mehr nachweisbar sind. Regelmäßige Kontrollen der Serumelektrolyte sowie des Serumkreatinins sollten durchgeführt werden. Eine Dosissteigerung sollte erfolgen, wenn es nicht gelingt, einen Gewichtsverlust von mindestens $1 \mathrm{~kg}$ in der ersten bzw. $2 \mathrm{~kg} /$ Woche in den folgenden Wochen zu erreichen (Evidenzgrad V).

Eine additive Therapie mit einem Schleifendiuretikum (Furosemid 20-40 mg/Tag) wird eingeleitet, wenn der Patient auf $200 \mathrm{mg} /$ Tag Spironolacton in den ersten 2-3 Wochen nicht ausreichend anspricht (Evidenzgrad IIb). Bei nicht ausreichendem Ansprechen kann die Diuretikatherapie bis auf $400 \mathrm{mg} /$ Tag Spironolacton $[135,138,139]$ und $160 \mathrm{mg} /$ Tag Furosemid gesteigert werden. Bei diesen hohen Dosen ist eher mit Elektrolyt- und Nierenfunktionsstörungen zu rechnen (Evidenzgrad IV).

Eine neue Studie [140] kam zu dem Ergebnis, dass auch bei Patienten mit moderatem Aszites eine initiale Kombinationstherapie Vorteile bietet: Verglichen wurde eine sequenzielle Therapie mit Kaliumcanrenoat (dem aktiven Metaboliten von Spironolacton), bei Bedarf ergänzt um Furosemid, mit einer fixen initialen Kombinationstherapie aus Kaliumcanrenoat und Furosemid. Hierbei wurden die Patienten der Sequenztherapiegruppe mit Kaliumcanrenoat behandelt (initial $200 \mathrm{mg} / \mathrm{Tag}$, später $400 \mathrm{mg} / \mathrm{Tag})$. Nonresponder erhielten $400 \mathrm{mg} / \mathrm{Tag}$ Kaliumcanrenoat und initial $50 \mathrm{mg}$ Furosemid/Tag (Steigerung bis auf $150 \mathrm{mg} / \mathrm{Tag}$ ). Die Patienten in der Kombinationstherapiegruppe erhielten initial $200 \mathrm{mg} /$ Tag Kaliumcanrenoat und $50 \mathrm{mg} /$ Tag Furosemid (bei Bedarf Steigerung bis auf $400 \mathrm{mg} /$ Tag Kaliumcanrenoat und $150 \mathrm{mg} /$ Tag Furosemid). Ein ausreichendes Ansprechen ließ sich in beiden Therapiegruppen feststellen, jedoch war die Rate an Komplikationen (in erster Linie Hyperkaliämie) bei den Patienten mit der Sequenztherapie hö- 
her [140]. Wichtig für die Interpretation der Daten ist, dass in die Studie von Angeli et al. [140] auch Patienten mit länger bestehendem Aszites und GFR-Reduktion eingeschlossen wurden. Die Studie von Santos et al. [136] hingegen untersuchte ausschließlich Patienten mit neu aufgetretenem Aszites mit normalem Serumkreatinin. Bei diesen Patienten wies die Kombinationstherapie eine zur sequenziellen Behandlung vergleichbare Wirksamkeit, aber mehr Nebenwirkungen auf (Evidenzgrad Ib).

Nach Möglichkeit sollte Furosemid oral appliziert werden, da die intravenöse Gabe durch die akute Reduktion der glomerulären Filtrationsrate ein höheres Risiko für eine Nierenfunktionsstörung aufweist [141, 142]. In der größten zur Diuretikatherapie des massiven Aszites publizierten Studie wurden alle Patienten von Anfang an mit einer Kombinationstherapie behandelt [143]. Hierdurch ließ sich die Ansprechzeit auf die Diuretikatherapie verkürzen [143]. Ein bewährtes Schema zur initialen Therapie ist eine Kombination aus $100 \mathrm{mg}$ Spironolacton sowie $40 \mathrm{mg}$ Furosemid als einmalige morgendliche Gabe [144]. Sollte diese Dosierung nicht ausreichend sein, kann in diesem Verhältnis weiter gesteigert werden (z.B. $200 \mathrm{mg}$ Spironolacton $/ 80 \mathrm{mg}$ Furosemid). Auf diese Weise kann das Risiko einer Spironolacton-induzierten Hyperkaliämie gering gehalten werden. Mittels einer kombinierten Therapie aus kochsalzreduzierter Diät, Spironolacton und Furosemid lässt sich bei bis zu $90 \%$ der Patienten mit Aszites und Leberzirrhose ein Therapieerfolg erzielen $[124,135,139]$ (Evidenzgrad IIb). Wenn eine ausreichende Aszitesmobilisation erreicht worden ist, sollte die Diuretikadosis so weit wie möglich reduziert werden.

Mehrere Studien untersuchten das neuere Schleifendiuretikum Torasemid in seiner Wirkung bei Patienten mit Leberzirrhose und Aszites [145-147]. Torasemid zeigte sich hierbei als mindestens gleich effektiv und sicher wie Furosemid und kann somit als Alternative zu Furosemid angesehen werden [145147] (Evidenzgrad Ib).

Bei Patienten, die nicht ausreichend auf die diuretische Therapie ansprechen, sollte die Natriumexkretion im 24-h-Sammelurin gemessen werden, um echte Nonresponder von Patienten zu unterscheiden, die keine Kochsalzrestriktion einhalten. Bei einer 24-h-Natriumausscheidung über $85 \mathrm{mmol}$ ohne Gewichtsverlust ist davon auszugehen, dass die Kochsalzaufnahme über $5 \mathrm{~g} /$ Tag liegt.

Ein Teil der männlichen Patienten entwickelt unter Spironolacton eine schmerzhafte Gynäkomastie, die einen Abbruch der Therapie erforderlich machen kann. In diesem Fall stellt Amilorid in einer Dosierung von $10-40 \mathrm{mg} / \mathrm{Tag}$ eine Alternative dar. Amilorid hat sich in einer kontrollierten Studie allerdings als weniger effektiv als Kaliumcanrenoat gezeigt [148] (Evidenzgrad Ib).

Auch andere Diuretika wie Triamteren, Hydrochlorothiazid und Xipamid wurden zur Aszitestherapie eingesetzt [149-151]. Insbesondere Hydrochlorothiazid kann in der Kombination mit Spironolacton und Furosemid eine ausgeprägte Hyponatriämie auslösen [151].

Der Aldosteronantagonist Epleneron [152], der seltener zur Gynäkomastie führt als Spironolacton, ist bisher in der Therapie des Aszites bei Leberzirrhose nicht untersucht worden.

Einen neuen Therapieansatz stellen selektive, orale Vasopressin-V2-Rezeptorantagonisten, die sog. Vaptane, dar. Sie steigern die Wasserausscheidung ohne gleichzeitige Natriurese und sind daher für den Einsatz bei Hyponatriämie entwickelt wor- den. Einzige aktuell zugelassene Substanz ist das Tolvaptan. In Kombination mit Spironolacton konnte für Satavaptan eine signifikante Gewichtsabnahme verglichen mit Placebo sowie eine Besserung der vorbestehenden Hyponatriämie gezeigt werden [153]. Da für Satavaptan bisher keine Zulassung vorliegt und Daten zur Langzeitbehandlung noch nicht in voller Form publiziert sind, kann derzeit keine Empfehlung gegeben werden.

\section{II.4. Wie wird der therapierefraktäre und rezidivierende Aszites behandelt?}

\section{Definition}

Der therapierefraktäre Aszites ist als Diuretika resistenter oder intraktabler Aszites definiert. Diuretikaresistenz bedeutet inadäquates Ansprechen auf Natriumrestriktion und eine hoch dosierte diuretische Therapie (Spironolacton max. $400 \mathrm{mg} /$ Tag und Furosemid max. $160 \mathrm{mg} / \mathrm{Tag}$ ) [263].

Beim intraktablen Aszites bestehen Komplikationen wie hepatische Enzephalopathie oder ausgeprägte Hyponatriämie, die eine adäquate diuretische Therapie verhindern [263].

Rezidivierender Aszites ist definiert als Aszites, der trotz Natriumrestriktion und Verschreibung von Diuretika in adäquater Dosierung mindestens 3-mal in einem Zeitraum von 1 Jahr wieder auftritt [263].

\section{Empfehlung}

Bei therapierefraktärem oder rezidivierendem Aszites ist die TIPSAnlage bei fehlenden Kontraindikationen wiederholten großvolumigen Parazentesen vorzuziehen. (A), Konsens: 100\%

Eine TIPS-Anlage zur Aszitestherapie ist in der Regel kontraindiziert bei vorbestehender chronischer hepatischer Enzephalopathie $>$ Grad 1 oder einem Serum-Bilirubin $>5$ mg/dl (weitere Kontraindikationen siehe Kommentar). (D), Konsens: 100\%

Bei Durchführung einer großvolumigen Parazentese $(>5 \mathrm{I}$ ) soll eine intravenöse Albumingabe (6-8g/Liter Aszites) erfolgen. (A), Konsens: $100 \%$

\section{Kommentar}

Abgesehen von der Lebertransplantation, die bei therapierefraktärem oder intraktablem Aszites immer erwogen werden sollte, stehen die wiederholte großvolumige Parazentese und der transjuguläre intrahepatische portosystemische Shunt (TIPS) als therapeutische Alternativen zur Verfügung. Die Anlage eines peritoneovenösen Shunts ist mit einem sehr hohen Komplikationsrisiko behaftet und dient lediglich in ausgewählten Einzelfällen noch als Reserveverfahren [154].

Die Parazentese ist ein relativ sicheres Verfahren [23]. Eine Aszites-Neubildung ist dadurch allerdings nicht zu verhindern. Bei fast allen Patienten müssen wiederholte Parazentesen durchgeführt werden. Beachtet werden muss, dass eine großvolumige Parazentese zu hämodynamischen Veränderungen führen kann, die als postparazentese zirkulatorische Dysfunktion bezeichnet werden [155-157]. Zentraler pathophysiologischer Aspekt dabei ist eine Aggravation der schon vorbestehenden Verminderung des effektiven zentralen Blutvolumens mit der Folge einer weiteren Stimulation vasokonstriktorischer Systeme. Die klinische Manifestation dieser Veränderungen ist die Verschlechterung der Nierenfunktion bis hin zum hepato- 
renalen Syndrom. Da das Auftreten einer postparazentese zirkulatorischen Dysfunktion mit einer reduzierten Lebenserwartung assoziiert ist [155], sollte dieser vorgebeugt werden. Die Gabe von Albumin ist nach kontrollierten Studien die beste Vorbeugung einer zirkulatorischen Dysfunktion nach großvolumiger (>51) Parazentese und daher anderen Plasmaexpandern vorzuziehen [155] (Evidenzgrad Ib). Ist das abpunktierte Aszitesvolumen kleiner als 51, ist keine Gabe von Humanalbumin oder eines Plasmaexpanders notwendig.

Die Effektivität einer kontinuierlichen peritonalen Drainage zur Aszitestherapie ist nicht belegt. Zudem scheint dadurch eine erhöhte Infektionsgefahr möglich.

Die Rationale der TIPS-Anlage besteht darin, den portalen Druck und damit die Transsudation in die Peritonealhöhle zu reduzieren und das zentrale effektive Herzvolumen zu erhöhen. Vier Wochen nach TIPS-Anlage zeigen sich Natriumausscheidung und Nierenfunktion verbessert [158, 159]. Weiterhin sinken die Plasma-Renin-Aktivität sowie die Aldosteronund Noradrenalin-Konzentrationen. Dadurch werden die zirkulatorische Dysfunktion bei Leberzirrhose, die portale Hypertension und die Nierenfunktion verbessert.

Im Vergleich zur wiederholten großvolumigen Parazentese ist die TIPS-Anlage zur Aszitestherapie effektiver [160-162]. Bezüglich der Mortalität waren die Daten zunächst uneinheitlich mit Vorteilen für die Parazentese [158], ohne Mortalitätsdifferenzen $[160,163]$ und bei größerer Patientenzahl mit Vorteilen für den TIPS [161, 164]. Die methodisch beste Metaanalyse auf der Basis individueller Patientendaten konnte allerdings eine niedrigere Mortalität nach TIPS im Vergleich zur Parazentese belegen [162] (Evidenzgrad Ia). Andere Komplikationen der portalen Hypertension, wie die gastrointestinale Blutung, die spontan bakterielle Peritonitis und das hepatorenale Syndrom, traten signifikant seltener nach TIPS-Anlage als bei regelmäßiger Parazentese auf (23/149 vs. 45/156 Patienten) [162]. Ein positiver Effekt der TIPS-Anlage auf die Lebensqualität wurde in einer Studie gezeigt [165]. Eine andere Studie stellte diesbez. keinen Unterschied zwischen TIPS und Parazentese fest [163].

Eine eindeutige Empfehlung zur Verwendung expandierter Polytetrafluoroethylen(e-PTFE)-beschichteter Stents bei therapierefraktärem Aszites kann aktuell auf der Basis der bestehenden Datenlage nicht ausgesprochen werden. Die einzige publizierte prospektiv-randomisierte Studie [166], die unbeschichtete Stents mit e-PTFE-Stents vergleicht, zeigt nach 2 Jahren eine signifikant höhere Offenheitsrate der beschichteten Stents (76 vs. 36\%). Dementsprechend waren in der Gruppe der Patienten mit beschichteten Stents deutlich weniger Reinterventionen notwendig (9 vs. 31). Entsprechend der besseren Offenheit ist das Enzephalopathierisiko nach beschichteten Stents etwas erhöht (67 vs. 51\%). Dies steht im Widerspruch zu früher publizierten Arbeiten [167-169]. Hier muss jedoch beachtet werden, dass der Stentdurchmesser einen Einfluss auf die Effektivität und Komplikationsrate hat $[170,171]$. Für die Differenzialindikation beschichteter vs. unbeschichteter Stents mag es daher vorteilhaft sein, bei Patienten mit einem erhöhten Hepatischen Enzephalopathie(HE)-Risiko (Lebensalter > 65 Jahre, vorbestehende HE, schlechte Leberfunktion) zunächst unbeschichtete Stents einzusetzen. Bei gutem Ergebnis kann dann im Falle einer Shuntinsuffizienz ein beschichteter Stent eingesetzt werden [172]. Argumente für den primären Einsatz eines beschichteten Stents sind geringes HE-Risiko, gute Leber- funktion und technische Komplikationen bei der TIPS-Anlage (z.B. Gallengangspunktionen) (Evidenzgrad V).

Einschränkungen und Kontraindikationen für die TIPS-Anlage Hepatische Enzephalopathie. Bei Patienten mit refraktärem Aszites ist die HE multifaktorieller Genese (eingeschränkte Leberund Nierenfunktion, Exsikkose, reduzierte arterielle Organperfusion [162], Infekt, Hypoglykämie). Während die Leberperfusion durch eine TIPS-Anlage in der Regel verschlechtert wird, werden andere HE-relevante Faktoren verbessert. Daher unterscheidet sich das kumulative Auftreten der ersten HE-Episode nicht zwischen den Behandlungsgruppen (TIPS vs. wiederholte Parazentese) [162]. Allerdings erhöht der TIPS die Anzahl der HE-Episoden insgesamt sowie die Anzahl schwerer HE-Episoden [162]. Bei Vorliegen von Risikofaktoren für eine HE (höheres Lebensalter, vorbestehende HE, mittlerer arterieller Blutdruck < $80 \mathrm{mmHg}$, MELD-Score>15), aber dringlicher TIPSIndikation ist eine limitierte Drucksenkung des portosystemischen Druckgradienten (z.B. 30-50\%) sinnvoll (Evidenzgrad $\mathrm{V})$.

Leberfunktion. Die Verschlechterung der Leberfunktion nach TIPSAnlage wird durch einen Anstieg des Bilirubins angezeigt. Ein Bilirubin über $3 \mathrm{mg} / \mathrm{dl}$ korreliert eng mit einer erhöhten Mortalität nach TIPS-Anlage [173]. Jede Erhöhung des Bilirubins um $1 \mathrm{mg} / \mathrm{dl}$ über $3 \mathrm{mg} / \mathrm{dl}$ hinaus steigert das Risiko der 30-Tages-Mortalität um 40\% [174]. Deshalb ist eine Erhöhung des Gesamtbilirubins über $3 \mathrm{mg} / \mathrm{dl}$ als relative und eine Erhöhung über $5 \mathrm{mg} / \mathrm{dl}$ als absolute Kontraindikation einer TIPS-Anlage zur Behandlung von Aszites anzusehen [175] (Evidenzgrad III b).

Malignome. Maligne Raumforderungen der Leber (HCC) stellten in den meisten Studien ein Ausschlusskriterium für die TIPS-Anlage dar. Daher wird ein Malignom in der Leber von vielen Experten als Kontraindikation gegen eine TIPS-Anlage gesehen. In Einzelfällen eines rein palliativen Therapieansatzes gibt es z.B. bei Spannungsaszites mit der Notwendigkeit hochfrequenter Parazentesen auch bei Patienten mit HCC positive Erfahrungen nach TIPS-Implantation. Es muss sichergestellt sein, dass der Aszites durch die portale Hypertension und nicht den malignen Tumor bedingt ist und dass der TIPS-Trakt nicht durch das HCC läuft (Evidenzgrad V).

Kardiale Funktion. In der klinischen Praxis spielt die Herzinsuffizienz bei der TIPS-Indikation eine untergeordnete Rolle. Eine entsprechende Routinediagnostik ist bei kardial unauffälligen Patienten nicht erforderlich. Bei offensichtlicher, sehr schlechter kardialer Pumpfunktion kann nach Wegfall der portalen Perfusion durch den TIPS eine mangelhafte arterielle Leberperfusion resultieren. Deshalb wird für die TIPS-Anlage eine untere Grenze der Ejektionsfraktion von 40\% festgelegt. Diese Grenze ist willkürlich, da keine entsprechenden Studienergebnisse vorliegen. Auch eine vorbestehende Rechtsherzinsuffizienz sowie eine signifikante pulmonalarterielle Hypertonie können Kontraindikationen für eine TIPS-Anlage darstellen: Nach TIPS-Anlage kommt es zu einem vorübergehenden Anstieg des ZVD und einem kräftigen Anstieg des Herzminutenvolumens um etwa 41/min, das nach wenigen Stunden auf etwa $1 \mathrm{l} / \mathrm{min}$ abfällt. Dies erklärt eine evtl. Verschlechterung der diastolischen Funktion, wie dies in verschiedenen Studien gezeigt wurde. Ein echokardiografischer Grenzwert existiert bislang nicht. Es konnte allerdings gezeigt werden, dass die Mortalität nach TIPS-Anlage bei einer E/A-Ratio $<1$ deutlich höher ist als bei einer E/A-Ratio > 1 [176] (Evidenzgrad IIIb). 
Pfortaderthrombose. Die langfristig komplett verschlossene oder kavernös transformierte Pfortader stellt in der Regel eine technische Kontraindikation für die TIPS-Anlage dar. Dies gilt nicht für frische Thrombosen des Pfortaderhauptstamms oder Teilverschlüsse (Evidenzgrad V).

\section{Spontan bakterielle Peritonitis \\ $\nabla$}

\section{III.1. Einleitung}

Definition, Inzidenz und Prognose einer spontan bakteriellen Peritonitis (SBP) bzw. eines Bakteraszites

Eine SBP ist definiert als Nachweis von $>250$ polymorphonukleäre (PMN)-Zellen, d. h. neutrophile Granulozyten, pro $\mathrm{mm}^{3}$ im Aszites. Bei einer SBP handelt es sich um eine bakterielle Entzündung der Peritonealhöhle ohne Hinweis auf eine anderweitige intraabdominelle Ursache der Infektion (z. B. Cholezystitis, Divertikulitis etc.), Peritonealmetastasen oder Tuberkulose. Ein Bakteraszites ist definiert als mikrobiologischer Nachweis einer Kolonisation des Aszites mit Bakterien ohne erhöhte PMN-Zahl im Aszites (d.h. <250 $\mathrm{PMN} / \mathrm{mm}^{3}$ ).

Diese Definition beruht auf folgenden Gesichtspunkten:

1. Da mehr als $40 \%$ der mikrobiologischen Aszitesuntersuchungen bei SBP kulturnegativ bleiben und eine verzögerte Antibiotika-Therapie (durch Warten auf ein Kulturergebnis) fatale Auswirkungen für den Patienten haben kann, wird die Indikation zur empirischen Antibiotikatherapie durch die AszitesPMN-Zahl gestellt.

2. Der initial verwendete Grenzwert zur Detektion und Definition einer SBP von > $500 \mathrm{PMN} / \mathrm{mm}^{3}$, der für eine kulturpositive SBP eine Spezifität von 98\% und eine Sensitivität von 90\% erzielt [33] wurde aufgrund der suboptimalen Sensitivität korrigiert. Bei einem Grenzwert von $250 \mathrm{PMN} / \mathrm{mm}^{3}$ wird hierbei die höchste Sensitivität erzielt und hierdurch das Risiko, eine tatsächliche Therapieindikation fälschlicherweise zu übersehen, minimiert. Ein Bakteraszites definiert dagegen eine Kolonisation des Aszites mit Bakterien ohne Nachweis einer inflammatorischen Reaktion im Peritonealraum, d.h. PMN-Zahl $<250 / \mathrm{mm}^{3}$ [177]. Beides, SBP und Bakteraszites, stellen eine Therapie-Indikation dar.

Die SBP ist die häufigste bakterielle spontane Infektion bei der Leberzirrhose und wird in prospektiven Fallserien mit etwa 24\% aller bakteriellen Infektionen bei hospitalisierten Patienten angegeben [178]. Während im ambulanten Sektor bei asymptomatischen Patienten, auch bei Vorliegen eines therapierefraktären Aszites, eine Prävalenz der SBP von 3,5\% [8] oder weniger $[7,179]$ berichtet wird, steigt die Zahl im hospitalisierten Patientengut auf $8-36 \%$ an $[32,180]$. Hierbei unterscheidet sich auch das Keimspektrum entscheidend. Im ambulanten Sektor dominieren Gram-negative Keime, während nosokomial vor allem Gram-positive Erreger ursächlich sind [178]. Risikofaktoren für das Auftreten einer SBP sind a) eine bereits stattgehabte SBP [181, 182], b) eine gastrointestinale Blutung [183, 184] und c) ein niedriger Gesamteiweißgehalt im Aszites (<1,5 bzw. <1,0 g/dl) [185-187]. Bei Verwendung eines Grenzwerts von $<1,5 \mathrm{~g} / \mathrm{dl}$ liegt die Wahrscheinlichkeit, eine erste SBP innerhalb eines Jahres zu entwickeln, bei $14-$ $23 \%$. Weitere Risikofaktoren, die mit einer zusätzlichen unabhängigen Erhöhung des Risikos einer ersten SBP-Episode ein- hergehen, sind Bilirubinerhöhung $(>3,2 \mathrm{mg} / \mathrm{dl})$ und Thrombopenie $\left(<98000 / \mathrm{mm}^{3}\right)$ [37]. Zudem steigt das Risiko einer SBP mit zunehmendem MELD-Score [188] sowie dem Einsatz von Protonenpumpenhemmern [189]. Ferner scheint das Vorliegen einer NOD2-Genmutation das Auftreten einer SBP zu begünstigen [190]. Die Wahrscheinlichkeit des Rezidivs einer SBP nach Erstmanifestation ohne Einleitung einer Prophylaxe beträgt zwischen 30 und 68\% innerhalb eines Jahres [181, 182]. Als unabhängige Risikofaktoren hierfür wurden ebenfalls der Gesamteiweißgehalt des Aszites $(<1 \mathrm{~g} / \mathrm{dl})$, aber auch eine Prothrombin-Aktivität $<45 \%$ oder Bilirubin $>4 \mathrm{mg} / \mathrm{dl}$ identifiziert [182]. Die Prävalenz des Bakteraszites bei asymptomatischen ambulanten Patienten liegt bei $2-3 \%$ [7, 8, 179], hingegen bei hospitalisierten Patienten bis zu 11\% [180, 191]. Für das Wiederauftreten eines Bakteraszites finden sich in der Literatur keine zuverlässigen prospektiven Daten.

Die Krankenhausmortalität einer ersten SBP-Episode wird je nach begleitenden Risikofaktoren mit 10-50\% angegeben [180, 182, $192-196]$. Die 1-Jahres-Mortalität nach Auftreten einer ersten SBP liegt zwischen 31\% und 93\% [8, 182, 197 199]. Als prädiktive Risikofaktoren für einen ungünstigen Verlauf ließen sich in unterschiedlichen Kollektiven verschiedene Faktoren identifizieren, welche u.a. beinhalten: Alter des Patienten [195, 198], Child-Pugh-Score [196, 198, 200], Intensivaufenthalt [195, 196], nosokomiale SBP [196], hepatische Enzephalopathie [201, 202], Serum-Kreatinin und -Bilirubin [203], fehlende Infektresolution und kultureller Erregernachweis [204, 205] sowie Auftreten einer Bakteriämie [206]. Der Verlauf eines Bakteraszites ist variabel, kann spontan reversibel sein oder in eine SBP übergehen [177, 191]. Dabei beträgt die Krankenhausmortalität $21-50 \%$ [191].

\section{III.2. Wann und wie sollte eine Primärprophylaxe einer SBP durchgeführt werden?}

\section{Empfehlung}

Bei Vorliegen eines Aszites mit erniedrigtem Gesamteiweißgehalt $(<1,5 \mathrm{~g} / \mathrm{dl})$ kann eine Primärprophylaxe mit Antibiotika erfolgen (C). Bei Patienten mit zusätzlichem Vorliegen eines der beiden Kriterien (1. schwere Leberinsuffizienz, d. h. Child-Pugh-Score $>9$ mit Bilirubin $>3 \mathrm{mg} / \mathrm{dl}$ oder 2 . Niereninsuffizienz mit Serum-Kreatinin $>1,2 \mathrm{mg} / \mathrm{dl}$, Harnstoff $>25 \mathrm{mg} / \mathrm{dl}$ oder Natrium $<130 \mathrm{mEq} / \mathrm{l}$ ) sollte eine antibiotische Primärprophylaxe erfolgen. (B), Konsens: $94,4 \%$

Bei einer gastrointestinalen Blutung bei Leberzirrhose (mit oder ohne Aszites) soll immer eine antibiotische Primärprophylaxe erfolgen. (A), Konsens: $100 \%$

\section{Kommentar}

Zirrhose mit Aszites ohne gastrointestinale (GI) Blutung, aber mit erhöhter Risikokonstellation

Ein erniedrigter Gesamteiweißgehalt des Aszites unter (1 bzw. $1,5 \mathrm{~g} / \mathrm{dl}$ bedingt ein deutlich erhöhtes Risiko für das Auftreten einer SBP [37, 197]. Insgesamt 8 randomisierte kontrollierte klinische Studien mit Ziel der Vermeidung einer ersten SBP bei dieser Konstellation wurden bisher publiziert [185-187, 207-211]. Hierbei gilt es zu betonen, dass die Arbeiten von Singh et al., Rolachon et al., Soriano et al. und Alvarez et al. auch Patienten mit bereits stattgehabter SBP beinhalten [185, $186,207,208]$, sodass diese Studien die Frage der Primärprävention bei Zirrhosepatienten mit erniedrigtem Gesamteiweiß 
im Aszites nicht adäquat beantworten können. Zur Beurteilung der anderen 4 placebokontrollierten Studien liegen 2 Metaanalysen vor [212, 213]. Dabei muss betont werden, dass die Metaanalyse von Saab et al. [213] eine inkorrekte Datenextraktion aufweist und daher qualitativ inakzeptabel ist [214]. Die Metaanalyse von Loomba et al. zeigt eine signifikante Reduktion der Inzidenz einer SBP wie auch der Mortalität in der Chinolon-behandelten Patientengruppe vs. Placebo (OR 0,18 [95\%KI: 0,09-0,35] bzw. 0,60 [95\%-KI: 0,37-0,97], respektive) (Evidenzgrad Ia). Die entsprechende „number needed to treat“ (NNT), um eine erste SBP-Episode oder Mortalität zu verhindern, liegt bei 7 (95\%-KI: 4,7-10,6) bzW. 12 (95\%-KI: 5,8261,2) [212]. Kritisch muss hierzu angemerkt werden, dass das Kollektiv der Untersuchung von Novella et al. einen erheblichen Anteil an Patienten mit GI-Blutung beinhaltet [209]. Berücksichtigt man jedoch auch nur die verbleibenden 3 Studien mit verfügbarer Nachbeobachtung über 6 Monate, so ergibt eine Metaanalyse dieser Daten, die jedoch bisher nur in Abstraktform publiziert ist [215], dass eine Primärprophylaxe mittels Chinolon die Inzidenz einer SBP und die Mortalität signifikant senkt. Dieselbe Metaanalyse berechnet für die beiden jüngsten und qualitativ hochwertigsten Studien (optimale Punktzahl im Jadad-Scoring-System der Qualitätsbeurteilung randomisierter klinischer Studien) mit Nachbeobachtungszeit von 12 Monaten [187, 210] ebenso eine signifikante Risikoreduktion bez. des Auftretens einer SBP und der Mortalität. Allerdings umfassen die Einschlusskriterien bei Terg et al. [187] außer einer Altersbegrenzung (18.-80. Lebensjahr) im Wesentlichen nur den Gesamteiweißgehalt des Aszites ( $<1,5 \mathrm{~g} / \mathrm{dl})$. Im Gegensatz dazu selektierte die Untersuchung von Fernandez et al. [210] hieraus ein Kollektiv von „Hoch-Risikopatienten“, in dem zusätzlich noch einer der beiden Faktoren (1. schwere Leberinsuffizienz: Child-Pugh-Score $>9$ mit Bilirubin $>3 \mathrm{mg} / \mathrm{dl}$ oder 2. Vorliegen einer Niereninsuffizienz: Serum-Kreatinin $>1,2 \mathrm{mg} / \mathrm{dl}$, -Harnstoff $>25 \mathrm{mg} / \mathrm{dl}$ oder -Natrium $<130 \mathrm{mEq} / \mathrm{l}$ ) bestehen musste. Dabei erreichte die Untersuchung von Terg et al. den primären Endpunkt der Verhinderung einer ersten SBP-Episode nicht $(p=0,08)$, was vermutlich auf dem im Vergleich zum Kollektiv der Fernandez-Daten niedrigeren SBP-Risiko beruht. Im o.g. „Hoch-Risikokollektiv“ bei Fernandez et al. dagegen erzielt der Einsatz von Norfloxacin eine signifikante Reduktion der Inzidenz einer ersten SBP wie auch der Mortalität im Beobachtungszeitraum von 12 Monaten. Daher sind zur Selektion von Patienten, bei denen eine Primärprophylaxe einer SBP empfohlen wird, die genannten Kriterien der „Hochrisiko-Konstellation“ angeraten (Evidenzgrad Ib).

Die berichteten Nebenwirkungen einer Antibiotika-Therapie im Rahmen der o.g. Studien sind als mild und klinisch nicht limitierend einzuschätzen. Dagegen ist das Risiko der Entwicklung Antibiotika-resistenter Keime und möglicherweise assoziierter Infekte mit verändertem Keimspektrum und/oder kompliziertem Resistenzprofil als problematisch einzustufen. Dabei scheinen Chinolon-resistente Infektionen in der Regel auf Ceftriaxon anzusprechen [216]. Berichte aus Zentren mit routinemäßigem Einsatz einer selektiven Darmdekontamination bei Risikopatienten über mehrere Jahre haben aber gezeigt, dass auch eine Änderung der Flora, welche bakterielle Infekte verursacht, stattfindet, und häufiger Gram-positive Infektionen auftreten [178]. Ferner ist der prophylaktische Einsatz von Antibiotika mit einem erhöhten Risiko einer Clostridium-difficile-Infektion assoziiert, welche bei Zirrhosepatienten mit einer erhöhten Mortalität einhergeht [217] (Evidenzgrad IIIa). Daher ist vor dem unse- lektionierten längeren Einsatz von Antibiotika zur selektiven Darmdekontamination zu warnen.

Der Überlebensvorteil durch eine Primärprophylaxe mit Antibiotika ist v.a. in den ersten 3 Monaten evident [210, 213, 2-18] (Evidenzgrad Ia). Mit zunehmender Dauer der Prophylaxe lässt der Effekt nach, vermutlich bedingt durch z.B. infektunabhängige Mortalität der zugrunde liegenden fortgeschrittenen Lebererkrankung und/oder Entwicklung Antibiotikaresistenter Bakterien. Daher erscheint es sinnvoll, v.a. bei Patienten mit einem zeitlich absehbaren Behandlungszeitraum, z.B. mit dem Ziel einer in diesem Zeitraum zu erwartenden Lebertransplantation, prophylaktisch zu behandeln. Dabei gilt es jedoch zu bedenken, dass der verlängerte Einsatz von Ciprofloxacin prä-LTx als Risikofaktor einer erhöhten Inzidenz an Pilzinfektionen post-LTx identifiziert wurde [219] (Evidenzgrad IIb). Allerdings hat bisher keine randomisiert kontrollierte Studie die Durchführung einer selektiven Darmdekontamination placebokontrolliert im LTx-Klientel untersucht.

Die Mehrzahl der o.g. Studien wurde mit Chinolonen (Norfloxacin oder Ciprofloxacin) durchgeführt. Dabei wird Norfloxacin nur in geringem Maße systemisch absorbiert (versus Ciprofloxaxin mit guter systemischer Bioverfügbarkeit) und ist daher vermutlich hinsichtlich der Selektion Chinolon-resistenter Keime günstiger einzuschätzen als Ciprofloxacin. Der Einsatz von Trimethoprim-Sulfamethoxazol scheint vergleichbar effektiv zu sein, jedoch basiert diese Information auf einer retrospektiven Beobachtung [220] (Evidenzgrad IV) und lediglich einer randomisiert-kontrollierten Studie von suboptimaler Qualität (JadadScore 2 von 5) [208] (Evidenzgrad IIb). Ferner berichten einzelne Studien auch von einer effektiven Prophylaxe durch eine einzelne Ciprofloxacin-Gabe pro Woche [185]. Allerdings führt eine intermittierende Applikation zu einer beschleunigten Selektion von resistenten Keimen [221]. Daher ist eine tägliche Applikation zu empfehlen (Evidenzgrad Ib).

\section{Zirrhose mit Gl-Blutung als Risikofaktor}

Eine GI-Blutung begünstigt das Auftreten einer bakteriellen Infektion durch verschiedene Mechanismen: gesteigerte bakterielle Translokation, Störung der intestinalen Permeabilität, Hemmung der Phagozytoseaktivität des retikuloendothelialen Systems (RES) etc. [222]. Gleichzeitig sind bakterielle Infektionen mit einem erhöhten Therapieversagen bei Varizenblutung assoziiert (Rezidivblutung und Überleben) [223, 224]. Aerob Gram-negative Darmbakterien sind die häufigsten Erreger. Daher wurde der Einsatz einer selektiven intestinalen Dekontamination bei Zirrhosepatienten mit GI-Blutung multipel untersucht. Mittlerweile ist eine prophylaktische Antibiotika-Gabe als Standard akzeptiert, spätestens seitdem 2 Metaanalysen diese Maßnahme als signifikant hinsichtlich einer Abnahme des Auftretens einer SBP und/oder Bakteriämie mit signifikanter Reduktion der Mortalität bewertet haben [225, 226] (Evidenzgrad Ia). Dabei ist von einer relativen Risikoreduktion für die Zahl an Todesfällen von 27\% (95\%-KI 5-45\%) bzw. Inzidenz einer bakteriellen Infektion von 60\% (95\%-KI 49-68\%) und einer SBP von 69\% (95\%-KI $47-85 \%$ ) auszugehen [226]. Weitere Angaben zur Empfehlung der Antibiotikatherapie bei GI-Blutung bei Zirrhose können dem Baveno-Statement entnommen werden [227]. 


\section{III.3. Wie sollte eine SBP behandelt werden?}

\section{Empfehlung}

Unmittelbar nach Diagnosestellung einer SBP soll eine empirische Antibiotikatherapie eingeleitet werden. (A), Konsens: 100\%

Eine ambulante unkomplizierte Erstmanifestation einer SBP kann mittels Chinolon per os behandelt werden (C). Alle anderen SBPFormen sollen in erster Linie mit Cephalosporinen der Gruppe 3a behandelt werden (A). Eine Abweichung hiervon kann in Abhängigkeit von der lokalen Resistenzlage, insbesondere im Falle einer nosokomialen Infektion oder dem Bestehen einer antibiotischen Vorbehandlung, erfolgen. (C), Konsens: 100\%

Der Erfolg der Antibiotikatherapie der SBP sollte klinisch sowie mittels diagnostischer Kontrollpunktion des Aszites ca. $48 \mathrm{~h}$ nach Beginn der Therapie beurteilt werden. (B), Konsens: 100\%

\section{Kommentar}

Antibiotikawahl, Therapiedauer und Applikationsart

Bei der Auswahl von Antiinfektiva zur Behandlung der SBP sollte zwischen der ambulant erworbenen und der nosokomialen Situation unterschieden werden. Bei einer ambulant erworbenen ersten Episode einer SBP kann diese mit einem Chinolon per os behandelt werden, wenn es sich dabei um eine unkomplizierte SBP handelt und der Patient keine wesentliche Antibiotika-Vortherapie aufweist (Evidenzgrad IIa) [228, 229]. Eine unkomplizierte SBP liegt vor bei Fehlen von Schock, lleus, gastrointestinaler Blutung, schwergradige Enzephalopathie oder Serumkreatinin $<3 \mathrm{mg} / \mathrm{dl}$ [229]. Ferner sollte eine ausreichende Compliance sowie suffiziente Resorption bei funktionierendem Gastrointestinaltrakt des Patienten bestehen. Eine Sequenztherapie mit intravenösem Beginn und oraler Fortsetzung nach Antibiogramm erscheint bei unkompliziertem Verlauf ebenso möglich [230-232].

Allerdings wird in der internationalen Literatur ein deutlicher Anstieg von multiresistenten Gram-negativen Erregern (vor allem E. coli) bei Patienten mit SBP beschrieben [233, 234]. So betrug die Rate multiresistenter Bakterienisolate aus Aszites im Zeitraum 1991-1995 noch 8\% und im Vergleichszeitraum 1996-2001 bereits 38\% [178]. Dabei ist insbesondere die Durchführung einer SBP-Prophylaxe mittels z.B. dauerhafter Chinolon-Einnahme mit einer hohen Rate an Chinolonresistenz bei den Gram-negativen Isolaten assoziiert (65 vs. 29\%) [178]. Resistenzdaten aus Deutschland liegen speziell zur SBP nicht vor. Bisher kann man die Resistenzsituation im asiatischen und südeuropäischen Raum, auf die sich die Publikationen beziehen, nicht ohne Weiteres auf die deutschen Verhältnisse übertragen. Allerdings wird auch in Deutschland in den vergangenen Jahren bei Gram-negativen Isolaten ganz allgemein ein Trend zu häufigerer und komplexerer Antibiotika-Resistenz beobachtet $[235,236]$. Insbesondere scheint auch im ambulanten Bereich die Inzidenz ESBL-bildender E. coli zuzunehmen. Zum Zeitpunkt der Erstellung der Leitlinie ist die Empfindlichkeit der häufigsten Erreger einer SBP, E. coli und andere Enterobacteriaceae, gegen Cephalosporine der Gruppe 3a (z.B. Ceftriaxon, Cefotaxim) jedoch als günstig einzustufen, sodass diese Antibiotika in erster Linie zur empirischen Therapie der ambulant erworbenen SBP empfohlen werden [237-240] (Evidenzgrad Ia). Untersuchungen haben keinen Unterschied zwischen einer hohen $(4 \times 2 \mathrm{~g}$ i.v. $)$ und einer niedrigen $(2 \times 2 \mathrm{~g}$ i. v.) Cefotaximdosis ergeben. Aus pharmakokinetischen Erwägungen ist jedoch der häufigeren Verabreichung von Cefotaxim
(z.B. $3 \times 1-2$ g i.v.) oder Ceftriaxon mit deutlich längerer Halbwertszeit und einmal täglicher Gabe $(1 \times 2 \mathrm{~g}$ i.v. $)$ der Vorzug bei der Behandlung der SBP zu geben.

Frühere Untersuchungen zeigten eine vergleichbare Effektivität von Aminopenicillin/ $\beta$-Laktamase-Inhibitor-Kombinationen und Cephalosporinen der Gruppe 3 bei der Therapie der SBP [241]. Allerdings hat sich die Resistenz-Epidemiologie für die Aminopenicillin/ß-Laktamase-Inhibitor-Kombinationen deutlich ungünstiger entwickelt als für die Gruppe-3-Cephalosporine mit aktuellen E.-coli-Resistenzraten in Deutschland von deutlich über $30 \%[235,236]$. Aufgrund des dadurch erhöhten Risikos für eine inadäquate Initialtherapie können Aminopenicillin/ $\beta$ Laktamase-Inhibitor-Kombinationen nicht mehr für die empirische Behandlung einer SBP empfohlen werden.

Bei nosokomialer Situation muss zunehmend mit (multi-)resistenten Erregern der SBP gerechnet werden, was mit einer deutlich erhöhten Mortalität assoziiert zu sein scheint [242]. Insbesondere ist bei der in den letzten Jahren stark gestiegenen Chinolon-Resistenz von E. coli die Möglichkeit der Resistenz gegen diese Antibiotika-Klasse zu beachten. Zudem finden sich bereits Berichte über eine zunehmende Ineffektivität der Cephalosporine in der nosokomialen Situation, wobei auch hier als entscheidender Risikofaktor die Vortherapie mit Antibiotika zu nennen ist [243-245]. Daher sollte bei jeglicher Antibiotikatherapie die lokale Resistenzlage vor Ort, d.h. in dem behandelnden Setting, Berücksichtigung finden. Bei nosokomialer SBP kommen aufgrund der aktuellen Resistenzsituation bei Gramnegativen Erregern zur Initialtherapie alternativ zu Cephalosporinen aufgrund ihres breiten Wirkspektrums v.a. Carbapeneme infrage [246, 247] (Evidenzgrad IV). Es liegen jedoch bisher keine prospektiv kontrollierten Untersuchungen dazu vor.

Auch muss bei nosokomialer SBP vermehrt mit resistenten Gram-positiven Erregern gerechnet werden (z.B. MRSA, E. faecium, Vancomycin-resistente Enterokokken). Dies betrifft vornehmlich wiederum Patienten mit Antibiotika-Vortherapie. So ist eine Chinolon-Prophylaxe bei Zirrhosepatienten mit einem erhöhten Risiko einer MRSA-Besiedlung, in manchen Kollektiven bis zu $50 \%$ assoziiert $[248,249]$. Bei solchen Patienten muss mit der Entwicklung von spontan bakteriellen Peritonitiden durch MRSA gerechnet werden [250, 251]. Allerdings können diese Daten aus Ländern mit sehr hoher MRSA-Prävalenz nicht ohne Weiteres auf die Situation in Deutschland übertragen werden. Dennoch sollte eine bekannte MRSA-Kolonisierung eines Zirrhose-Patienten beim Auftreten einer (nosokomialen) SBP bei der Auswahl der zur empirischen Therapie einzusetzenden Antiinfektiva berücksichtigt werden. Dies ist von Bedeutung, da eine inadäquate, d.h. den verursachenden Erreger bei der Initialtherapie nicht erfassende Antibiotikatherapie mit einer höheren Letalität assoziiert ist [252, 253].

Bei komplizierter schwer verlaufender SBP sollten die Antiinfektiva parenteral gegeben werden. Bei unkomplizierter SBP dagegen kann die Behandlung durch orale Präparate erfolgen (Evidenzgrad Ila). Eine Sequenztherapie intravenös $\rightarrow$ oral erscheint bei klinischer Besserung unter Berücksichtigung des Antibiogramms möglich (Evidenzgrad II b). Nach Erhalt der Resistenztestung sollte die Antibiotikatherapie gezielt umgestellt werden, und zwar auf ein Präparat, welches das Isolat mit möglichst schmalem Spektrum und hoher antimikrobieller Aktivität erfasst. Zur Therapie der Rekurrenz einer SBP unter Sekundärprophylaxe liegen keine prospektiv randomisierten Studien vor. Auswertungen der SBP-Fälle im Rahmen der Primärprophylaxestudien und damit vorbestehender Chinolongabe weisen jedoch 
daraufhin, dass Cephalosporine der Gruppe 3a auch im Falle der stattgehabten Entwicklung einer Chinolonresistenz wirksam sind [187] (Evidenzgrad IV). Bei anderer Antibiotikaprophylaxe sollte mit einer von der Vortherapie unterschiedlichen Substanzklasse je nach lokaler Resistenzsituation behandelt werden (Evidenzgrad IV).

Eine Behandlung mit Aminoglykosiden sollte wegen des hohen Risikos von additiver Nephrotoxizität bei Patienten mit Leberzirrhose und SBP nach Möglichkeit vermieden werden (Evidenzgrad Ia). Dies gilt insbesondere, wenn bereits eine eingeschränkte Nierenfunktion vorliegt, z. B. bei HRS. Ferner scheint die Effektivität der SBP-Behandlung mit Aminoglykosiden ohnehin geringer zu sein als mit $\beta$-Laktam-Antibiotika [254256]. Patienten mit bekannter Penicillin-Allergie können mit geringem Kreuzallergie-Risiko mit Cephalosporinen, solche mit Cephalosporin-Allergie evtl. mit Carbapenemen behandelt werden. Gegenüber Chinolonen besteht bei Penicillinallergie keinerlei Kreuzallergie.

\section{Verlaufsbeurteilung der Therapie}

Durch die o.g. Antibiotika wird in etwa 90\% der Fälle eine Ausheilung der SBP erzielt. Dies ist mit einem Abklingen bestehender Symptome und Verschwinden von Infektzeichen (falls vorher vorhanden) begleitet. Allerdings sind diese Kriterien nicht zuverlässig. Daher wird als Parameter für den Therapieerfolg die Kinetik der PMN-Zahl im Aszites verwendet und eine Verlaufspunktion des Aszites nach $48 \mathrm{~h}$ Antibiotikatherapie empfohlen. Hierbei gilt zu betonen, dass die Höhe der peripheren Leukozytose nicht mit der PMN-Zahl im Aszites und oder deren Verlauf korreliert [257]. Als Kriterium für einen adäquaten Therapieerfolg wird ein Abfall der PMN-Zahl im Aszites idealerweise auf $\leq 250 / \mathrm{mm}^{3}$ gefordert, da dies sich in einer Beobachtungsstudie als positiv prädiktiv für das Ausbleiben einer Rezidiv-SBP zeigte [258]. Obwohl keine gezielte Untersuchung einen klaren minimalen Grenzwert für den Abfall der PMN in der Verlaufspunktion des Aszites definiert hat, wurde vormals eine Abnahme um wenigstens 25\% des Ausgangswerts als sinnvoll erachtet [32]. Dies beruht auf einer retrospektiven Beobachtung zur Halbwertszeit der PMN im Aszites nach Einleitung einer Antibiotikatherapie bei Vorliegen einer SBP [259]. Ferner zeigte eine prospektive Evaluation, dass der prozentuale Abfall der PMN-Zahl im Aszites nach $48 \mathrm{~h}$ einer Antibiotikabehandlung bei Patienten, welche überlebten, mit $92+9 \%$ signifikant stärker ausfiel als bei Patienten, die verstarben $(66+38 \%)$ [260]. Im Falle einer klinischen Besserung und Nachweis eines PMN-Abfalls im Aszites auf <250/ $\mathrm{mm}^{3}$ sollte die antibiotische Behandlung nach 5 Tagen beendet werden und eine Sekundärprophylaxe (s.u.) eingeleitet werden (Evidenzgrad IIb). Eine Verlängerung der Behandlungsdauer auf 10 Tage bringt in diesem Fall keinen Vorteil [261]. Sinkt die PMN-Zahl im Aszites in der Kontrollparazentese $48 \mathrm{~h}$ nach Beginn der Antibiotikatherapie nicht um mindestens 25\% des Ausgangswerts ab, sollte die Behandlung modifiziert werden (Evidenzgrad IIIb). Ferner sollte jegliche klinische Verschlechterung im Verlauf der Therapie frühzeitig Anlass zum Überdenken des Antibiotikaregimes geben. Dabei ist im Falle einer Kultur-positiven SBP das Antibiogramm und in der empirischen Therapiesituation das Resistenzspektrum vor Ort zu berücksichtigen. Ferner sollte das Vorliegen einer sekundären Peritonitis differenzialdiagnostisch in dieser Situation betrachtet werden.

\section{III.4. Wie sollten die Sekundärprophylaxe und Nachsorge} einer SBP aussehen?

\section{Empfehlung}

Nach erfolgreicher Therapie einer SBP sollte eine Sekundärprophylaxe durchgeführt werden. (B), Konsens: $100 \%$

Diese sollte mittels Chinolon (oder alternativ mittels Trimethoprim-Sulfamethoxazol) in mikrobiologisch wirksamer Dosis erfolgen. (B), Konsens: 94,4\%

\section{Kommentar}

Die Wahrscheinlichkeit des erneuten Auftretens einer SBP nach Erstmanifestation ohne Einleitung einer Prophylaxe beträgt zwischen 30 und 68\% innerhalb eines Jahres. Daher ist eine sekundär-prophylaktische Therapie indiziert und sollte durchgeführt werden. Dabei sind keine zusätzlichen Parameter zur evtl. Risikostratifizierung bekannt. Bisher untersucht im Rahmen kontrollierter Studien ist lediglich der Einsatz von Chinolonen, insbesondere von Norfloxacin. Zwei randomisiert-kontrollierte Studien mit Untersuchung eines Patientenkollektivs mit stattgehabter SBP und Frage der Effektivität einer Sekundärprophylaxe sind verfügbar [181, 262] (Evidenzgrad Ib). Dabei liegt nur eine placebokontrollierte Studie vor, welche durch den Einsatz von Norfloxacin ( $400 \mathrm{mg} / \mathrm{Tag}$ ) die 1-Jahreswahrscheinlichkeit eines SBP-Rezidivs von 68\% in der Placebo-Gruppe auf $20 \%$ in der Verumgruppe signifikant senken konnte [181]. Bauer et al. verglichen dagegen den täglichen Einsatz von Norfloxacin $(400 \mathrm{mg} /$ Tag) mit dem von Rufloxacin ( $400 \mathrm{mg} /$ Woche) [262]. Hierbei fand sich eine 1-Jahreswahrscheinlichkeit eines SBP-Rezidivs von 26 vs. 36\% (n.s.). Allerdings zeigten sich unter einer nur einmal wöchentlichen Rufloxacin-Gabe signifikant mehr SBP-Fälle mit Enterbacteriaceae-Nachweis (22 vs. 0\%). Primärer Endpunkt der placebokontrollierten Studie war das Wiederauftreten einer SBP und nicht Mortalität. Weitere 3 Studien untersuchten die Wirksamkeit von Ciprofloxacin, Trimethoprim-Sulfamethoxazol und Norfloxacin, schlossen jedoch Patienten mit und ohne bisher stattgehabte SBP ein [185, 186, 208] (Evidenzgrad IIb). Die sinnvolle Dauer einer derartigen Maßnahme wurde bisher in keiner prospektiven Studie evaluiert. Allerdings erscheint aufgrund des erhöhten Risikos der Selektion resistenter Keime eine zeitliche Limitierung sinnvoll, z.B. dann, wenn eine Verbesserung der Child-Pugh-Klasse und/oder Resolution des Aszites erreicht wird.

\section{Hepatorenales Syndrom}

$\nabla$

\section{IV.1. Einleitung}

\section{Definition}

Das hepatorenale Syndrom (HRS) ist definiert als potenziell reversible Nierenfunktionsstörung bei Patienten mit Leberzirrhose und Aszites oder bei Patienten mit alkoholischer Steatohepatitis. Es werden 2 Formen unterschieden [263, 264]:

HRS Typ I ist charakterisiert durch rasches Nierenversagen, definiert als Verdoppelung des Serumkreatinins auf über $2,5 \mathrm{mg} / \mathrm{dl}$ (226 mmol/l) in weniger als 2 Wochen.

HRS Typ II ist oft mit refraktärem Aszites vergesellschaftet und zeigt ein moderates Nierenversagen mit Serumkreatininwerten zwischen 1,5 und $2,5 \mathrm{mg} / \mathrm{dl}(133-226 \mathrm{mmol} / \mathrm{l})$ bei stabilem oder langsam fortschreitendem Verlauf. 


\section{Diagnostische Kriterien}

- Zirrhose mit Aszites (oder alkoholische Steatohepatitis)

- Serumkreatinin $>1,5 \mathrm{mg} / \mathrm{dl}(>133 \mathrm{mmol} / \mathrm{l})$

- keine Besserung des Serumkreatinin auf Werte $<1,5 \mathrm{mg} / \mathrm{dl}$ nach mindestens 2-tägiger Pausierung aller Diuretika und Volumenexpansion mit Albumin. Die empfohlene Albumindosierung beträgt $1 \mathrm{~g} / \mathrm{kg}$ Körpergewicht pro Tag bis zu einem Maximum von $100 \mathrm{~g} / \mathrm{Tag}$.

- Ausschluss eines Schockgeschehens

- keine laufende oder kürzlich erfolgte Therapie mit nephrotoxischen Medikamenten.

- Ausschluss einer parenchymatösen Nierenerkrankung (keine Proteinurie $>500 \mathrm{mg} / \mathrm{Tag}$ und unauffälliges Urinsediment und keine Mikrohämaturie > 50 Erythrozyten/HPF und unauffällige Nierensonografie).

\section{Kommentar}

Ein Nierenversagen kann aufgrund der niedrigen Muskelmasse von Patienten mit Leberzirrhose auch bei einem niedrigeren Kreatinin vorliegen. Im klinischen Alltag soll deshalb bei raschem Anstieg des Serumkreatinins oder signifikantem Abfall der Diurese bereits vor Erreichen der o.g. Grenzwerte eine rasche Diagnostik und gegebenenfalls therapeutische Intervention erfolgen. Patienten mit Lebererkrankungen weisen auch häufig eine Nierenfunktionsstörung auf. Dabei ist zu beachten, dass die gängigen Labormethoden die glomeruläre Filtrationsrate bei Patienten mit Lebererkrankungen meist überschätzen. Auch weisen zahlreiche Patienten mit Erkrankungen der Leber eine organische Nierenerkrankung auf (z.B. IgA Nephropathie). Dies muss bei der Diagnose und Differenzialdiagnose eines hepatorenalen Syndroms bedacht werden. Die nephrologische Mitbetreuung von Patienten mit Proteinurie oder Mikrohämaturie ist zu empfehlen.

\section{IV.2. Welchen Stellenwert hat die Albumingabe in der Therapie des HRS?}

\section{Empfehlung}

Die intravenöse Albumingabe zum Ausschluss eines Volumenmangels bzw. zur Sicherung der Diagnose eines hepatorenalen Syndroms sollte in einer Dosierung von $1 \mathrm{~g}$ pro kg Körpergewicht, bis maximal $100 \mathrm{~g} /$ Tag, erfolgen. (B), Konsens: $100 \%$

Die Kombinationsbehandlung aus Albumininfusion 20 - $40 \mathrm{~g} / \mathrm{Tag}$ und Vasokonstriktortherapie ist Therapie der ersten Wahl bei hepatorenalem Syndrom Typ I (A). Die fortgesetzte alleinige Albumininfusion soll nicht durchgeführt werden (A). Andere Plasmaexpander können in dieser Indikation aufgrund der unzureichenden Datenlage nicht empfohlen werden. (D), Konsens: 100\%

\section{Kommentar}

Während in der ersten Fassung der diagnostischen Kriterien des HRS u.a. das fehlende Ansprechen auf Volumenexpansion mit 1,51 isotoner Kochsalzlösung gefordert wurde [263], wurde dies in der Revision durch die Volumenexpansion mit Humanalbumin in einer Dosierung von $1 \mathrm{~g}$ pro kg Körpergewicht bis zu einem Maximum von $100 \mathrm{~g}$ pro Tag geändert [264]. Hintergrund war die pathophysiologische Überlegung, dass isotone Kochsalzlösung bei Patienten mit HRS rasch in die Peritonealhöhle filtriert wird und somit eine Erhöhung des zentralen Blutvolumens schlechter möglich ist als mit Albumin (Evidenzgrad V).
In mehreren kontrollierten Studien zum Nutzen von Terlipressin wurden die Patienten im Kontrollarm mit Albumininfusionen behandelt [265-268]. Hierbei kam es in einer Studie bei keinem der ausschließlich mit Albumin behandelten Patienten zu einem Ansprechen und alle Patienten aus dem Kontrollarm waren an Tag 15 verstorben [265]. Bessere Ansprechraten ergaben sich in den Kontrollarmen der Studien von Sanyal et al. (komplettes Ansprechen bei 13\%), Martin-Llahí et al. (Besserung der Nierenfunktion bei 9\%) und Neri et al. (komplettes Ansprechen bei 19\%, partielles Ansprechen bei 16\%) [266268].

Zusammenfassend führt die alleinige Albumininfusion somit nur bei wenigen Patienten mit HRS zu einer Besserung der Nierenfunktion (Evidenzgrad Ib).

Die Frage, ob eine Albumininfusion zusätzlich zur Terlipressingabe erforderlich ist, wurde in einer Fall-Kontrollstudie an Patienten mit HRS Typ I oder II untersucht [269]. In dieser Studie wurde bei 13 Patienten, die Terlipressin mit Albumin erhielten, ein Abfall der Serumkreatininkonzentration von 3,6 $\pm 0,5 \mathrm{mg} / \mathrm{dl}$ auf $1,5 \pm 0,2 \mathrm{mg} / \mathrm{dl}$ zum Studienende beobachtet, wohingegen die mittlere Kreatininkonzentration bei 8 Patienten, die nur Terlipressin erhielten, weitgehend konstant blieb $(3,4 \pm 0,3 \mathrm{mg} / \mathrm{dl}$ vs. $3,4 \pm 0,7 \mathrm{mg} / \mathrm{dl}$ ). Hieraus kann gefolgert werden, dass der Effekt der Vasokonstriktortherapie mit Terlipressin durch die regelmäßige Albumininfusion signifikant verbessert werden kann (Evidenzgrad IIIc).

Lediglich eine Fallserie zum Einsatz von Gelatinepolysuccinat in Kombination mit Terlipressin [270] zeigte eine Verbesserung der Nierenfunktion bei 5 von 7 Patienten mit HRS Typ I oder II. Hierbei kam es zu einem Abfall der mittleren Serumkreatininkonzentration von $3,9 \pm 0,4 \mathrm{mg} / \mathrm{dl}$ auf $1,9 \pm 0,3 \mathrm{mg} / \mathrm{dl}$. Direkte Vergleichsstudien zwischen Albumin und synthetischen Plasmaexpandern existieren für Patienten mit HRS nicht, sodass eine Gleichwertigkeit zur Albumininfusion nicht belegt ist (Evidenzgrad IV). Gerade bei sehr schlechter Nierenfunktion sollte die Gabe von Hydroxyäthylstärke mit größter Zurückhaltung betrieben werden, da sie insbesondere bei septischen Patienten zu einem akuten Nierenversagen führen kann [271] (Evidenzgrad Ia).

\section{IV.3. Welchen Stellenwert haben Vasokonstriktoren in der Therapie des HRS?}

\section{Empfehlung}

Sofern keine Kontraindikationen vorliegen, sollen Patienten mit hepatorenalem Syndrom Typ I mit Terlipressin und Albumin behandelt werden, da dies das kurzfristige Überleben signifikant verbessert. (A), Konsens: 100\%

Diese Therapie soll mit einer Terlipressindosis von $2-4 \mathrm{mg} / \mathrm{Tag}$ begonnen werden und über einen Zeitraum von mindestens $3 \mathrm{Ta}$ gen durchgeführt werden. Terlipressin soll maximal in einer Dosis von $8-12 \mathrm{mg} /$ Tag eingesetzt werden. (A), Konsens: $100 \%$

Ein Nutzen dieser Therapie für Patienten mit HRS Typ II ist bislang nicht klar belegt, deswegen sollten diese Patienten analog zu Patienten mit refraktärem Aszites behandelt werden. (KKP), Konsens: $100 \%$

Andere Vasokonstriktoren sind hinsichtlich Wirksamkeit, Überlebensvorteil und Nebenwirkungsprofil noch unzureichend untersucht und sollten daher nicht außerhalb von Studien eingesetzt werden. (KKP), Konsens: 100\% 
Tab.4 Dosierung und Therapiedauer mit Terlipressin in randomisierten, kontrollierten Studien.

\begin{tabular}{|c|c|c|c|}
\hline Autor & Behandlungserfolg (n/n) & Dosierung & Therapiedauer \\
\hline Hadengue A et al. 1998 [276] & $6 / 9$ & $1 \mathrm{mg}$ Bolus alle $12 \mathrm{~h} \mathrm{i.v.}$ & 2 Tage \\
\hline Solanki P et al. 2003 [265] & $5 / 12$ & $1 \mathrm{mg}$ Bolus alle $12 \mathrm{~h} \mathrm{i.v.}$ & maximal 15 Tage \\
\hline Sanyal A] et al. 2008 [266] & $19 / 56$ & $\begin{array}{l}1 \mathrm{mg} \text { Bolus alle } 6 \mathrm{~h} \text { i.v. falls kein Ansprechen ab Tag } 4 \\
2 \mathrm{mg} \text { Bolus alle } 6 \mathrm{~h} \text { i.v. }\end{array}$ & im Mittel 6,3 Tage, maximal 14 Tage \\
\hline Martin-Llahí M et al. 2008 [267] & $10 / 23$ & $\begin{array}{l}1 \mathrm{mg} \text { Bolus alle } 4 \mathrm{~h} \mathrm{i.v.} \mathrm{falls} \mathrm{kein} \mathrm{Ansprechen} \mathrm{ab} \mathrm{Tag} 4 \\
2 \mathrm{mg} \text { Bolus alle } 4 \mathrm{~h} \text { i.v }\end{array}$ & im Mittel 7 Tage, maximal 14 Tage \\
\hline Neri S et al. 2008 [268] & $21 / 26$ & $1 \mathrm{mg}$ Bolus alle $8 \mathrm{~h}$ i.v. ab Tag $80,5 \mathrm{mg}$ Bolus alle $8 \mathrm{~h} \mathrm{i.v.}$ & maximal 14 Tage \\
\hline
\end{tabular}

Tab.5 Dosierung der Albumininfusion in Kombination mit Terlipressin.

\begin{tabular}{|c|c|c|c|}
\hline Autor & Tag 1 & Folgetherapie & Stopp-Kriterium \\
\hline Ortega R et al. 2002 [269] & $1 \mathrm{~g} / \mathrm{kg} \mathrm{KG} / \mathrm{Tag}$ & $20-40 \mathrm{~g} / \mathrm{Tag}$ & falls $Z V D>18 \mathrm{~cm} \mathrm{H} 2 \mathrm{O}$ \\
\hline Solanki P et al. 2003 [265] & $20 \mathrm{~g} / \mathrm{Tag}$ & $20 \mathrm{~g} / \mathrm{Tag}$ & bis ZVD $10-12 \mathrm{~cm} \mathrm{H} 2 \mathrm{O}$ erreicht \\
\hline Sanyal AJ et al. 2008 [266] & $100 \mathrm{~g} / \mathrm{Tag}$ & $25 \mathrm{~g} / \mathrm{Tag}$ & - \\
\hline Martín-Llahí M et al. 2008 [267] & $1 \mathrm{~g} / \mathrm{kg} \mathrm{KG} / \mathrm{Tag}$ & $40 \mathrm{~g} / \mathrm{Tag}$ & falls ZVD > $15 \mathrm{~cm} \mathrm{H} 2020 \mathrm{~g} / \mathrm{Tag}$ \\
\hline Neri S et al. 2008 [268] & $1 \mathrm{~g} / \mathrm{kg} \mathrm{KG} / \mathrm{Tag}$ & $20-40 \mathrm{~g} / \mathrm{Tag}$ & - \\
\hline
\end{tabular}

Tab. 6 Kontraindikationen zur Terlipressingabe.

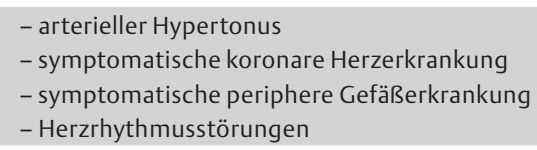

\section{Kommentar}

Der Nutzen der Vasokonstriktortherapie, insbesondere mit Terlipressin, ist durch zahlreiche Studien belegt und mittlerweile in 3 Metaanalysen bestätigt (Evidenzgrad Ia) [272-274]. In die Analyse von Fabrizi et al. flossen 5 Studien ein, in denen je 126 Patienten mit HRS entweder mit Terlipressin oder Placebo behandelt wurden. Es zeigte sich eine signifikante Verbesserung der Nierenfunktion mit Terlipressin (OR 8,09 95\% CI3,52-18,59), ischämische Nebenwirkungen traten häufiger auf (OR 2,91 95\%-KI 1,09-7,72), ein Überlebensvorteil wurde nicht beobachtet (OR 2,06 95\%-KI 0,94-4,54). Eine weitere Metaanalyse [273] fasste 10 Studien zusammen, in denen 188 Patienten mit HRS mit Vasokonstriktoren (Terlipressin, Midodrin + Octreotid und Noradrenalin) und 190 ausschließlich mit Albumin behandelt wurden. Es fand sich eine reduzierte Mortalität bei allen Vasokonstriktoren vs. Albumin (OR 0,82 95\%-KI 0,70-0,96), in der Subgruppenanalyse nur an Tag 15, nicht jedoch nach 30, 90 oder 180 Tagen. Stratifiziert nach der Art der Behandlung ergab sich eine reduzierte Mortalität nur bei Terlipressin (OR 0,81 95\%-KI 0,68-0,97). Die Metaanalyse von Sagi et al. wertete 4 Studien aus, in denen ausschließlich Patienten mit HRS Typ 1 behandelt wurden, davon erhielten 111 Terlipressin und 112 Placebo plus Albumin. Es zeigte sich eine signifikante Verbesserung der Nierenfunktion unter Terlipressin (OR 3,66 95\%-KI 2,15-6,23), schwere Nebenwirkungen bei $6,8 \%$ und ein tendenzieller Überlebensvorteil an Tag 90 (OR 1,86 95\%-KI 1,0-3,4).

Aufgrund der geringen Zahl an Patienten mit HRS Typ II, die in kontrollierten Studien untersucht wurden, kann auch in Anbetracht der signifikanten Nebenwirkungen für diese Patienten derzeit keine Therapieempfehlung ausgesprochen werden. Für Patienten mit HRS Typ I scheint nach mindestens 3-tägiger Terlipressingabe die kurzfristige Überlebenswahrscheinlichkeit verbessert (Evidenzgrad Ia) [272-274], was für Patienten auf der Transplantationswarteliste relevant sein kann. Die bisher in Studien untersuchten Dosierungen von Terlipressin sind in - Tab. 4 zusammengefasst. Kontraindikationen finden sich in - Tab. 6.

Ob die kontinuierliche Gabe von Terlipressin [275] der intermittierenden Bolusgabe hinsichtlich des Nebenwirkungsprofils überlegen ist, ist Gegenstand einer laufenden kontrollierten Studie und kann derzeit nicht beantwortet werden (Evidenzgrad IV).

Bezüglich anderer Vasokonstriktoren (Noradrenalin, Midodrin plus Octreotid) kann derzeit aufgrund der sehr niedrigen Fallzahlen keine eindeutige Empfehlung ausgesprochen werden. Die Kontrolle des Ansprechens auf die Vasokonstriktortherapie erfolgt klinisch (Zunahme der Diurese) und laborchemisch (Abfall des Serumkreatinins). Zeigt sich innerhalb von 3 Tagen kein Ansprechen, sollte die Terlipressindosis stufenweise auf die Höchstdosis von 8-12mg gesteigert werden. Fehlendes Ansprechen auf diese Dosis macht einen Therapieerfolg unwahrscheinlich. Zeigt sich ein Ansprechen auf die Vasokonstriktortherapie, sollte bis zu einer Normalisierung der Nierenfunktion, zumindest aber bis zum Erreichen eines Serumkreatinin $<1,5 \mathrm{mg} / \mathrm{dl}$ behandelt werden. Wichtig ist in jedem Fall die Kombination der Therapie mit Albumin-Infusionen (siehe 0 Tab.5) [269].

$\mathrm{Zu}$ den letztgenannten Empfehlungen liegen keine ausreichenden Studien vor. Trotz niedriger Evidenzlage waren sich die Experten im Empfehlungsgrad einig.

IV.4. Gibt es einen Stellenwert des transjugulären intrahepatischen portosystemischen Shunts (TIPS) bei HRS?

\section{Empfehlung}

Die Anlage eines transjugulären intrahepatischen portosystemischen Shunts (TIPS) sollte bei allen Patienten mit HRS erwogen werden. (B), Konsens: 100\%

\section{Kommentar}

Nach TIPS-Anlage wird eine Verbesserung der Nierenfunktion bei Patienten mit refraktärem Aszites beobachtet [172, 277]. In bislang 4 prospektiv unkontrollierten Studien wurde der Effekt 
des TIPS auf die Nierenfunktion bei Patienten mit HRS untersucht [278-281]. In der ersten Studie wurden 7 Patienten mit HRS Typ I (Serumkreatinin 2,7-7,9 mg/dl, Bilirubin 0,8$19 \mathrm{mg} / \mathrm{dl}$ ) einer TIPS-Anlage unterzogen. Eine Verbesserung der Nierenfunktion wurde bei 6 von 7 Patienten bereits nach 7 Tagen beobachtet. Bei diesen 6 Patienten kam es bis Tag 30 nach TIPS zu einem weiteren, deutlichen Abfall des Kreatinins auf $1,8 \pm 0,8 \mathrm{mg} / \mathrm{dl}$ (vs. $5,0 \pm 0,8 \mathrm{mg} / \mathrm{dl}$ vor TIPS). Das mediane Überleben dieser Patienten betrug 4,7 $\pm 2,0$ Monate.

Eine weitere Kohorte [279] umfasste 41 Patienten, davon 21 mit HRS Typ I und 20 mit HRS Typ II. 14 Patienten mit HRS Typ I (66\%) und 17 mit HRS Typ II (85\%) wurden einer TIPSAnlage unterzogen, die restlichen Patienten wurden wegen Kontraindikationen (Bilirubin $\geq 15 \mathrm{mg} / \mathrm{dl}$, Child-Pugh-Score $>12$ Punkte oder spontane hepatische Enzephalopathie) nicht mit einem TIPS versorgt und der spontane Krankheitsverlauf beobachtet. Bei 24 von 31 Patienten zeigte sich eine Verbesserung der Nierenfunktion mit Mobilisierung des Aszites, was mit einer signifikanten Verlängerung des Überlebens verbunden war (50 vs. $0 \%$ nach 12 Monaten). Das Überleben von Patienten mit HRS Typ II nach TIPS-Anlage war signifikant besser als das von Patienten mit HRS Typ I (59 vs. 14\% nach 12 Monaten). In einer Multivarianzanalyse wurden das Serumbilirubin und der Child-Pugh-Score vor TIPS, nicht aber das Serumkreatinin als Prädiktoren für das Überleben identifiziert.

In einer weiteren Studie [280] wurden 14 Patienten mit HRS Typ I zunächst medikamentös mit Midodrin und Octreotid behandelt. 4 Non-Responder verstarben, von den 10 Respondern erhielten 5 einen TIPS. Alle 5 Patienten zeigten eine kontinuierliche Verbesserung der Nierenfunktion über einen Verlauf von 6-30 Monaten, wobei ein Patient im Beobachtungszeitraum lebertransplantiert wurde.

Bei 18 Patienten mit HRS Typ II wurde sowohl eine Verbesserung der Nierenfunktion als auch eine komplette (8 Patienten) oder partielle Mobilisierung (10 Patienten) des Aszites berichtet. Angaben zum medianen Überleben fehlen jedoch in dieser Studie [281].

Zusammenfassend führt die Anlage eines TIPS sowohl bei Patienten mit HRS Typ I als auch Typ II zu einer (längerfristigen) Verbesserung der Nierenfunktion und dadurch möglicherweise auch zu einer Überlebensverlängerung (Evidenzgrad IIc). Kontraindikationen, wie eine vorbestehende Enzephalopathie $\geq$ Grad 2 oder eine eingeschränkte Leberfunktion (Bilirubin $>3-5 \mathrm{mg} / \mathrm{dl}$ ) müssen jedoch beachtet werden (Evidenzgrad IIIb).

\section{IV.5. Wann ist ein Nierenersatzverfahren beim HRS indiziert und welchen Stellenwert haben Leberersatz- verfahren?}

\section{Empfehlung}

Da Nierenersatzverfahren allein die Prognose bei HRS nicht verbessern, können sie bei Vorliegen von Dialysekriterien vor allem als Überbrückung bis zur Lebertransplantation eingesetzt werden. (D), Konsens: $100 \%$

Die extrakorporale Albumindialyse hat keinen Einfluss auf Nierenfunktion und Überleben bei Patienten mit HRS. Leberersatzverfahren sollten daher derzeit bei Patienten mit HRS nur im Rahmen kontrollierter Studien zum Einsatz kommen. (B), Konsens: 100\%

\section{Kommentar}

Zum möglichen Nutzen von intermittierender Hämodialyse bzw. kontinuierlicher Hämofiltration existiert lediglich eine Outcome-Research-Studie [282]. In dieser Studie war das mediane Überleben unter Nierenersatztherapie 21 Tage. Neben Parametern der Leberfunktion war in einer Multivarianzanalyse die mechanische Beatmung ein unabhängiger Prädiktor für eine frühe Sterblichkeit. Die Autoren schlussfolgern, dass durch intermittierende Hämodialyse Patienten mit HRS bis zur Lebertransplantation überbrückt werden können, bei Patienten mit zusätzlicher respiratorischer Insuffizienz Nierenersatzverfahren aber sinnlos sind (Evidenzgrad IIc).

In einer prospektiven, randomisierten Studie wurde die extrakorporale Albumindialyse $\left(\mathrm{MARS}^{\circledR}\right.$ ) in Kombination mit Hämodiafiltration bei 8 Patienten verglichen mit der medikamentösen „Standardtherapie“ plus Hämodiafiltration bei 5 Patienten [283]. Keiner der Patienten erhielt einen TIPS oder Vasokonstriktoren. Die Kaplan-Meier-Analyse ergab einen signifikanten Überlebensvorteil bis Tag 30 bei Abfall des Serumkreatinins unter laufender Behandlung mit MARS ${ }^{\circledR}$. In einer neueren Untersuchung [284] wurden 6 Patienten mit HRS Typ I, die auf eine Therapie mit Vasokonstriktoren plus Albumin nicht angesprochen hatten, einer fünftägigen Behandlung mit MARS $^{\circledR}$ unterzogen. Hierbei konnte keine Verbesserung von renalem Blutfluss, glomerulärer Filtrationsrate oder Diurese gezeigt werden. Entsprechend konnte in einer aktuell als Abstrakt publizierten prospektiven kontrollierten Studie zur Behandlung mit MARS ${ }^{\circledR}$ bei Patienten mit akut auf chronischem Leberversagen kein Überlebensvorteil nachgewiesen werden [285].

Auch unter dem extrakorporalen Leberunterstützungsverfahren Prometheus $^{\circledR}$ zeigte sich eine temporäre Besserung der Nierenfunktionswerte [286]. Eine aktuell als Abstrakt publizierte randomisierte kontrollierte Studie konnte keine Überlebensverlängerung für das Gesamtkollektiv der Patienten mit akut auf chronischem Leberversagen nachweisen, in einer vordefinierten Subgruppenanalyse war das Überleben von Patienten mit HRS Typ I oder einem MELD-Score über 30 durch die Behandlung mit Prometheus ${ }^{\circledR}$ allerdings signifikant verlängert [287].

Zusammenfassend senken extrakorporale Leberunterstützungsverfahren die Serumkonzentration harnpflichtiger Substanzen. Sie haben jedoch keinen langfristigen Einfluss auf die renale Hämodynamik und Diurese bei Patienten mit HRS (Evidenzgrad IIc). Leberersatzverfahren sollten daher derzeit bei Patienten mit HRS nur im Rahmen kontrollierter Studien zum Einsatz kommen (Evidenzgrad IV). Nierenersatzverfahren können, falls erforderlich, auch nach einer Lebertransplantation eingesetzt werden.

\section{IV.6. Wie beeinflusst das HRS die Indikation zur und den Verlauf nach Lebertransplantation?}

\section{Empfehlung}

Die Lebertransplantation ist die einzige potenziell kurative Therapie des HRS und soll bei geeigneten Patienten angestrebt werden. (A), Konsens: $100 \%$

Auch bei beabsichtigter Lebertransplantation sollten Albumin und Terlipressin verabreicht werden, da Patienten mit Niereninsuffizienz bei Transplantation eine deutlich schlechtere postoperative Prognose haben. (B), Konsens: $100 \%$

Bei einer Dauer des HRS von mehr als 6 Wochen sollte die Indikation zur Leber- und Nierentransplantation erwogen werden. (B), Konsens: $100 \%$ 


\section{Kommentar}

Da die eingeschränkte Leberfunktion mit ihren Folgen die Ursache des hepatorenalen Syndroms ist, stellt die Lebertransplantation die einzige kausale Therapie dar. Nach Normalisierung der Leberfunktion sowie der durch die zirrhotische Leber gestörten Physiologie und Hämodynamik kann es nach Lebertransplantation zu einer deutlichen Besserung oder Normalisierung der Nierenfunktion bei einem Patienten mit HRS kommen [288].

Bei Patienten, die im Zustand eines HRS transplantiert werden, kommt es jedoch in der perioperativen Situation vorübergehend sogar zu einer Verschlechterung der Nierenfunktion, bedingt durch das operative Trauma, eine weitere Nierenschädigung im Rahmen des Ischämie/Reperfusions-Syndroms der Leber, eine perioperative Flüssigkeitsrestriktion (zur Erreichung eines niedrigen zentralen Venendrucks) sowie die postoperative Immunsuppression mit nephrotoxischen Medikamenten (wie z.B. Calcineurin-Inhibitoren). Diese problematischen Aspekte sollen daher perioperativ im Management berücksichtigt werden (z.B. Flüssigkeitsmanagement, Art/Dosis der Immunsuppression etc.).

Da das HRS oft ein Zeichen einer Dekompensation der Leberzirrhose darstellt, ist es ein indirekter Parameter, der auf eine ungünstige Ausgangssituation der Transplantation hinweist. In der Tat ist das Überleben nach Transplantation direkt beeinflusst durch die präoperative Nierenfunktion (Evidenzgrad IIc) [289, 290].

Das Serum Kreatinin stellt einen der drei Parameter dar, aus denen sich der MELD-Score errechnet. Dieser Score diente ursprünglich zur Abschätzung des Überlebens von Patienten mit Leberzirrhose ohne Transplantation. Der MELD-Score wird inzwischen in vielen Ländern (und auch in Deutschland) als Basis der Organallokation zur Lebertransplantation (d.h. zur Zuteilung von Organen verstorbener Organspender) angewendet. Da die „klinische Dringlichkeit“ bei der Allokation im Vordergrund steht, bedeutet dies, dass nur Patienten mit hohem MELD-Score (i.d.R. über 30) die Chance haben, ein Organ alloziert zu bekommen. Dies sind häufig Patienten mit einer eingeschränkten Nierenfunktion oder einem HRS.

Eine Stabilisierung der Nierenfunktion durch konservative Maßnahmen führt daher in vielen Fällen zu einer deutlichen Stabilisierung des Patienten - aber auch dazu, dass der MELD-Score wieder abfällt, und der Patient damit eine deutlich geringere Chance hat, ein Organangebot zu erhalten. Andererseits führt eine Verbesserung der Nierenfunktion vor Transplantation zu einer geringeren postoperativen Morbidität und Mortalität [291]. Ein Unterlassen konservativer Maßnahmen zur Stabilisierung der Nierenfunktion vor Lebertransplantation kann daher nicht empfohlen werden. insbesondere weil ein hoher MELD-Score nicht zwangsläufig zu einem raschen Organangebot führt. Da der für eine Transplantation erforderliche MELD-Score in Deutschland aufgrund des Spendermangels höher ist als in anderen Ländern, sind die Ergebnisse auch schlechter, d.h. die Mortalität ist höher. Falls bei einem solchen Lebertransplantationskandidaten die Notwendigkeit zu einer Nierentransplantation gesehen wird, soll bei Vorliegen eines HRS und einer glomerulären Filtrationsrate $<15 \mathrm{ml} / \mathrm{min}$ die Nierentransplantation sequenziell nach erfolgreicher Lebertransplantation und nicht simultan erfolgen [292]. Eine Indikation zu einer zusätzlichen Nierentransplantation sollte in folgenden Situationen erwogen werden: länger bestehendes Nierenversagen mit der Notwendigkeit zum Einsatz von Nierenersatzverfahren (da dann die Wahrscheinlichkeit einer Er- holung der Nierenfunktion von Patienten mit HRS nach Lebertransplantation reduziert ist). Dies ist in Anlehnung an die Empfehlungen des „United network for organ sharing (UNOS)“ [293] gegeben bei Dialysepflichtigkeit von $\geq 6$ Wochen und/ oder organischem Nierenversagen (Evidenzgrad III a).

\section{Hepatischer Hydrothorax \\ $\nabla$}

\section{V.1. Einleitung}

\section{Definition}

Als hepatischer Hydrothorax werden transsudative Pleuraergüsse bei Patienten mit Leberzirrhose und/oder portaler Hypertension nach Ausschluss einer primären Herz- oder Lungenerkrankung bezeichnet [294]

\section{Kommentar}

Circa 4-10\% der Patienten mit fortgeschrittener Leberzirrhose entwickeln einen Hydrothorax. In der bisher größten Untersuchung konnte mittels Computertomografie bei 49 (4,7\%) von 1038 Patienten ein hepatischer Pleuraerguss nachgewiesen werden, in der Mehrzahl der Fälle rechtsseitig (70\%), seltener bilateral (18\%) oder linksseitig (12\%) [295]. Pathophysiologisch beruht der Hydrothorax auf denselben Mechanismen wie der Aszites [296-300]. Bei den meisten Patienten mit Hydrothorax lassen sich mikro- und makroskopisch Zwerchfellläsionen nachweisen [294, 301]. Die derzeit favorisierte Hypothese zur Pathogenese geht daher von einer transdiaphragmalen Passage der Flüssigkeit aus dem Peritoneal- in den Pleuraraum entweder über Zwerchfelldefekte oder über Lymphgefäße aus. Typischerweise finden sich bei den Patienten daher gleichzeitig Aszites und Hydrothorax, ein isoliertes Auftreten eines hepatischen Hydrothoraxes ist aber aufgrund des negativen intrathorakalen Druckes möglich [300, 302].

\section{V.2. Welche Untersuchungen sind zur Abklärung eines hepatischen Hydrothorax notwendig?}

\section{Empfehlung}

Zur initialen Darstellung des Hydrothorax sollte eine Röntgen-Thorax-Aufnahme oder eine Ultraschalluntersuchung durchgeführt werden. (B), Konsens: 100\%

Sowohl bei Erstdiagnose als auch bei Wiedervorstellung sollte eine diagnostische Pleurapunktion mit Bestimmung der Zellzahl wenn verfügbar mit Zelldifferenzierung - sowie der Eiweißkonzentration erfolgen. Die erste Punktion sollte dabei nach sonografischer Kontrolle durchgeführt werden. (B), Konsens: 100\%

\section{Kommentar}

Die führenden klinischen Symptome des hepatischen Hydrothorax sind Dyspnoe und nicht produktiver Husten. Weiterhin klagen Patienten über Pleuraschmerz und Müdigkeit als Folge der Hypoxämie. Differenzialdiagnostisch müssen andere Komplikationen der Zirrhose wie das hepatopulmonale Syndrom und die porto-pulmonale Hypertonie ebenso in Betracht gezogen werden wie nicht hepatische Erkrankungen, z.B. Herzinsuffizienz, Tuberkulose, Bronchialkarzinom oder parapneumonischer Pleuraerguss [303] (Evidenzgrad IV). 
Zur initialen Darstellung des Pleuraergusses eignet sich neben dem Röntgen-Thorax die Sonografie [304-306] (Evidenzgrad IIb). Zusätzlich sollte bei jedem Patienten sowohl bei Erstdiagnose als auch bei Wiedervorstellung eine diagnostische Pleurapunktion durchgeführt werden, um 1. andere Erkrankungen und 2. eine Infektion (Empyem) auszuschließen [303, 307] (Evidenzgrad IV/IIa). Häufige Komplikationen diagnostischer Pleurapunktionen sind der Pneumothorax (1,0-5,2\%), Blutungen $(<1 \%)$ und vasovagale Reaktionen $(<1 \%)$ [303, 308-310]. Dabei konnte in einer 2010 publizierten Metaanalyse nachgewiesen werden, dass die sonografische Kontrolle der Punktionsstelle die Inzidenz eines interventionsassoziierten Pneumothorax signifikant senkt (Odds Ratio 0,3) (Evidenzgrad Ia) [310]. Eine andere Studie zeigte, dass Blutungen auch bei moderaten Gerinnungsstörungen (PT/PTT $\leq 2 \times$ Normwert, Thrombozyten $\geq 50000 /$ $\mathrm{mm}^{3}$ ) nicht vermehrt auftraten; eine prophylaktische Substitution von Blutprodukten (Thrombozytenkonzentrate, „fresh frozen Plasma“ [FFP], Gerinnungsfaktoren) wurde daher bei diesen Patienten nicht empfohlen (Evidenzgrad IIb) [28]. Da für Punktionen bei ausgeprägten Gerinnungsstörungen (PT/PTT $>2 \times$ Normwert, Thrombozyten $<50000 / \mathrm{mm}^{3}$ ) jedoch keine auswertbaren Publikationen vorliegen, muss unter diesen Umständen eine entsprechende Substitution erwogen werden (Evidenzgrad IV).

Die Diagnose eines hepatischen Hydrothorax basiert auf dem Nachweis eines Transsudats unter gleichzeitigem Ausschluss einer primären renalen, kardialen oder pneumologischen Erkrankung. Die Punktion dient zuvorderst dem Ausschluss einer Infektion sowie der Unterscheidung zwischen Transsudat und Exsudat. Folgende Parameter sollten daher aus dem Pleurapunktat bestimmt und mit den entsprechenden Werten im Serum verglichen werden: Zellzahl/-differenzierung und Eiweißkonzentration (ggf. Albuminkonzentration). Der hepatische Hydrothorax ist gekennzeichnet durch eine Zellzahl <500 pro $\mathrm{mm}^{3}$, eine totale Proteinkonzentration kleiner $2,5 \mathrm{~g} / \mathrm{dl}$ und einen Albumingradienten $>1,1 \mathrm{~g} / \mathrm{dl}$ zwischen Serum und Pleuraflüssigkeit (Sensitivität $87 \%$, Spezifität 92\%) [311, 312] (Evidenzgrad Ila). Alternativ können auch die sog. Light's Kriterien für ein Pleura-Transsudat bestimmt werden, die sich durch eine höhere Sensitivität (98\%) bei etwas schlechterer Spezifität (83\%) auszeichnen und die folgenden Parameter umfassen, von denen einer oder mehrere erfüllt sein sollten: ein Proteinquotient $<0,5$ (Pleura/Serum) und/oder ein LDH-Gradient <0,6 (Pleura/Serum) und/oder eine LDH-Konzentration in der Pleuraflüssigkeit $<2 / 3$ des oberen Normwerts des Serums [307, 313] (Evidenzgrad IIa). Im Falle eines Transsudats müssen schließlich für die Diagnose hepatischer Hydrothorax noch eine renale und eine kardiale Ursache (Echo, Kreatinin-/Eiweißausscheidung im Urin) sowie eine Lungenembolie klinisch/laborchemisch, ggf. auch durch weitere diagnostische Verfahren ausgeschlossen werden. Bei einem Exsudat muss eine Differenzialdiagnose zwischen spontan bakteriellem Empyem und anderen Erkrankungen erfolgen [307] (Evidenzgrad IIa).

In unklaren Fällen - insbesondere bei linksseitigem/isoliert auftretendem Pleuraerguss - oder bei spezifischer klinischer Fragestellung kann zusätzlich nach einer Verbindung zwischen Peritoneal- und Pleuraraum gesucht werden. Die Datenlage zu den einzelnen Verfahren ist aber insgesamt unbefriedigend und stützt sich lediglich auf Fallserien, eine Empfehlung kann daher nicht ausgesprochen werden. Am besten untersucht ist die szintigrafische Darstellung des Übertritts von radiomarkiertem Albumin oder Schwefel nach intraperitonealer Applikation mit einer Spezifität bis $100 \%$ bei einer Sensitivität von $70 \%$, die jedoch durch vorherige Pleurapunktion zur Reduktion des intrapleuralen Druckes erhöht werden kann [302, 314-316]. Eine potenzielle Alternative bietet sich mit Doppler- und Kontrastmittel-Sonografie an. Die verfügbaren Einzelfallberichte lassen aber eine Einschätzung der Sensitivität und Spezifität dieser Methoden noch nicht zu $[317,318]$. Der direkte Nachweis eines makroskopisch sichtbaren diaphragmalen Defekts durch Thorakoskopie mit/ohne Einsatz von Farbstoffen sollte dagegen aufgrund seiner hohen Invasivität der Vorbereitung eines therapeutischen Eingriffs vorbehalten bleiben [301, 319, 320].

\section{V.3. Wie sollten Patienten mit hepatischem Hydrothorax therapiert werden?}

\section{Empfehlung}

Die Behandlung des klinisch relevanten hepatischen Hydrothorax unterscheidet sich nicht von der Standardtherapie bei Aszites. (C), Konsens: $100 \%$

Aufgrund der geringeren Komplikationsrate sollte ein symptomatischer Hydrothorax zuerst - sofern Aszites vorhanden - mittels therapeutischer, abdomineller Parazentese, bei weiter bestehenden Symptomen mittels therapeutischer Thorakozentese behandelt werden. (B), Konsens: $100 \%$

Das Volumen des drainierten Pleurapunktats sollte 1,5 - 2I/Punktion nicht überschreiten, eine Volumensubstitution ist nicht notwendig (B). Protrahierte Thoraxdrainagen sollten wegen vermehrt auftretender renaler und septischer Komplikationen vermieden werden. Falls doch eine Thoraxdrainage notwendig wird, kann eine intravenöse Albumingabe ( 6 - $8 \mathrm{~g} /$ I Pleuraerguss) empfohlen werden. (C), Konsens: 100\%

\section{Kommentar}

Da dem hepatischen Aszites und dem hepatischen Hydrothorax gemeinsame pathogenetische Mechanismen zugrunde liegen, können die Prinzipien der Standardtherapie eines Aszites auf den hepatischen Hydrothorax übertragen werden, auch ohne dass spezifische Untersuchungen hierzu vorliegen [297, 299] (Evidenzgrad V). Entsprechend muss davon ausgegangen werden, dass ein hepatischer Hydrothorax nicht nur zu einer erhöhten Morbidität führt [321] (Evidenzgrad IIb), sondern bei vorliegender Leberzirrhose auch als Zeichen der Dekompensation zu werten und mit einer erhöhten Mortalität verbunden ist [322] (Evidenzgrad IIa). Der hepatische Hydrothorax stellt somit grundsätzlich eine behandlungsbedürftige Erkrankung dar, eine Therapie sollte in jedem Fall unter Berücksichtigung von Nutzen, Risiken und Kontraindikationen evaluiert werden. Die Standardtherapie richtet sich nach den Therapieprinzipien und Kontraindikationen der Standardtherapie bei Aszites.

Aufgrund der anatomischen Begrenzung können bereits bei geringer Flüssigkeitsmenge im Pleuraraum Symptome wie Dyspnoe, nicht produktiver Husten, Schmerzen oder Müdigkeit durch Hypoxämie auftreten [297]. In Fallberichten wurde auch über respiratorisches Versagen und Spannungshydrothorax mit kardialem Versagen berichtet [323]. Da eine therapeutische Parazentese häufig zu einer Besserung der Symptome führt [324] (Evidenzgrad IV) und therapeutische Thorakozentesen mit einer Komplikationsrate >9\% einhergehen [308, 310] (Evidenzgrad IIc), sollte bei symptomatischem Hydrotho- 
rax zuerst eine Parazentese durchgeführt werden. Bei weiterbestehenden Symptomen kann kurzfristig eine Besserung durch Thorakozentesen erreicht werden. Das Risiko insbesondere eines Pneumothorax erhöht sich aber bei Patienten mit Leberzirrhose mit jeder Wiederholung. So steigt die Komplikationsrate von $7,7 \%$ bei der ersten auf $34,7 \%$ bei der vierten Thorakozentese an [308] (Evidenzgrad IIc).

Die bisher gültige Empfehlung, das Volumen des drainierten Pleurapunktats auf 1,5-2 1/Punktion zu beschränken, stützt sich auf wenige Fallberichte über Reexpansions-Lungenödeme bei großvolumigen Thorakozentesen [325]. Das Risiko dieser Komplikation liegt aber laut einer neueren Studie bei hepatischem Hydrothorax unter 3\% [326] (Evidenzgrad IIc). Andere Komplikationen wie renale Dysfunktion, Elektrolyt-Verschiebungen und Infektionen wurden in dieser Studie nicht untersucht, treten aber bei $80 \%$ der Patienten mit Leberzirrhose nach Anlage einer Thoraxdrainage wegen des kontinuierlichen Verlusts großer Flüssigkeitsmengen auf [327] (Evidenzgrad IV). Die interventionsassoziierte Mortalität innerhalb des stationären Aufenthalts (Median 8 [1-39] Tage) nach Anlage der Thoraxdrainage erreichte in dieser Serie $16 \%$ bei Child-Pugh-Score-B- und $40 \%$ bei Child-Pugh-Score-C-Patienten. Bei kleinvolumigen Thorakozentesen bis 21 oder gleichzeitiger Albuminsubstitution wurden vergleichbare Komplikationen bisher nicht beschrieben, randomisierte Untersuchungen fehlen aber [303, 308] (Evidenzgrad IIc). Aufgrund der derzeitigen Datenlage muss daher eine Beschränkung des drainierten Volumens empfohlen werden, eine Volumensubstitution scheint dann nicht notwendig. Wird eine kontinuierliche Thoraxdrainage verwendet, sollte analog zum Vorgehen bei Aszites 6-8g Albumin pro Liter entferntem Pleuraerguss substituiert werden (Evidenzgrad IV).

\section{V.4. Wie sollten Patienten mit rezidivierendem hepatischem Hydrothorax therapiert werden?}

\section{Empfehlung}

Bei rezidivierendem hepatischem Hydrothorax sollte die Anlage eines transjugulären intrahepatischen portosystemischen Shunts (TIPS) erwogen werden. (B), Konsens: 100\%

Bei Kontraindikationen für eine TIPS-Anlage kann eine Video-assistierte Thorakoskopie mit Pleurodese und/oder Verschluss erkennbarer Läsionen des Zwerchfells erwogen werden (C), Konsens: $100 \%$

Ein hepatischer Hydrothorax stellt keine Kontraindikation für eine Lebertransplantation dar. (B), Konsens: 100\%

\section{Kommentar}

Aufgrund der steigenden Komplikationsrate bei wiederholten Thorakozentesen sollten bei rezidivierendem hepatischem Hydrothorax andere Therapieoptionen erwogen werden [308] (Evidenzgrad IIc). Als Therapie der Wahl muss derzeit die Anlage eines transjugulären intrahepatischen portosystemischen Shunts (TIPS) angesehen werden, die kausal die portale Hypertension als pathogenetische Ursache des Hydrothorax beseitigt [328]. Bereits in einer Reihe von kleineren Studien erwies sich eine TIPS-Anlage kurzfristig als sehr effektiv, war aber auch mit erhöhter Morbidität und Mortalität bei fehlender Selektion der Patienten sowie häufigen Rezidiven aufgrund von Stentokklusionen verbunden [329-336]. In den 2 größten bisher publizierten Serien von 2001 und 2010 mit 40 bzw. 73 Patienten konnte jedoch eine erfolgreiche Kontrolle des Hydrothorax über 6 Monate bei mehr als 70\% der Patienten sowie 1-JahresÜberlebensraten von 64 bzw. 48\% nachgewiesen werden [334, 337] (Evidenzgrad IIc). Ausschlusskriterien waren Rechtsherzinsuffizienz, pulmonale Hypertonie, klinisch relevante Infektion oder Enzephalopathie, Pfortaderthrombose sowie hepatozelluläres Karzinom. Als Komplikationen der TIPS-Anlage traten Enzephalopathien, Infektionen, interventionsbedingte Blutungen, akutes Nierenversagen sowie ein „acute respiratory distress syndrome“ (ARDS) auf. Eine schlechte Leberfunktion (MELD-Score > 15) erwies sich neben einem erhöhten Kreatinin als negativer prädiktiver Faktor für das Langzeitüberleben. Im Gegensatz zum TIPS wird die chirurgische Anlage eines peritoneo-venösen Shunts bei hepatischem Hydrothorax heute in der Regel nicht mehr durchgeführt, da der gegenüber dem zentralvenösen Druck niedrigere intrathorakale Druck zu einer erneuten Flüssigkeitsansammlung im Pleuraraum führt und den Effekt der Shunt-Anlage aufheben kann [338, 339] (Evidenzgrad IV).

Während die alleinige Pleurodese mittels sklerosierender Substanzen über eine Thoraxdrainage in kleineren Fallserien nur eine unzureichende Erfolgsrate zeigte [340, 341] (Evidenzgrad IV), erwies sich die therapeutische videoassistierte Thorakoskopie (VATS) zumindest in den neueren Fallserien als weitere potenzielle Behandlungsoption neben der TIPS-Anlage [319, 342 -344] (Evidenzgrad IV). Alternativ wurde in den Studien während der Thorakoskopie eine Pleurodese mit verschiedenen sklerosierenden Substanzen (Talkum, OK-432, Pikibanil, Minozyklin), ein Naht- oder plastischer Verschluss erkennbarer Läsionen des Zwerchfells oder eine Kombination beider Verfahren durchgeführt. Die postinterventionelle Erfolgsrate lag bei bis zu $80 \%$, teilweise mussten jedoch mehrere Sitzungen durchgeführt werden. Aufgrund fehlender Langzeitdaten sowohl zur Effektivität als auch zur Mortalität ist aber eine abschließende Beurteilung der Methode noch nicht möglich.

Aufgrund der gemeinsamen pathogenetischen Mechanismen muss zwar der hepatische Hydrothorax wie der Aszites als Zeichen der Dekompensation einer Leberzirrhose angesehen werden [322] (Evidenzgrad IIa), jedoch wurde er in keiner der bisherigen Allokationsmodelle berücksichtigt und kann daher nicht als alleinige Indikation zur Lebertransplantation herangezogen werden. Der hepatische Hydrothorax selbst scheint aber weder das perioperative Management bei noch die langfristige Überlebensrate (70\% nach 8 Jahren) nach Lebertransplantation zu beeinflussen [345, 346] (Evidenzgrad IIIb).

\section{V.5. Spontan bakterielles Empyem (SBEM)}

\section{Definition}

Das spontan bakterielle Empyem (SBEM) ist eine spezifische Komplikation des hepatischen Hydrothorax und setzt eine bakterielle Infektion, aber nicht notwendigerweise einen eitrigen Pleuraerguss voraus.

\section{Kommentar}

Risikofaktoren für die Entwicklung eines SBEM sind eine schlechte Leberfunktion, niedrige Eiweiß- und Albuminkonzentrationen in Serum und/oder Pleuraflüssigkeit sowie eine bereits vorliegende spontan bakterielle Peritonitis (SBP) [347, 348]. Inzidenz (13-30\%) und Letalität (20\%) sind vergleichbar mit Inzidenz und Letalität einer SBP [321, 349]. Da sich auch das Keimspektrum (E. coli, Klebsiellen, Streptokokken und En- 
terokokken) bei beiden Erkrankungen und die pathophysiologischen Eigenschaften der intraperitonealen und -pleuralen Flüssigkeiten ähneln, wird bei dem SBEM ein ähnlicher pathogenetischer Mechanismus mit bakterieller Translokation wie bei der SBP vermutet [317-319].

\section{V.5.1. Wie wird ein spontan bakterielles Empyem (SBEM) diagnostiziert und therapiert?}

\section{Empfehlung}

Bei Verdacht auf ein SBEM oder bei klinischer Verschlechterung des Patienten sollte eine diagnostische Pleurapunktion unter sterilen Bedingungen mit Bestimmung des pH-Werts und der Zellzahl/-differenzierung sowie einer Gramfärbung und Beimpfung von Kulturflaschen durchgeführt werden. (B), Konsens: 100\% Die medikamentöse Standardtherapie beim SBEM kann analog zur Standardtherapie bei einer SBP erfolgen. (C), Konsens: 100\% Bei hohem Komplikationsrisiko (Erregernachweis, pH-Wert <7,2) sollte das SBEM mittels kontinuierlicher Thoraxdrainage unter Albuminsubstitution behandelt werden (B). Bei nachweisbarem Eiter oder gekammertem Erguss kann zusätzlich eine lokale Fibrinolyse oder videoassistierte Thorakoskopie (VATS) therapeutisch eingesetzt werden. (C), Konsens: 100\%

\section{Kommentar}

Patienten mit SBEM leiden häufig unter unspezifischen Symptomen (Fieber, Enzephalopathie, hepato-renale Dekompensation), eine diagnostische Pleurapunktion wird daher sowohl bei Erstdiagnose eines Pleuraergusses als auch bei klinischer Verschlechterung des Patienten empfohlen. Da eigenständige Daten fehlen, erfolgt die Diagnostik des SBEM üblicherweise analog zur SBP und beinhaltet die Bestimmung der Granulozyten (WBC) im Pleurapunktat sowie den mikrobiologischen kulturellen Nachweis der Erreger, der jedoch nur in 2/3 der Fälle gelingt [347, 348] (Evidenzgrad V). Eine Granulozyten-Konzentration über $250 / \mu l$ verbunden mit einem positiven Erregernachweis bzw. eine Granulozyten-Konzentration von über 500/ul auch bei einem negativem Erregernachweis gelten als diagnostisch für das Vorliegen eines SBEM. Die Verwendung von Teststreifen für Leukozytenesterase als Schnelltest kann aufgrund der geringen Datenlage nicht empfohlen werden [350] (Evidenzgrad IV).

Auch die Basistherapie wird analog zur SBP mittels intravenöser Gabe eines Cephalosporins der 3. Generation für mindestens 7-10 Tage sowie Albumin-Substitution durchgeführt. Da sich aber aufgrund der Lokalisation das Potenzial an Komplikationen zwischen SBEM und SBP grundsätzlich unterscheidet, sollten bis zum Vorliegen besserer Daten die Risikostratifizierung und therapeutischen Prinzipien der S3-Leitlinie zur ambulant erworbenen Pneumonie (Kapitel 16.1 Pleuraerguss e46-e47) für das SBEM adaptiert werden [351] (Evidenzgrad IIa). Die Behandlung verfolgt demnach „die zentralen Ziele der Kontrolle der Infektion, der Drainage des infizierten Ergusses, der (Re-)Expansion der Lunge und der Vermeidung der Ausbildung von Pleuraschwarten“. Bei Patienten mit positiver Kultur-/Gramfärbung oder einem pH-Wert $<7,2$ im Pleuraerguss wird daher statt rezidivierender Thorakozentesen eine kontinuierliche Thoraxdrainage empfohlen, unterstützt durch lokale Fibrinolyse (Streptokinase) oder VATS bei gekammertem Erguss oder nachweisbarem Eiter [351, 352] (Evidenzgrad IIa). Abweichend von der angesprochenen Leitlinie [351] sollte je- doch die Thoraxdrainage bei Patienten mit Leberzirrhose wegen der damit verbundenen Morbidität und Mortalität (renale Dysfunktion, Elektrolyt-Verschiebungen) mit einer Volumensubstitution mittels Albumin- und Elektrolytlösungen kombiniert werden [321, 327] (Evidenzgrad IV). Eine Kontrolle des Therapieerfolgs durch eine diagnostische Pleurapunktion sollte in jedem Fall vor Beendigung der Antibiose erfolgen. Für eine antibiotische Sekundär-Prophylaxe wie bei der SBP liegen keine Daten vor, eine Empfehlung kann daher nicht gegeben werden.

\section{Abkürzungsverzeichnis}

$\nabla$

AFP: Alphafetoprotein

AP: Alkalische Phosphatase

ARDS: Acute Respiratory Distress Syndrome (engl.)

BCS: Budd-Chiari-Syndrom

BMI: Body-Mass-Index (engl.)

CEA: Carcino-Embryonales Antigen

CI: Confidence Interval (engl.)

CT: Computertomografie

DIC: Disseminierte Intravasale Koagulopathie (Coagulation, engl.)

DNA: Desoxyribonukleinsäure (acid, engl.)

e-PTFE: expandiertes Polytetrafluorethen

ESBL: Extended-Spectrum- $\beta$-Lactamase (engl.)

FFP: Fresh Frozen Plasma (engl.)

GI-Blutung: Gastrointestinale Blutung

GFR: Glomeruläre Filtrationsrate

HCC: Hepatocellular carcinoma (engl.)

HE: Hepatische Enzephalopathie

INR: International Normalized Ratio (engl.)

JAK2: Janus Kinase 2

HRS: Hepatorenales Syndrom

KG: Körpergewicht

LDH: Lactatdehydrogenase

MELD-Score: Model of End Stage Liver Disease-Score (engl.)

MGG: May-Grünwald-Giemsa

MRSA: Methicillin-resistenter Staphylococcus

MRT: Magnetresonanztomografie

NNT: Number Needed to Treat (engl.)

NOD2: Nucleotide-binding Oligomerization Domain containing 2 (engl.)

OR: Odds Ratio (engl.)

PAS: Periodic Acid-Schiff Stain (engl.)

PMN-Zellen: Polymorphonukleäre-Zellen

PNH: Paroxysmale Nächtliche Hämoglobinurie

PT: Prothrombinzeit (time, engl.)

PTT: Partielle Thromboplastinzeit (time, engl.)

RES: Retikuloendotheliales System

SAAG: Serum-Aszites-Albumin-Gradient

SBP: Spontan Bakterielle Peritonitis

SBEM: Spontan Bakterielles Empyem

TIPS: transjugulärer intrahepatischer portosystemischer Shunt

VATS: Videoassistierte Thorakoskopie

WBC: White Blood Cells (engl.) 


\section{Affiliations}

Med. Klinik und Poliklinik 2, Leber Centrum München, Klinikum der LMU München

Medizinische Klinik Innenstadt mit Schwerpunkt Gastroenterologie, Klinikum der Universität München

Medizinische Klinik und Poliklinik I, Universitätsklinikum Bonn

Innere Medizin I, Universitätsklinikum Regensburg

5 Medizinische Klinik I, Sana Kliniken, Lübeck

6 Universitätsklinik und Poliklinik für Innere Medizin I, Universitätsklinikum Halle

Facharzt für innere Medizin, Gastroenterologie/Endokrinologie, Freiburg

${ }^{8}$ Medizinische Klinik für Gastroenterologie u. Hepatologie, Helios-Klinikum Siegburg

\section{Literatur}

1 Runyon BA. Management of adult patients with ascites due to cirrhosis. Hepatology 2004; 39: 841-856

2 Arroyo V, Fernandez-Esparrach $G$, Gines $P$. Diagnostic approach to the cirrhotic patient with ascites. J Hepatol 1996; 25 (Suppl 1): 35-40

3 Cardenas A, Chopra S. Chylous ascites. Am J Gastroenterol 2002; 97: 1896-1900

4 Almakdisi T, Massoud S, Makdisi G. Lymphomas and chylous ascites: review of the literature. Oncologist 2005; 10: 632-635

5 Runyon BA. Early events in spontaneous bacterial peritonitis. Gut 2004; 53: 782-784

6 Castellote J. Spontaneous bacterial peritonitis and reagent strips. Hepatology 2007; 46: 1667-1668; author reply 1669 - 1670

7 Jeffries MA, Stern MA, Gunaratnam NT et al. Unsuspected infection is infrequent in asymptomatic outpatients with refractory ascites undergoing therapeutic paracentesis. Am J Gastroenterol 1999; 94: 2972-2976

8 Evans LT, Kim WR, Poterucha JJ et al. Spontaneous bacterial peritonitis in asymptomatic outpatients with cirrhotic ascites. Hepatology 2003; 37: 897-901

9 Romney R, Mathurin P, Ganne-Carrie $N$ et al. Usefulness of routine analysis of ascitic fluid at the time of therapeutic paracentesis in asymptomatic outpatients. Results of a multicenter prospective study. Gastroenterol Clin Biol 2005; 29: 275-279

10 Robert Koch-Institut. Anforderungen der Hygiene bei Operationen und anderen invasiven Eingriffen - Mitteilung der Kommission für Krankenhaushygiene und Infektionsprävention am Robert KochInstitut. Bundesgesundheitsblatt 2000; 43: 644-648

11 Schlottmann K, Gelbmann C, Grune S et al. A new paracentesis needle for ascites and pleural effusion compared with the venous indwelling catheter. A prospective, randomized study. Med Klin 2001; 96: 321324

12 Gines P, Arroyo V, Rodes J. Treatment of ascites and renal failure in cirrhosis. Baillieres Clin Gastroenterol 1989; 3: 165-186

13 Shaheen NJ, Grimm IS. Comparison of the Caldwell needle/cannula with Angiocath needle in large volume paracentesis. Am J Gastroenterol 1996; 91: 1731-1733

14 Boccia S, Rollo V, Accorsi L et al. Paracentesis: a new needle for an old technique. Endoscopy 1991; 23: 83-84

15 Nazeer SR, Dewbre H, Miller AH. Ultrasound-assisted paracentesis performed by emergency physicians vs. the traditional technique: a prospective, randomized study. Am J Emerg Med 2005; 23: 363-367

16 Sakai H, Sheer TA, Mendler MH et al. Choosing the location for nonimage guided abdominal paracentesis. Liver Int 2005; 25: 984-986

17 CattauJr EL, Benjamin SB, Knuff TE et al. The accuracy of the physical examination in the diagnosis of suspected ascites. JAMA 1982; 247: 1164-1166

18 Irshad A, Ackerman SJ, Anis $M$ et al. Can the smallest depth of ascitic fluid on sonograms predict the amount of drainable fluid? J Clin Ultrasound 2009; 37: 440-444

19 De Gottardi A, Thevenot T, Spahr L et al. Risk of complications after abdominal paracentesis in cirrhotic patients: a prospective study. Clin Gastroenterol Hepatol 2009; 7: 906-909

20 Martinet 0 , Reis ED, Mosimann F. Delayed hemoperitoneum following large-volume paracentesis in a patient with cirrhosis and ascites. Dig Dis Sci 2000; 45: 357-358

21 Arnold C, Haag K, Blum HE et al. Acute hemoperitoneum after largevolume paracentesis. Gastroenterology 1997; 113: 978-982

22 Grabau CM, Crago SF, Hoff LK et al. Performance standards for therapeutic abdominal paracentesis. Hepatology 2004; 40: 484-488
23 Pache I, Bilodeau M. Severe haemorrhage following abdominal paracentesis for ascites in patients with liver disease. Aliment Pharmacol Ther 2005; 21: 525-529

24 Lin CH, Shih FY, Ma MH et al. Should bleeding tendency deter abdominal paracentesis? Dig Liver Dis 2005; 37: 946-951

25 Mallory A, Schaefer JW. Complications of diagnostic paracentesis in patients with liver disease. JAMA 1978; 239: 628-630

26 Webster ST, Brown KL, Lucey MR et al. Hemorrhagic complications of large volume abdominal paracentesis. Am J Gastroenterol 1996; 91: 366-368

27 Minocha A. A fatal case of paracentesis. Am J Gastroenterol 1999; 94: 856

28 McVay PA, Toy PT. Lack of increased bleeding after paracentesis and thoracentesis in patients with mild coagulation abnormalities. Transfusion 1991; 31: 164-171

29 Runyon BA. Paracentesis of ascitic fluid. A safe procedure. Arch Intern Med 1986; 146: 2259-2261

30 Mannucci PM. Abnormal hemostasis tests and bleeding in chronic liver disease: are they related? No. J Thromb Haemost 2006; 4: 721723

31 Angeloni S, Nicolini G, Merli M et al. Validation of automated blood cell counter for the determination of polymorphonuclear cell count in the ascitic fluid of cirrhotic patients with or without spontaneous bacterial peritonitis. Am J Gastroenterol 2003; 98: 1844-1848

32 Rimola A, Garcia-Tsao G, Navasa M et al. Diagnosis, treatment and prophylaxis of spontaneous bacterial peritonitis: a consensus document. International Ascites Club. J Hepatol 2000; 32: 142-153

33 Albillos A, Cuervas-Mons V, Millan I et al. Ascitic fluid polymorphonuclear cell count and serum to ascites albumin gradient in the diagnosis of bacterial peritonitis. Gastroenterology 1990; 98: 134-140

34 Jones SR. The absolute granulocyte count in ascites fluid. An aid to the diagnosis of spontaneous bacterial peritonitis. West J Med 1977; 126 : 344-346

35 Runyon $B A$. Low-protein-concentration ascitic fluid is predisposed to spontaneous bacterial peritonitis. Gastroenterology 1986; 91: 13431346

36 Llach J, Rimola A, Navasa M et al. Incidence and predictive factors of first episode of spontaneous bacterial peritonitis in cirrhosis with ascites: relevance of ascitic fluid protein concentration. Hepatology 1992; 16: 724-727

37 Guarner C, Sola R, Soriano G et al. Risk of a first community-acquired spontaneous bacterial peritonitis in cirrhotics with low ascitic fluid protein levels. Gastroenterology 1999; 117: 414-419

38 Canete N, Erice E, Bargallo A et al. Natural history of spontaneous bacterial peritonitis: A longitudinal study in 263 cirrhotic patients after the first ascites decompensation. J Hepatol 2007; 46: S90-S91

39 Pare P, Talbot J, Hoefs JC. Serum-ascites albumin concentration gradient: a physiologic approach to the differential diagnosis of ascites. Gastroenterology 1983; 85: 240-244

40 Runyon BA, Montano AA, Akriviadis EA et al. The serum-ascites albumin gradient is superior to the exudate-transudate concept in the differential diagnosis of ascites. Ann Intern Med 1992; 117: 215-220

41 Dittrich S, Yordi LM, de Mattos AA. The value of serum-ascites albumin gradient for the determination of portal hypertension in the diagnosis of ascites. Hepatogastroenterology 2001; 48: 166-168

42 Runyon BA, Canawati HN, Akriviadis EA. Optimization of ascitic fluid culture technique. Gastroenterology 1988; 95: 1351-1355

43 Castellote J, Xiol X, Verdaguer $R$ et al. Comparison of two ascitic fluid culture methods in cirrhotic patients with spontaneous bacterial peritonitis. Am J Gastroenterol 1990; 85: 1605-1608

44 Bobadilla M, Sifuentes J, Garcia-Tsao G. Improved method for bacteriological diagnosis of spontaneous bacterial peritonitis. J Clin Microbiol 1989; 27: 2145-2147

45 Caly WR, Strauss E. A prospective study of bacterial infections in patients with cirrhosis. J Hepatol 1993; 18: 353-358

46 Kuiper IJ, van Buuren HR, de Man RA. Limited role for routine ascites culture as a diagnostic tool for spontaneous bacterial peritonitis in the era of prophylactic antibiotics. J Hepatol 2007; 46: S96

47 Butani RC, Shaffer RT, Szyjkowski RD et al. Rapid diagnosis of infected ascitic fluid using leukocyte esterase dipstick testing. Am J Gastroenterol 2004; 99: 532-537

48 Castellote J, Lopez C, Gornals J et al. Rapid diagnosis of spontaneous bacterial peritonitis by use of reagent strips. Hepatology 2003; 37 : 893-896 
49 Sapey T, Kabissa D, Fort E et al. Instant diagnosis of spontaneous bacterial peritonitis using leukocyte esterase reagent strips: Nephur-Test vs. MultistixSG. Liver Int 2005; 25: 343-348

50 Thevenot T, Cadranel JF, Nguyen-Khac E et al. Diagnosis of spontaneous bacterial peritonitis in cirrhotic patients by use of two reagent strips. Eur J Gastroenterol Hepatol 2004; 16: 579-583

51 Vanbiervliet G, Rakotoarisoa C, Filippi J et al. Diagnostic accuracy of a rapid urine-screening test (Multistix8SG) in cirrhotic patients with spontaneous bacterial peritonitis. Eur J Gastroenterol Hepatol 2002; 14: $1257-1260$

52 Campillo B, Richardet JP, Dupeyron C. Diagnostic value of two reagent strips (Multistix 8 SG and Combur 2 LN) in cirrhotic patients with spontaneous bacterial peritonitis and symptomatic bacterascites. Gastroenterol Clin Biol 2006; 30: 446-452

53 Nousbaum JB, Cadranel JF, Nahon P et al. Diagnostic accuracy of the Multistix 8 SG reagent strip in diagnosis of spontaneous bacterial peritonitis. Hepatology 2007; 45: 1275-1281

54 Nguyen-Khac E, CadranelJF, Thevenot T et al. Review article: the utility of reagent strips in the diagnosis of infected ascites in cirrhotic patients. Aliment Pharmacol Ther 2008; 28: 282-288

55 Runyon BA, Hoefs JC, Morgan TR. Ascitic fluid analysis in malignancyrelated ascites. Hepatology 1988; 8: 1104-1109

56 Decker D, Stratmann H, Springer W et al. Benign and malignant cells in effusions: diagnostic value of image DNA cytometry in comparison to cytological analysis. Pathol Res Pract 1998; 194: 791-795

57 Jungst D, Gerbes AL, Martin R et al. Value of ascitic lipids in the differentiation between cirrhotic and malignant ascites. Hepatology 1986; 6: 239-243

58 Gerbes AL, Xie YN, Mezger J et al. Ascitic fluid concentrations of fibronectin and cholesterol: comparison of differential diagnostic value with the conventional protein determination. Liver 1990; 10: 152157

59 Gerbes AL, Jungst D, Xie YN et al. Ascitic fluid analysis for the differentiation of malignancy-related and nonmalignant ascites. Proposal of a diagnostic sequence. Cancer 1991; 68: 1808-1814

60 Gulyas M, Kaposi AD, Elek G et al. Value of carcinoembryonic antigen (CEA) and cholesterol assays of ascitic fluid in cases of inconclusive cytology. J Clin Pathol 2001; 54: 831-835

61 Boyer TD, Kahn AM, Reynolds TB. Diagnostic value of ascitic fluid lactic dehydrogenase, protein, and WBC levels. Arch Intern Med 1978; 138 1103-1105

62 Scholmerich J, Volk BA, Kottgen E et al. Fibronectin concentration in ascites differentiates between malignant and nonmalignant ascites. Gastroenterology 1984; 87: 1160-1164

63 Runyon BA. Elevated ascitic fluid fibronectin concentration. A nonspecific finding. J Hepatol 1986; 3: 219-222

64 Chen SJ, Wang SS, Lu CW et al. Clinical value of tumour markers and serum-ascites albumin gradient in the diagnosis of malignancy-related ascites. J Gastroenterol Hepatol 1994; 9: 396-400

65 Khandwalla HE, Fasakin Y, El-Serag HB. The utility of evaluating low serum albumin gradient ascites in patients with cirrhosis. Am J Gastroenterol 2009; 104: 1401-1405

66 Böcking A, Motherby H, Pomjanski N. Treffsicherheit der Ergusszytologie samt adjuvanten Untersuchungsmethoden. Dtsch Ärztebl 2000; 97: A-2626

67 Feichter G, Dalquen P. Zytopathologie. Berlin: Springer, 2000

68 Motherby H, Nadjari B, Friegel P et al. Diagnostic accuracy of effusion cytology. Diagn Cytopathol 1999; 20: 350-357

69 Rohn BL. Verbesserung der Treffsicherheit der Ergusszytologie mittels AgNOR-Analyse als adjuvante Untersuchungsmethode. Düsseldorf: Institut für Cytopathologie. Medizinische Fakultät der Heinrich-Heine Universität, 2004: 45

70 Moore KP, Aithal GP. Guidelines on the management of ascites in cirrhosis. Gut 2006; 55 (Suppl 6): vi1-12

71 Böcking A. DNA measurements: When and why? In: Wied GL, Keebler CM, Rosenthal DL, eds. Compendium on quality assurance, proficiency testing, and workload limitations. Tutorials of Cytology 1995. Chicago IL; 1995: 170-188

72 Schlake W, Kreipe H. Mitteilungen Deutsche Gesellschaft für Pathologie. Erklärung zur Zytopathologie. Unter Mitarbeit von: A. Böcking, R. Bollmann, S. Falk, V. Fritzsche, A. Wellmann. Pathologe 2007; 28: 393

73 Spriggs AI, Boddington MM. The Cytology of Effusions in the Pleural, Pericardial and Peritoneal Cavities and of Cerebrospinal Fluid. 2nd ed. London: Heinemann, 1968
74 Giroud F, Haroske G, Reith A et al. 1997 ESACP consensus report on diagnostic DNA image cytometry. Part II: Specific recommendations for quality assurance. European Society for Analytical Cellular Pathology. Anal Cell Pathol 1998; 17: 201-208

75 Haroske G, Giroud F, Reith A et al. 1997 ESACP consensus report on diagnostic DNA image cytometry. Part I: basic considerations and recommendations for preparation, measurement and interpretation. European Society for Analytical Cellular Pathology. Anal Cell Pathol 1998; 17: 189-200

76 Motherby H, Nadjari B, Remmerbach T et al. Static DNA cytometry as a diagnostic aid in effusion cytology: II. DNA aneuploidy for identification of neoplastic cells in equivocal effusions. Anal Quant Cytol Histol 1998; 20: 162-168

77 Pomjanski N, Motherby H, Buckstegge B et al. Early diagnosis of mesothelioma in serous effusions using AgNOR analysis. Anal Quant Cytol Histol 2001; 23: 151-160

78 Darwish Murad S, Plessier A, Hernandez-Guerra M et al. Etiology, management, and outcome of the Budd-Chiari syndrome. Ann Intern Med 2009; 151: 167-175

79 Valla DC. Budd-Chiari syndrome and veno-occlusive disease/sinusoidal obstruction syndrome. Gut 2008; 57: 1469-1478

80 Darwish Murad S, Valla DC, de Groen PC et al. Determinants of survival and the effect of portosystemic shunting in patients with Budd-Chiari syndrome. Hepatology 2004; 39: 500-508

81 Menon KV, Shah V, Kamath PS. The Budd-Chiari syndrome. N Engl J Med 2004; 350: 578-585

82 Ludwig J, Hashimoto E, McGill DB et al. Classification of hepatic venous outflow obstruction: ambiguous terminology of the Budd-Chiari syndrome. Mayo Clin Proc 1990; 65: 51-55

83 Okuda K, Kage M, Shrestha SM. Proposal of a new nomenclature for Budd-Chiari syndrome: hepatic vein thrombosis versus thrombosis of the inferior vena cava at its hepatic portion. Hepatology 1998; 28 1191-1198

84 Hoekstra J, Leebeek FW, Plessier A et al. Paroxysmal nocturnal hemoglobinuria in Budd-Chiari syndrome: findings from a cohort study. J Hepatol 2009; 51: 696-706

85 Bolondi L, Gaiani S, Li Bassi S et al. Diagnosis of Budd-Chiari syndrome by pulsed Doppler ultrasound. Gastroenterology 1991; 100: 13241331

86 Miller WJ, Federle MP, Straub WH et al. Budd-Chiari syndrome: imaging with pathologic correlation. Abdom Imaging 1993; 18: 329335

87 Janssen HL, Garcia-Pagan JC, Elias E et al. Budd-Chiari syndrome: a review by an expert panel. J Hepatol 2003; 38: 364-371

88 Valla D, Casadevall N, Lacombe C et al. Primary myeloproliferative disorder and hepatic vein thrombosis. A prospective study of erythroid colony formation in vitro in 20 patients with Budd-Chiari syndrome. Ann Intern Med 1985; 103: 329-334

89 Valla $D$. Hepatic venous outflow tract obstruction etiopathogenesis: Asia versus the West. J Gastroenterol Hepatol 2004; 19: S204-S211

90 Shulman HM, Fisher LB, Schoch HG et al. Veno-occlusive disease of the liver after marrow transplantation: histological correlates of clinical signs and symptoms. Hepatology 1994; 19: 1171-1181

91 Soriano G, Castellote J, Alvarez C et al. Secondary bacterial peritonitis in cirrhosis: a retrospective study of clinical and analytical characteristics, diagnosis and management. J Hepatol 2010; 52: 39-44

92 Caralis PV, Sprung $C L$, Schiff ER. Secondary bacterial peritonitis in cirrhotic patients with ascites. South Med J 1984; 77: 579-583

93 Runyon BA, Hoefs JC. Ascitic fluid analysis in the differentiation of spontaneous bacterial peritonitis from gastrointestinal tract perforation into ascitic fluid. Hepatology 1984; 4: 447-450

94 Akriviadis EA, Runyon BA. Utility of an algorithm in differentiating spontaneous from secondary bacterial peritonitis. Gastroenterology 1990; 98: 127-133

95 Garrison RN, Cryer HM, Howard DA et al. Clarification of risk factors for abdominal operations in patients with hepatic cirrhosis. Ann Surg 1984; 199: 648-655

$96 \mathrm{Wu}$ SS, Lin OS, Chen YY et al. Ascitic fluid carcinoembryonic antigen and alkaline phosphatase levels for the differentiation of primary from secondary bacterial peritonitis with intestinal perforation. J Hepatol 2001; 34: 215-221

97 Mullen KD. Review of the final report of the 1998 Working Party on definition, nomenclature and diagnosis of hepatic encephalopathy Aliment Pharmacol Ther 2007; 25 Suppl 1: 11-16 
98 Moreau R, Lebrec D. Diagnosis and treatment of acute renal failure in patients with cirrhosis. Best Pract Res Clin Gastroenterol 2007; 21: 111-123

99 D’Amico G, Morabito A, Pagliaro L et al. Survival and prognostic indicators in compensated and decompensated cirrhosis. Dig Dis Sci 1986; 31: 468-475

100 Guardiola J, Baliellas C, Xiol X et al. External validation of a prognostic model for predicting survival of cirrhotic patients with refractory ascites. Am J Gastroenterol 2002; 97: 2374-2378

101 Planas R, Montoliu S, Balleste B et al. Natural history of patients hospitalized for management of cirrhotic ascites. Clin Gastroenterol Hepatol 2006; 4: 1385-1394

102 Gines P, Cardenas A, Arroyo V et al. Management of cirrhosis and ascites. N Engl J Med 2004; 350: 1646-1654

103 Llovet JM, Planas R, Morillas R et al. Short-term prognosis of cirrhotics with spontaneous bacterial peritonitis: multivariate study. Am J Gastroenterol 1993; 88: 388-392

104 Peng S, Plank LD, McCall JL et al. Body composition, muscle function, and energy expenditure in patients with liver cirrhosis: a comprehensive study. Am J Clin Nutr 2007; 85: 1257-1266

105 Prijatmoko D, Strauss BJ, Lambert JR et al. Early detection of protein depletion in alcoholic cirrhosis: role of body composition analysis. Gastroenterology 1993; 105: 1839-1845

106 Cabre E, Gonzalez-Huix F, Abad-Lacruz A et al. Effect of total enteral nutrition on the short-term outcome of severely malnourished cirrhotics. A randomized controlled trial. Gastroenterology 1990; 98: 715-720

107 Kearns PJ, Young H, Garcia G et al. Accelerated improvement of alcoholic liver disease with enteral nutrition. Gastroenterology 1992; 102: 200-205

108 Caregaro L, Alberino F, Amodio P et al. Malnutrition in alcoholic and virus-related cirrhosis. Am J Clin Nutr 1996; 63: 602-609

109 Selberg O, Bottcher J, Tusch G et al. Identification of high- and low-risk patients before liver transplantation: a prospective cohort study of nutritional and metabolic parameters in 150 patients. Hepatology 1997; 25: 652-657

110 Pirlich M, Schutz T, Spachos T et al. Bioelectrical impedance analysis is a useful bedside technique to assess malnutrition in cirrhotic patients with and without ascites. Hepatology 2000; 32: 1208-1215

111 Selberg 0 , Selberg D. Norms and correlates of bioimpedance phase angle in healthy human subjects, hospitalized patients, and patients with liver cirrhosis. Eur J Appl Physiol 2002; 86: 509-516

112 Plauth M, Cabre E, Riggio 0 et al. ESPEN Guidelines on Enteral Nutrition: Liver disease. Clin Nutr 2006; 25: 285-294

113 Plauth $M$, Cabre E, Campillo $B$ et al. ESPEN Guidelines on Parenteral Nutrition: hepatology. Clin Nutr 2009; 28: 436-444

114 Plauth M, Schutz T, Buckendahl DP et al. Weight gain after transjugular intrahepatic portosystemic shunt is associated with improvement in body composition in malnourished patients with cirrhosis and hypermetabolism. J Hepatol 2004; 40: 228-233

115 Plank LD, Gane EJ, Peng S et al. Nocturnal nutritional supplementation improves total body protein status of patients with liver cirrhosis: a randomized 12-month trial. Hepatology 2008; 48: 557-566

116 Zillikens MC, van den Berg JW, Wattimena JL et al. Nocturnal oral glucose supplementation. The effects on protein metabolism in cirrhotic patients and in healthy controls. J Hepatol 1993; 17: 377-383

117 Cordoba J, Lopez-Hellin J, Planas M et al. Normal protein diet for episodic hepatic encephalopathy: results of a randomized study. J Hepatol 2004; 41: 38-43

118 Madden AM, Bradbury W, Morgan MY. Taste perception in cirrhosis: its relationship to circulating micronutrients and food preferences. Hepatology 1997; 26: 40-48

119 Soulsby CT, Madden AM, Morgan MY. The effect of dietary sodium restriction on energy and protein intake in patients with cirrhosis (Abstract). Hepatology 1997; 26: 382A

120 Chobanian AV, Bakris GL, Black HR et al. Seventh report of the Joint National Committee on Prevention, Detection, Evaluation, and Treatment of High Blood Pressure. Hypertension 2003; 42: 1206-1252

121 Mancia G, De Backer G, Dominiczak A et al. 2007 Guidelines for the Management of Arterial Hypertension: The Task Force for the Management of Arterial Hypertension of the European Society of Hypertension (ESH) and of the European Society of Cardiology (ESC). J Hypertens 2007; 25: 1105-1187
122 Reynolds TB, Lieberman FL, Goodman AR. Advantages of treatment of ascites without sodium restriction and without complete removal of excess fluid. Gut 1978; 19: 549-553

123 Gauthier A, Levy VG, Quinton A et al. Salt or no salt in the treatment of cirrhotic ascites: a randomised study. Gut 1986; 27: 705-709

124 Bernardi M, Laffi G, Salvagnini $M$ et al. Efficacy and safety of the stepped care medical treatment of ascites in liver cirrhosis: a randomized controlled clinical trial comparing two diets with different sodium content. Liver 1993; 13: 156-162

125 Ring-Larsen H, Henriksen JH, Wilken C et al. Diuretic treatment in decompensated cirrhosis and congestive heart failure: effect of posture. Br Med J (Clin Res Ed) 1986; 292: 1351-1353

126 Angeli $P$, Wong $F$, Watson $H$ et al. Hyponatremia in cirrhosis: Results of a patient population survey. Hepatology 2006; 44: 1535-1542

127 Biggins SW, Kim WR, Terrault NA et al. Evidence-based incorporation of serum sodium concentration into MELD. Gastroenterology 2006; 130: $1652-1660$

128 Hecker $R$, Sherlock $S$. Electrolyte and circulatory changes in terminal liver failure. Lancet 1956; 271: 1121-1125

129 Kim WR, Biggins SW, Kremers WK et al. Hyponatremia and mortality among patients on the liver-transplant waiting list. N Engl J Med 2008; 359: 1018-1026

130 Abbasoglu O, Goldstein RM, Vodapally MS et al. Liver transplantation in hyponatremic patients with emphasis on central pontine myelinolysis. Clin Transplant 1998; 12: 263-269

131 Sterns $R H$. Severe symptomatic hyponatremia: treatment and outcome. A study of 64 cases. Ann Intern Med 1987; 107: 656-664

132 Runyon BA. Management of adult patients with ascites due to cirrhosis: an update. Hepatology 2009; 49: 2087-2107

133 Descos L, Gauthier A, Levy VG et al. Comparison of six treatments of ascites in patients with liver cirrhosis. A clinical trial. Hepatogastroenterology 1983; 30: 15-20

134 Fogel MR, Sawhney VK, Neal EA et al. Diuresis in the ascitic patient: a randomized controlled trial of three regimens. J Clin Gastroenterol 1981; 3 (Suppl 1): 73-80

135 Perez-Ayuso RM, Arroyo V, Planas $R$ et al. Randomized comparative study of efficacy of furosemide versus spironolactone in nonazotemic cirrhosis with ascites. Relationship between the diuretic response and the activity of the renin-aldosterone system. Gastroenterology 1983; 84: 961-968

136 Santos J, Planas R, Pardo A et al. Spironolactone alone or in combination with furosemide in the treatment of moderate ascites in nonazotemic cirrhosis. A randomized comparative study of efficacy and safety. J Hepatol 2003; 39: 187-192

137 Pockros PJ, Reynolds TB. Rapid diuresis in patients with ascites from chronic liver disease: the importance of peripheral edema. Gastroenterology 1986; 90: 1827-1833

138 Bernardi $M$, Servadei $D$, Trevisani $F$ et al. Importance of plasma aldosterone concentration on the natriuretic effect of spironolactone in patients with liver cirrhosis and ascites. Digestion 1985; 31: 189-193

139 Gatta A, Angeli P, Caregaro L et al. A pathophysiological interpretation of unresponsiveness to spironolactone in a stepped-care approach to the diuretic treatment of ascites in nonazotemic cirrhotic patients. Hepatology 1991; 14: 231-236

140 Angeli P, Fasolato S, Mazza E et al. Combined versus sequential diuretic treatment of ascites in non-azotaemic patients with cirrhosis: results of an open randomised clinical trial. Gut 2010; 59: 98-104

141 Daskalopoulos G, Laffi G, Morgan T et al. Immediate effects of furosemide on renal hemodynamics in chronic liver disease with ascites. Gastroenterology 1987; 92: 1859-1863

142 Sawhney VK, Gregory PB, Swezey SE et al. Furosemide disposition in cirrhotic patients. Gastroenterology 1981; 81: 1012-1016

143 Stanley MM, Ochi S, Lee KK et al. Peritoneovenous shunting as compared with medical treatment in patients with alcoholic cirrhosis and massive ascites. Veterans Administration Cooperative Study on Treatment of Alcoholic Cirrhosis with Ascites. N Engl J Med 1989; 321: 1632-1638

144 Runyon BA. Care of patients with ascites. N Engl J Med 1994; 330: 337-342

145 Abecasis R, Guevara M, Miguez C et al. Long-term efficacy of torasemide compared with frusemide in cirrhotic patients with ascites. Scand J Gastroenterol 2001; 36: 309-313

146 Fiaccadori F, Pedretti G, Pasetti G et al. Torasemide versus furosemide in cirrhosis: a long-term, double-blind, randomized clinical study. Clin Investig 1993; 71: 579-584 
147 Gerbes AL, Bertheau-Reith U, Falkner C et al. Advantages of the new loop diuretic torasemide over furosemide in patients with cirrhosis and ascites. A randomized, double blind cross-over trial. J Hepatol 1993; 17: 353-358

148 Angeli P, Dalla Pria M, De Bei E et al. Randomized clinical study of the efficacy of amiloride and potassium canrenoate in nonazotemic cirrhotic patients with ascites. Hepatology 1994; 19: 72-79

149 Ginsberg DJ, Saad A, Gabuzda GJ. Metabolic Studies with the Diuretic Triamterene in Patients with Cirrhosis and Ascites. N Engl J Med 1964; 271: 1229-1235

150 Knauf H, Mutschler E. Liver cirrhosis with ascites: pathogenesis of resistance to diuretics and long-term efficacy and safety of torasemide. Cardiology 1994; 84 (Suppl 2): 87-98

151 McHutchison JG, Pinto PC, Reynolds TB. Hydrochlorothiazide as a third diuretic in cirrhosis with refractory ascites (Abstract). Hepatology 1989; 10: 719

152 Pitt B, Remme W, Zannad F et al. Eplerenone, a selective aldosterone blocker, in patients with left ventricular dysfunction after myocardial infarction. N Engl J Med 2003; 348: 1309-1321

153 Gines $P$, Wong $F$, Watson $H$ et al. Effects of satavaptan, a selective vasopressin $\mathrm{V}(2)$ receptor antagonist, on ascites and serum sodium in cirrhosis with hyponatremia: a randomized trial. Hepatology 2008; 48: 204-213

154 Rosemurgy AS, Zervos EE, Clark WC et al. TIPS versus peritoneovenous shunt in the treatment of medically intractable ascites: a prospective randomized trial. Ann Surg 2004; 239: 883-889; discussion $889-$ 891

155 Gines A, Fernandez-Esparrach G, Monescillo A et al. Randomized trial comparing albumin, dextran 70, and polygeline in cirrhotic patients with ascites treated by paracentesis. Gastroenterology 1996; 111: 1002-1010

156 Gines $P$, Tito L, Arroyo $V$ et al. Randomized comparative study of therapeutic paracentesis with and without intravenous albumin in cirrhosis. Gastroenterology 1988; 94: 1493-1502

157 Pozzi M, Osculati G, Boari G et al. Time course of circulatory and humoral effects of rapid total paracentesis in cirrhotic patients with tense, refractory ascites. Gastroenterology 1994; 106: 709-719

158 Lebrec D, Giuily N, Hadengue A et al. Transjugular intrahepatic portosystemic shunts: comparison with paracentesis in patients with cirrhosis and refractory ascites: a randomized trial. French Group of Clinicians and a Group of Biologists. J Hepatol 1996; 25: 135-144

159 Wong F, Sniderman K, Liu P et al. Transjugular intrahepatic portosystemic stent shunt: effects on hemodynamics and sodium homeostasis in cirrhosis and refractory ascites. Ann Intern Med 1995; 122 : $816-822$

160 Gines P, Uriz J, Calahorra B et al. Transjugular intrahepatic portosystemic shunting versus paracentesis plus albumin for refractory ascites in cirrhosis. Gastroenterology 2002; 123: 1839-1847

161 Rossle M, Ochs A, Gulberg V et al. A comparison of paracentesis and transjugular intrahepatic portosystemic shunting in patients with ascites. N Engl J Med 2000; 342: 1701-1707

162 Salerno F, Camma C, Enea $M$ et al. Transjugular intrahepatic portosystemic shunt for refractory ascites: a meta-analysis of individual patient data. Gastroenterology 2007; 133: 825-834

163 Sanyal AJ, Genning C, Reddy KR et al. The North American Study for the Treatment of Refractory Ascites. Gastroenterology 2003; 124: 634641

164 Salerno F, Merli M, Riggio $O$ et al. Randomized controlled study of TIPS versus paracentesis plus albumin in cirrhosis with severe ascites. Hepatology 2004; 40: 629-635

165 Gulberg V, Liss I, Bilzer M et al. Improved quality of life in patients with refractory or recidivant ascites after insertion of transjugular intrahepatic portosystemic shunts. Digestion 2002; 66: 127-130

166 Bureau C, Garcia-Pagan JC, Otal P et al. Improved clinical outcome using polytetrafluoroethylene-coated stents for TIPS: results of a randomized study. Gastroenterology 2004; 126: 469-475

167 Albillos A, Banares R, Gonzalez M et al. A meta-analysis of transjugular intrahepatic portosystemic shunt versus paracentesis for refractory ascites. J Hepatol 2005; 43: 990-996

168 D'Amico G, Luca A, Morabito A et al. Uncovered transjugular intrahepatic portosystemic shunt for refractory ascites: a meta-analysis. Gastroenterology 2005; 129: 1282-1293

169 Deltenre $P$, Mathurin $P$, Dharancy $S$ et al. Transjugular intrahepatic portosystemic shunt in refractory ascites: a meta-analysis. Liver Int 2005; 25: 349-356
170 Riggio O, Ridola L, Angeloni S et al. Clinical efficacy of transjugular intrahepatic portosystemic shunt created with covered stents with different diameters: results of a randomized controlled trial. J Hepatol 2010; 53: 267-272

171 Rossle M, Mullen KD. Long-term patency is expected with covered TIPS stents: this effect may not always be desirable! Hepatology 2004: 40: 495-497

172 Rossle M, Gerbes AL. TIPS for the treatment of refractory ascites, hepatorenal syndrome and hepatic hydrothorax: a critical update. Gut 2010; 59: 988-1000

173 Chalasani N, Clark WS, Martin LG et al. Determinants of mortality in patients with advanced cirrhosis after transjugular intrahepatic portosystemic shunting. Gastroenterology 2000; 118: 138-144

174 Rajan DK, Haskal ZJ, Clark TW. Serum bilirubin and early mortality after transjugular intrahepatic portosystemic shunts: results of a multivariate analysis. J Vasc Interv Radiol 2002; 13: 155-161

175 Gerbes AL, Gulberg V. Benefit of TIPS for patients with refractory or recidivant ascites: serum bilirubin may make the difference. Hepatology $2005 ; 41: 217$

176 Cazzaniga M, Salerno F, Pagnozzi G et al. Diastolic dysfunction is associated with poor survival in patients with cirrhosis with transjugular intrahepatic portosystemic shunt. Gut 2007; 56: 869-875

177 Runyon BA. Monomicrobial nonneutrocytic bacterascites: a variant of spontaneous bacterial peritonitis. Hepatology 1990; 12: 710-715

178 Fernandez J, Navasa M, Gomez J et al. Bacterial infections in cirrhosis: epidemiological changes with invasive procedures and norfloxacin prophylaxis. Hepatology 2002; 35: 140-148

179 Castellote J, Girbau A, Maisterra S et al. Spontaneous bacterial peritonitis and bacterascites prevalence in asymptomatic cirrhotic outpatients undergoing large-volume paracentesis. J Gastroenterol Hepatol 2008; 23: 256-259

180 Conn HO, Fessel JM. Spontaneous bacterial peritonitis in cirrhosis: variations on a theme. Medicine 1971; 50: 161-197

181 Gines P, Rimola A, Planas $R$ et al. Norfloxacin prevents spontaneous bacterial peritonitis recurrence in cirrhosis: results of a double-blind, placebo-controlled trial. Hepatology 1990; 12: 716-724

182 Tito L, Rimola A, Gines P et al. Recurrence of spontaneous bacterial peritonitis in cirrhosis: frequency and predictive factors. Hepatology 1988: 8: 27-31

183 Hsieh WJ, Lin HC, Hwang SJ et al. The effect of ciprofloxacin in the prevention of bacterial infection in patients with cirrhosis after upper gastrointestinal bleeding. Am J Gastroenterol 1998; 93: 962-966

184 Pauwels A, Mostefa-Kara N, Debenes B et al. Systemic antibiotic prophylaxis after gastrointestinal hemorrhage in cirrhotic patients with a high risk of infection. Hepatology 1996; 24: 802-806

185 Rolachon A, Cordier L, Bacq Y et al. Ciprofloxacin and long-term prevention of spontaneous bacterial peritonitis: results of a prospective controlled trial. Hepatology 1995; 22: 1171-1174

186 Soriano G, Guarner C, Teixido M et al. Selective intestinal decontamination prevents spontaneous bacterial peritonitis. Gastroenterology 1991; 100: 477-481

187 Terg R, Fassio E, Guevara M et al. Ciprofloxacin in primary prophylaxis of spontaneous bacterial peritonitis: a randomized, placebo-controlled study. J Hepatol 2008; 48: 774-779

188 Obstein KL, Campbell MS, Reddy KR et al. Association between model for end-stage liver disease and spontaneous bacterial peritonitis. Am J Gastroenterol 2007; 102: 2732-2736

189 Bajaj JS, Zadvornova Y, Heuman DM et al. Association of proton pump inhibitor therapy with spontaneous bacterial peritonitis in cirrhotic patients with ascites. Am J Gastroenterol 2009; 104: 1130-1134

190 Appenrodt B, Grunhage F, Gentemann MG et al. Nucleotide-binding oligomerization domain containing 2 (NOD2) variants are genetic risk factors for death and spontaneous bacterial peritonitis in liver cirrhosis. Hepatology 2010; 51: 1327-1333

191 Chu CM, Chang KY, Liaw YF. Prevalence and prognostic significance of bacterascites in cirrhosis with ascites. Dig Dis Sci 1995; 40: 561-565

192 Follo A, Llovet JM, Navasa $M$ et al. Renal impairment after spontaneous bacterial peritonitis in cirrhosis: incidence, clinical course, predictive factors and prognosis. Hepatology 1994; 20: 1495-1501

193 Nobre SR, Cabral JE, Gomes IJ et al. In-hospital mortality in spontaneous bacterial peritonitis: a new predictive model. Eur J Gastroenterol Hepatol 2008; 20: 1176-1181

194 Pinzello G, Simonetti RG, Craxi A et al. Spontaneous bacterial peritonitis: a prospective investigation in predominantly nonalcoholic cirrhotic patients. Hepatology 1983; 3: 545-549 
195 Thuluvath PJ, Morss S, Thompson R. Spontaneous bacterial peritonitisin-hospital mortality, predictors of survival, and health care costs from 1988 to 1998. Am J Gastroenterol 2001; 96: 1232-1236

196 Toledo C, Salmeron JM, Rimola A et al. Spontaneous bacterial peritonitis in cirrhosis: predictive factors of infection resolution and survival in patients treated with cefotaxime. Hepatology 1993; 17: 251-257

197 Andreu M, Sola R, Sitges-Serra A et al. Risk factors for spontaneous bacterial peritonitis in cirrhotic patients with ascites. Gastroenterology 1993; 104: 1133-1138

198 Silvain C, Besson I, Ingrand P et al. Prognosis and long-term recurrence of spontaneous bacterial peritonitis in cirrhosis. J Hepatol 1993; 19: 188-189

199 Terg R, Levi D, Lopez Pet al. Analysis of clinical course and prognosis of culture-positive spontaneous bacterial peritonitis and neutrocytic ascites. Evidence of the same disease. Dig Dis Sci 1992; 37: 14991504

200 Altman C, Grange JD, Amiot X et al. Survival after a first episode of spontaneous bacterial peritonitis. Prognosis of potential candidates for orthotopic liver transplantation. J Gastroenterol Hepatol 1995; 10: 47-50

201 Almdal TP, Skinhoj P. Spontaneous bacterial peritonitis in cirrhosis. Incidence, diagnosis, and prognosis. Scand J Gastroenterol 1987; 22: 295-300

202 Weinstein MP, Iannini PB, Stratton CW et al. Spontaneous bacterial peritonitis. A review of 28 cases with emphasis on improved survival and factors influencing prognosis. Am J Med 1978; 64: 592-598

203 Terg R, Gadano A, Cartier M et al. Serum creatinine and bilirubin predict renal failure and mortality in patients with spontaneous bacterial peritonitis: a retrospective study. Liver Int 2009; 29: 415-419

204 Franca AV, De Souza JB, Silva CM et al. Long-term prognosis of cirrhosis after spontaneous bacterial peritonitis treated with ceftriaxone. J Clin Gastroenterol 2001; 33: 295-298

205 Kamani L, Mumtaz K, Ahmed US et al. Outcomes in culture positive and culture negative ascitic fluid infection in patients with viral cirrhosis: cohort study. BMC Gastroenterol 2008; 8: 59

206 Cho JH, Park KH, Kim SH et al. Bacteremia is a prognostic factor for poor outcome in spontaneous bacterial peritonitis. Scand J Infect Dis 2007; 39: 697-702

207 Alvarez RF, Mattos AA, Correa EB et al. Trimethoprim-sulfamethoxazole versus norfloxacin in the prophylaxis of spontaneous bacterial peritonitis in cirrhosis. Arq Gastroenterol 2005; 42: 256-262

208 Singh N, Gayowski T, Yu VL et al. Trimethoprim-sulfamethoxazole for the prevention of spontaneous bacterial peritonitis in cirrhosis: a randomized trial. Ann Intern Med 1995; 122: 595-598

209 Novella $M$, Sola $R$, Soriano $G$ et al. Continuous versus inpatient prophylaxis of the first episode of spontaneous bacterial peritonitis with norfloxacin. Hepatology 1997; 25: 532-536

210 Fernandez J, Navasa M, Planas $R$ et al. Primary prophylaxis of spontaneous bacterial peritonitis delays hepatorenal syndrome and improves survival in cirrhosis. Gastroenterology 2007; 133: 818-824

211 Grange JD, Roulot D, Pelletier G et al. Norfloxacin primary prophylaxis of bacterial infections in cirrhotic patients with ascites: a doubleblind randomized trial. J Hepatol 1998; 29: 430-436

212 Loomba R, Wesley R, Bain A et al. Role of fluoroquinolones in the primary prophylaxis of spontaneous bacterial peritonitis: meta-analysis. Clin Gastroenterol Hepatol 2009; 7: 487-493

213 Saab S, Hernandez JC, Chi AC et al. Oral antibiotic prophylaxis reduces spontaneous bacterial peritonitis occurrence and improves shortterm survival in cirrhosis: a meta-analysis. Am J Gastroenterol 2009; 104: 993-1001; quiz 1002

$214 \mathrm{Krag}$ A, Wiest R, Gluud LL. Fluoroquinolones in the primary prophylaxis of spontaneous bacterial peritonitis. Am J Gastroenterol 2010; 105: 1444; author reply $1444-1445$

215 Lo R, Austin AS, Freeman JG. Antibiotic prophylaxis for the primary prevention of spontaneous bacterial peritonitis in cirrhotic patients with low ascitic protein: A meta-analysis. J Hepatol 2009; 50: S82

216 Ortiz J, Vila MC, Soriano G et al. Infections caused by Escherichia coli resistant to norfloxacin in hospitalized cirrhotic patients. Hepatology 1999; 29: 1064-1069

217 Bajaj JS, Ananthakrishnan AN, Hafeezullah M et al. Clostridium difficile is associated with poor outcomes in patients with cirrhosis: A national and tertiary center perspective. Am J Gastroenterol 2010; 105: 106-113

218 Runyon BA. A pill a day can improve survival in patients with advanced cirrhosis. Gastroenterology 2007; 133: 1029-1031
219 Wade JJ, Rolando N, Hayllar K et al. Bacterial and fungal infections after liver transplantation: an analysis of 284 patients. Hepatology 1995; $21: 1328-1336$

220 Lontos S, Gow PJ, Vaughan RB et al. Norfloxacin and trimethoprim-sulfamethoxazole therapy have similar efficacy in prevention of spontaneous bacterial peritonitis. J Gastroenterol Hepatol 2008; 23: 252255

221 Terg R, Llano K, Cobas SM et al. Effects of oral ciprofloxacin on aerobic gram-negative fecal flora in patients with cirrhosis: results of shortand long-term administration, with daily and weekly dosages. J Hepatol 1998; 29: 437-442

222 Goulis J, Patch D, Burroughs AK. Bacterial infection in the pathogenesis of variceal bleeding. Lancet 1999; 353: 139-142

223 Bernard B, Cadranel JF, Valla D et al. Prognostic significance of bacterial infection in bleeding cirrhotic patients: a prospective study. Gastroenterology 1995; 108: 1828-1834

224 Goulis J, Armonis A, Patch D et al. Bacterial infection is independently associated with failure to control bleeding in cirrhotic patients with gastrointestinal hemorrhage. Hepatology 1998; 27: 1207-1212

225 Bernard B, Grange JD, Khac EN et al. Antibiotic prophylaxis for the prevention of bacterial infections in cirrhotic patients with gastrointestinal bleeding: a meta-analysis. Hepatology 1999; 29: 1655-1661

226 Chaves-Tapia NC, Barrientos-Gutierres T, Tellez-Avila FI et al. Antibiotic prophylaxis for cirrhotic patients with upper gastrointestinal bleeding. Cochrane Database Syst Rev 2010 Sep 8; (9): CD002907

227 de Franchis R. Evolving consensus in portal hypertension. Report of the Baveno IV consensus workshop on methodology of diagnosis and therapy in portal hypertension. J Hepatol 2005; 43: 167-176

228 Tuncer I, Topcu N, Durmus A et al. Oral ciprofloxacin versus intravenous cefotaxime and ceftriaxone in the treatment of spontaneous bacterial peritonitis. Hepatogastroenterology 2003; 50: 1426-1430

229 Navasa M, Follo A, Llovet JM et al. Randomized, comparative study of oral ofloxacin versus intravenous cefotaxime in spontaneous bacterial peritonitis. Gastroenterology 1996; 111: 1011-1017

230 Angeli P, Guarda S, Fasolato S et al. Switch therapy with ciprofloxacin vs. intravenous ceftazidime in the treatment of spontaneous bacterial peritonitis in patients with cirrhosis: similar efficacy at lower cost. Aliment Pharmacol Ther 2006; 23: 75-84

231 Taskiran B, Colakoglu O, Sozmen B et al. Comparison of cefotaxime and ofloxacin in treatment of spontaneous bacterial peritonitis. Turk J Gastroenterol 2004; 15: 34-38

$232 \operatorname{Terg}$ R, Cobas S, Fassio E et al. Oral ciprofloxacin after a short course of intravenous ciprofloxacin in the treatment of spontaneous bacterial peritonitis: results of a multicenter, randomized study. J Hepatol 2000; 33: 564-569

233 Park YH, Lee HC, Song HG et al. Recent increase in antibiotic-resistant microorganisms in patients with spontaneous bacterial peritonitis adversely affects the clinical outcome in Korea. J Gastroenterol Hepatol 2003; 18: 927-933

234 Singh N, Wagener MM, Gayowski T. Changing epidemiology and predictors of mortality in patients with spontaneous bacterial peritonitis at a liver transplant unit. Clin Microbiol Infect 2003; 9: 531-537

235 Kresken M, Hafner D, Schmitz FJ. et al. PEG-Resistenzstudie: Resistenzsituation bei klinisch wichtigen Infektionserregern gegenüber Antibiotika in Deutschland und im mitteleuropäischen Raum. Paul-Ehrlich-Gesellschaft für Chemotherapie e.V; 2007

236 Kresken M, Hafner D, Schmitz FJ. et al. PEG-Resistenzstudie: Daten zur Resistenzlage bei klinisch wichtigen Bakterienspezies gegenüber Antibiotika in Mitteleuropa. Paul-Ehrlich-Gesellschaft für Chemotherapie e.V; 2010

237 Felisart J, Rimola A, Arroyo V et al. Cefotaxime is more effective than is ampicillin-tobramycin in cirrhotics with severe infections. Hepatology $1985 ;$ : 457-462

238 Rimola A, Salmeron JM, Clemente G et al. Two different dosages of cefotaxime in the treatment of spontaneous bacterial peritonitis in cirrhosis: results of a prospective, randomized, multicenter study. Hepatology 1995; 21: 674-679

239 Rimola A, Navasa M, Arroyo V. Experience with cefotaxime in the treatment of spontaneous bacterial peritonitis in cirrhosis. Diagn Microbiol Infect Dis 1995; 22: 141-145

240 Gomez-Jimenez J, Ribera E, Gasser I et al. Randomized trial comparing ceftriaxone with cefonicid for treatment of spontaneous bacterial peritonitis in cirrhotic patients. Antimicrob Agents Chemother 1993; 37: 1587-1592 
241 Ricart E, Soriano G, Novella MT et al. Amoxicillin-clavulanic acid versus cefotaxime in the therapy of bacterial infections in cirrhotic patients. J Hepatol 2000; 32: 596-602

242 Acevedo JC, Fernandez J, Castro $M$ et al. Current efficacy of recommended empirical antibiotic therapy in patients with cirrhosis and bacterial infection (Abstract). J Hepatol 2009; 50: S5

243 Castellote J, Ariza X, Girbau A et al. Risk factors to cefotaxime-resistant spontaneous bacterial peritonitis (Abstract). J Hepatol 2010; 52: S69

244 Angeloni S, Leboffe C, Parente A et al. Efficacy of current guidelines for the treatment of spontaneous bacterial peritonitis in the clinical practice. World J Gastroenterol 2008; 14: 2757-2762

245 Yakar T, Guclu M, Serin E et al. A recent evaluation of empirical cephalosporin treatment and antibiotic resistance of changing bacterial profiles in spontaneous bacterial peritonitis. Dig Dis Sci 2010; 55: 1149-1154

246 Castellote J, Ariza X, Girbau A et al. Antibiotic-resistant bacteria in spontaneous bacterial peritonitis. Is it time to change? (Abstract). J Hepatol 2010; 52: S69

247 Cheong HS, Kang CI, Lee JA et al. Clinical significance and outcome of nosocomial acquisition of spontaneous bacterial peritonitis in patients with liver cirrhosis. Clin Infect Dis 2009; 48: 1230-1236

248 Dupeyron C, Mangeney N, Sedrati L et al. Rapid emergence of quinolone resistance in cirrhotic patients treated with norfloxacin to prevent spontaneous bacterial peritonitis. Antimicrob Agents Chemother $1994 ; 38$ : 340-344

249 Dupeyron C, Campillo SB, Mangeney N et al. Carriage of Staphylococcus aureus and of gram-negative bacilli resistant to third-generation cephalosporins in cirrhotic patients: a prospective assessment of hospital-acquired infections. Infect Control Hosp Epidemiol 2001; 22: 427-432

250 Campillo B, Dupeyron C, Richardet JP et al. Epidemiology of severe hospital-acquired infections in patients with liver cirrhosis: effect of long-term administration of norfloxacin. Clin Infect Dis 1998; 26 : 1066-1070

251 Campillo B, Dupeyron C, Richardet JP. Epidemiology of hospital-acquired infections in cirrhotic patients: effect of carriage of methicillin-resistant Staphylococcus aureus and influence of previous antibiotic therapy and norfloxacin prophylaxis. Epidemiol Infect 2001; 127: $443-450$

252 Song $K H$, Jeon JH, Park WB et al. Clinical outcomes of spontaneous bacterial peritonitis due to extended-spectrum beta-lactamaseproducing Escherichia coli and Klebsiella species: a retrospective matched case-control study. BMC Infect Dis 2009; 9: 41

253 Umgelter A, Reindl W, Miedaner $M$ et al. Failure of current antibiotic first-line regimens and mortality in hospitalized patients with spontaneous bacterial peritonitis. Infection 2009; 37: 2-8

254 Chavez-Tapia NC, Soares-Weiser K, Brezis M et al. Antibiotics for spontaneous bacterial peritonitis in cirrhotic patients. Cochrane Database Syst Rev 2009: CD002232

255 Chen TA, Lo GH, Lai KH et al. Single daily amikacin versus cefotaxime in the short-course treatment of spontaneous bacterial peritonitis in cirrhotics. World J Gastroenterol 2005; 11: 6823-6827

256 Rastegar LA, Umrani G, Dehbashi $N$ et al. Evaluation of the therapeutic effect of pefloxacin in comparison with ampicillin and gentamicin in cirrhotic patients with spontaneous bacterial peritonitis. Hepatogastroenterology 1998; 45: 783-785

257 Antillon MR, Runyon BA. Effect of marked peripheral leukocytosis on the leukocyte count in ascites. Arch Intern Med 1991; 151: 509-510

258 Ljubicic N, Spajic D, Vrkljan MM et al. The value of ascitic fluid polymorphonuclear cell count determination during therapy of spontaneous bacterial peritonitis in patients with liver cirrhosis. Hepatogastroenterology 2000; 47: 1360-1363

259 Runyon BA, Hoefs JC. Spontaneous vs secondary bacterial peritonitis. Differentiation by response of ascitic fluid neutrophil count to antimicrobial therapy. Arch Intern Med 1986; 146: 1563-1565

260 Fong TL, Akriviadis EA, Runyon BA et al. Polymorphonuclear cell count response and duration of antibiotic therapy in spontaneous bacterial peritonitis. Hepatology 1989; 9: 423-426

261 Runyon BA, McHutchison JG, Antillon MR et al. Short-course versus long-course antibiotic treatment of spontaneous bacterial peritonitis. A randomized controlled study of 100 patients. Gastroenterology 1991; 100: 1737-1742

262 Bauer TM, Follo A, Navasa M et al. Daily norfloxacin is more effective than weekly rufloxacin in prevention of spontaneous bacterial peritonitis recurrence. Dig Dis Sci 2002; 47: 1356-1361
263 Arroyo V, Gines P, Gerbes AL et al. Definition and diagnostic criteria of refractory ascites and hepatorenal syndrome in cirrhosis. International Ascites Club. Hepatology 1996; 23: 164-176

264 Salerno F, Gerbes A, Gines P et al. Diagnosis, prevention and treatment of hepatorenal syndrome in cirrhosis. Gut 2007; 56: 1310-1318

265 Solanki P, Chawla A, Garg $R$ et al. Beneficial effects of terlipressin in hepatorenal syndrome: a prospective, randomized placebo-controlled clinical trial. J Gastroenterol Hepatol 2003; 18: 152-156

266 Sanyal AJ, Boyer T, Garcia-Tsao G et al. A randomized, prospective, double-blind, placebo-controlled trial of terlipressin for type 1 hepatorenal syndrome. Gastroenterology 2008; 134: 1360-1368

267 Martin-Llahi M, Pepin MN, Guevara M et al. Terlipressin and albumin vs albumin in patients with cirrhosis and hepatorenal syndrome: a randomized study. Gastroenterology 2008; 134: 1352-1359

268 Neri S, Pulvirenti D, Malaguarnera M et al. Terlipressin and albumin in patients with cirrhosis and type I hepatorenal syndrome. Dig Dis Sci 2008; 53: 830-835

269 Ortega R, Gines P, Uriz J et al. Terlipressin therapy with and without albumin for patients with hepatorenal syndrome: results of a prospective, nonrandomized study. Hepatology 2002; 36: 941-948

270 Saner F, Kavuk I, Lang H et al. Terlipressin and gelafundin: safe therapy of hepatorenal syndrome. Eur J Med Res 2004; 9: 78-82

271 Dart AB, Mutter TC, Ruth CA et al. Hydroxyethyl starch (HES) versus other fluid therapies: effects on kidney function. Cochrane Database Syst Rev 2010: CD007594

272 Fabrizi F, Dixit V, Messa P et al. Terlipressin for hepatorenal syndrome: A meta-analysis of randomized trials. Int J Artif Organs 2009; 32: $133-140$

273 Gluud LL, Christensen K, Christensen E et al. Systematic review of randomized trials on vasoconstrictor drugs for hepatorenal syndrome. Hepatology 2010; 51: 576-584

274 Sagi SV, Mittal S, Kasturi KS et al. Terlipressin therapy for reversal of type 1 hepatorenal syndrome: a meta-analysis of randomized controlled trials. J Gastroenterol Hepatol 2010; 25: 880-885

275 Gerbes AL, Huber E, Gulberg V. Terlipressin for hepatorenal syndrome: continuous infusion as an alternative to i.v. bolus administration. Gastroenterology 2009; 137: 1179; author reply 1179-1181

276 Hadengue A, Gadano A, Moreau $R$ et al. Beneficial effects of the 2-day administration of terlipressin in patients with cirrhosis and hepatorenal syndrome. J Hepatol 1998; 29: 565-570

277 Gerbes AL, Gulberg V, Waggershauser T et al. Renal effects of transjugular intrahepatic portosystemic shunt in cirrhosis: comparison of patients with ascites, with refractory ascites, or without ascites. Hepatology 1998; 28: 683-688

278 Guevara M, Gines P, Bandi JC et al. Transjugular intrahepatic portosystemic shunt in hepatorenal syndrome: effects on renal function and vasoactive systems. Hepatology 1998; 28: 416-422

279 Brensing KA, Textor J, Perz J et al. Long term outcome after transjugular intrahepatic portosystemic stent-shunt in non-transplant cirrhotics with hepatorenal syndrome: a phase II study. Gut 2000; 47: 288295

280 Wong F, Pantea L, Sniderman K. Midodrine, octreotide, albumin, and TIPS in selected patients with cirrhosis and type 1 hepatorenal syndrome. Hepatology 2004; 40: 55-64

281 Testino G, Ferro C, Sumberaz A et al. Type-2 hepatorenal syndrome and refractory ascites: role of transjugular intrahepatic portosystemic stent-shunt in eighteen patients with advanced cirrhosis awaiting orthotopic liver transplantation. Hepatogastroenterology 2003; 50: 1753-1755

282 Witzke O, Baumann M, Patschan D et al. Which patients benefit from hemodialysis therapy in hepatorenal syndrome? J Gastroenterol Hepatol 2004; 19: 1369-1373

283 Mitzner SR, Stange J, Klammt S et al. Improvement of hepatorenal syndrome with extracorporeal albumin dialysis MARS: results of a prospective, randomized, controlled clinical trial. Liver Transpl 2000; 6: 277-286

284 Wong F, Raina N, Richardson R. Molecular adsorbent recirculating system is ineffective in the management of type 1 hepatorenal syndrome in patients with cirrhosis with ascites who have failed vasoconstrictor treatment. Gut 2010; 59: 381-386

285 Bannares $R$, Nevens F, Larsen FS et al. Extracorporeal liver support with the molecular adsorbent recirculating system (MARS) in patients with acute-on-chronic liver failure (AOCLF). The RELIEF trail (Abstract). J Hepatol 2010; 52: S459-S460 
286 Rifai K, Ernst T, Kretschmer U et al. Prometheus - a new extracorporeal system for the treatment of liver failure. J Hepatol 2003; 39 : 984-990

287 Rifai K, Kribben A, Gerken $G$ et al. Extracorporeal liver support by fractionated plasma separation and adsorption (Prometheus) in patients with acute-on-chronic liver failure (HELIOS study): A prospective randomized controlled multicenter study (Abstract). J Hepatol 2010; 52: S3

288 Gonwa TA, Poplawski S, Paulsen W et al. Pathogenesis and outcome of hepatorenal syndrome in patients undergoing orthotopic liver transplant. Transplantation 1989; 47: 395-397

289 Seu $P$, Wilkinson AH, Shaked A et al. The hepatorenal syndrome in liver transplant recipients. Am Surg 1991; 57: 806-809

290 Lafayette RA, Pare G, Schmid CH et al. Pretransplant renal dysfunction predicts poorer outcome in liver transplantation. Clin Nephrol 1997; 48: $159-164$

291 Restuccia T, Ortega R, Guevara M et al. Effects of treatment of hepatorenal syndrome before transplantation on posttransplantation outcome. A case-control study. J Hepatol 2004; 40: 140-146

292 Bundesärztekammer. Richtlinien zur Organtransplantation gem. §16 Abs.1 S.1 Nrn. 2, 4 u. 5 TPG. Dtsch Ärztebl 2010; 107: A1532-1541

293 Davis CL, Feng S, Sung $R$ et al. Simultaneous liver-kidney transplantation: evaluation to decision making. Am J Transplant 2007; 7: 17021709

294 Lieberman FL, Hidemura R, Peters RL et al. Pathogenesis and treatment of hydrothorax complicating cirrhosis with ascites. Ann Intern Med 1966; 64: 341-351

295 Malagari K, Nikita A, Alexopoulou E et al. Cirrhosis-related intrathoracic disease. Imaging features in 1038 patients. Hepatogastroenterology 2005 ; 52 : 558-562

296 Kinasewitz GT, Keddissi JI. Hepatic hydrothorax. Curr Opin Pulm Med 2003; 9: 261-265

297 Kiafar C, Gilani N. Hepatic hydrothorax: current concepts of pathophysiology and treatment options. Ann Hepatol 2008; 7: 313-320

298 Halank M. Strassburg CP, Hoeper MM. Pulmonary complications of liver cirrhosis: hepatopulmonary syndrome, portopulmonary hypertension and hepatic hydrothorax. Internist 2010; 51 (Suppl 1): 255263

299 Cardenas A, Arroyo V. Management of ascites and hepatic hydrothorax. Best Pract Res Clin Gastroenterol 2007; 21: 55-75

300 Cardenas A, Kelleher T, Chopra S. Review article: hepatic hydrothorax. Aliment Pharmacol Ther 2004; 20: 271-279

301 Huang PM, Chang YL, Yang CY et al. The morphology of diaphragmatic defects in hepatic hydrothorax: thoracoscopic finding. J Thorac Cardiovasc Surg 2005; 130: 141-145

302 Rubinstein D, McInnes IE, Dudley FJ. Hepatic hydrothorax in the absence of clinical ascites: diagnosis and management. Gastroenterology $1985 ; 88$ : 188-191

303 Xiol X, Castellote J, Cortes-Beut R et al. Usefulness and complications of thoracentesis in cirrhotic patients. Am J Med 2001; 111: 67-69

304 Reissig A, Heyne JP, Kroegel C. Ancillary lung parenchymal findings at spiral CT scanning in pulmonary embolism. Relationship to chest sonography. Eur J Radiol 2004; 49: 250-257

305 Kocijancic I, Vidmar K, Ivanovi-Herceg Z. Chest sonography versus lateral decubitus radiography in the diagnosis of small pleural effusions. J Clin Ultrasound 2003; 31: 69-74

306 Kohan JM, Poe RH, Israel RH et al. Value of chest ultrasonography versus decubitus roentgenography for thoracentesis. Am Rev Respir Dis 1986; 133: 1124-1126

307 Light RW. Clinical practice. Pleural effusion. N Engl J Med 2002; 346: 1971-1977

308 Castellote J, Xiol X, Cortes-Beut R et al. Complications of thoracentesis in cirrhotic patients with pleural effusion. Rev Esp Enferm Dig 2001; 93: 566-575

309 Jones PW, Moyers JP, Rogers JT et al. Ultrasound-guided thoracentesis: is it a safer method? Chest 2003; 123: 418-423

310 Gordon CE, Feller-Kopman D, Balk EM et al. Pneumothorax following thoracentesis: a systematic review and meta-analysis. Arch Intern Med 2010; 170: 332-339

311 Romero S, Candela A, Martin C et al. Evaluation of different criteria for the separation of pleural transudates from exudates. Chest 1993; 104: 399-404

312 Burgess LJ, Maritz FJ, Taljaard JJ. Comparative analysis of the biochemical parameters used to distinguish between pleural transudates and exudates. Chest 1995; 107: 1604-1609
313 Light RW, Macgregor MI, Luchsinger PC et al. Pleural effusions: the diagnostic separation of transudates and exudates. Ann Intern Med 1972; 77: 507-513

314 Mittal BR, Maini A, Das BK. Peritoneopleural communication associated with cirrhotic ascites: scintigraphic demonstration. Abdom Imaging 1996; 21: 69-70

315 Bhattacharya A, Mittal BR, Biswas T et al. Radioisotope scintigraphy in the diagnosis of hepatic hydrothorax. J Gastroenterol Hepatol 2001; 16: 317-321

316 Ajmi S, Hassine H, Guezguez M et al. Isotopic exploration of hepatic hydrothorax: ten cases. Gastroenterol Clin Biol 2004; 28: 462-466

317 Huang PM, Han YY, Kuo SW et al. Color Doppler ultrasonography in detecting transdiaphragmatic flow of hepatic hydrothorax: correlation with thoracoscopic findings. J Thorac Cardiovasc Surg 2009; 138: $1251-1252$

318 Tamano M, Hashimoto T, Kojima K et al. Diagnosis of hepatic hydrothorax using contrast-enhanced ultrasonography with intraperitoneal injection of Sonazoid. J Gastroenterol Hepatol 2010; 25: 383386

319 Takayama T, Kurokawa Y, Kaiwa Y et al. A new technique of thoracoscopic pleurodesis for refractory hepatic hydrothorax. Surg Endosc 2004; 18: 140-143

320 Lin DJ, Zhang M, Gao GX et al. Thoracoscopy for diagnosis and management of refractory hepatic hydrothorax. Chin Med J 2006; 119 : 430-434

321 Xiol X, Castellvi JM, Guardiola J et al. Spontaneous bacterial empyema in cirrhotic patients: a prospective study. Hepatology 1996; 23: 719723

322 D"Amico G, Garcia-Tsao G, Pagliaro L. Natural history and prognostic indicators of survival in cirrhosis: a systematic review of 118 studies. J Hepatol 2006; 44: 217-231

323 Kaplan LM, Epstein SK, Schwartz SL et al. Clinical, echocardiographic, and hemodynamic evidence of cardiac tamponade caused by large pleural effusions. Am J Respir Crit Care Med 1995; 151: 904-908

324 Angueira CE, Kadakia SC. Effects of large-volume paracentesis on pulmonary function in patients with tense cirrhotic ascites. Hepatology 1994: $20: 825-828$

325 Heller BJ, Grathwohl MK. Contralateral reexpansion pulmonary edema. South Med J 2000; 93: 828-831

326 Feller-Kopman D, Berkowitz D, Boiselle P et al. Large-volume thoracentesis and the risk of reexpansion pulmonary edema. Ann Thorac Surg 2007; 84: 1656-1661

327 Liu LU, Haddadin HA, Bodian CA et al. Outcome analysis of cirrhotic patients undergoing chest tube placement. Chest 2004; 126: 142 148

328 Colombato $L$. The role of transjugular intrahepatic portosystemic shunt (TIPS) in the management of portal hypertension. J Clin Gastroenterol 2007; 41 (Suppl 3): S344-S351

329 Strauss RM, Martin LG, Kaufman SL et al. Transjugular intrahepatic portal systemic shunt for the management of symptomatic cirrhotic hydrothorax. Am J Gastroenterol 1994; 89: 1520-1522

330 Chalasani N, Gitlin N. TIPS for patients with refractory hepatic hydrothorax: what is the take-home message? Am J Gastroenterol 1997; 92: 2129-2130

331 Gordon FD, Anastopoulos HT, Crenshaw W et al. The successful treatment of symptomatic, refractory hepatic hydrothorax with transjugular intrahepatic portosystemic shunt. Hepatology 1997; 25: 13661369

332 Degawa M, Hamasaki K, Yano K et al. Refractory hepatic hydrothorax treated with transjugular intrahepatic portosystemic shunt. J Gastroenterol 1999; 34: 128-131

333 Conklin LD, Estrera AL, Weiner MA et al. Transjugular intrahepatic portosystemic shunt for recurrent hepatic hydrothorax. Ann Thorac Surg 2000; 69: 609-611

334 Siegerstetter $V$, Deibert $P$, Ochs A et al. Treatment of refractory hepatic hydrothorax with transjugular intrahepatic portosystemic shunt: long-term results in 40 patients. Eur J Gastroenterol Hepatol 2001; 13: $529-534$

335 Spencer EB, Cohen DT, Darcy MD. Safety and efficacy of transjugular intrahepatic portosystemic shunt creation for the treatment of hepatic hydrothorax. J Vasc Interv Radiol 2002; 13: 385-390

336 Wilputte JY, Goffette P, Zech F et al. The outcome after transjugular intrahepatic portosystemic shunt (TIPS) for hepatic hydrothorax is closely related to liver dysfunction: a long-term study in 28 patients. Acta Gastroenterol Belg 2007; 70: 6-10 
337 Dhanasekaran R, West JK, Gonzales PC et al. Transjugular intrahepatic portosystemic shunt for symptomatic refractory hepatic hydrothorax in patients with cirrhosis. Am J Gastroenterol 2010; 105: 635-641

338 Ikard RW, Sawyers JL. Persistent hepatic hydrothorax after peritoneojugular shunt. Arch Surg 1980; 115: 1125-1127

339 Ghandour E, Carter J, Feola M et al. Management of hepatic hydrothorax with a peritoneovenous (Denver) shunt. South Med J 1990; 83: 718-719

340 Falchuk KR, Jacoby I, Colucci WS et al. Tetracycline-induced pleural symphysis for recurrent hydrothorax complicating cirrhosis. A new approach to treatment. Gastroenterology 1977; 72: 319-321

341 de Milanez Campos JR, Filho LO, de Campos Werebe E et al. Thoracoscopy and talc poudrage in the management of hepatic hydrothorax. Chest 2000; 118: 13-17

342 Ferrante D, Arguedas MR, Cerfolio RJ et al. Video-assisted thoracoscopic surgery with talc pleurodesis in the management of symptomatic hepatic hydrothorax. Am J Gastroenterol 2002; 97: 3172-3175

343 Cerfolio RJ, Bryant AS. Efficacy of video-assisted thoracoscopic surgery with talc pleurodesis for porous diaphragm syndrome in patients with refractory hepatic hydrothorax. Ann Thorac Surg 2006; 82: 457-459

344 Huang PM, Kuo SW, Lee JM. Thoracoscopic diaphragmatic repair for refractory hepatic hydrothorax: application of pleural flap and mesh onlay reinforcement. Thorac Cardiovasc Surg 2006; 54: 47-50
345 Xiol X, Tremosa G, Castellote J et al. Liver transplantation in patients with hepatic hydrothorax. Transpl Int 2005; 18: 672-675

346 Serste T, Moreno C, Francoz C et al. The impact of preoperative hepatic hydrothorax on the outcome of adult liver transplantation. Eur J Gastroenterol Hepatol 2010; 22: 207-212

347 Sese E, Xiol X, Castellote J et al. Low complement levels and opsonic activity in hepatic hydrothorax: its relationship with spontaneous bacterial empyema. J Clin Gastroenterol 2003; 36: 75-77

348 Ackerman Z, Reynolds TB. Evaluation of pleural fluid in patients with cirrhosis. J Clin Gastroenterol 1997; 25: 619-622

349 Xiol X, Castellote J, Baliellas C et al. Spontaneous bacterial empyema in cirrhotic patients: analysis of eleven cases. Hepatology 1990; 11: 365-370

350 Castellote J, Lopez C, Gornals J et al. Use of reagent strips for the rapid diagnosis of spontaneous bacterial empyema. J Clin Gastroenterol 2005; 39: 278-281

351 Hoffken G, Lorenz J, Kern W et al. Epidemiology, diagnosis, antimicrobial therapy and management of community-acquired pneumonia and lower respiratory tract infections in adults. Guidelines of the Paul-Ehrlich-Society for Chemotherapy, the German Respiratory Society, the German Society for Infectiology and the Competence Network CAPNETZ Germany. Pneumologie 2009; 63: e1-68

352 Maskell NA, Davies CW, Nunn AJ et al. U.K. Controlled trial of intrapleural streptokinase for pleural infection. N Engl J Med 2005; 352 865-874 